University of Louisville

ThinkIR: The University of Louisville's Institutional Repository

$5-2004$

\title{
Employees' perceptions of barriers in e-Learning : the relationship among barriers, demographics, and e-Learning self-efficacy.
}

Penina Mungania 1974-

University of Louisville

Follow this and additional works at: https://ir.library.louisville.edu/etd

\section{Recommended Citation}

Mungania, Penina 1974-, "Employees' perceptions of barriers in e-Learning : the relationship among barriers, demographics, and e-Learning self-efficacy." (2004). Electronic Theses and Dissertations. Paper 1027.

https://doi.org/10.18297/etd/1027

This Doctoral Dissertation is brought to you for free and open access by ThinkIR: The University of Louisville's Institutional Repository. It has been accepted for inclusion in Electronic Theses and Dissertations by an authorized administrator of ThinkIR: The University of Louisville's Institutional Repository. This title appears here courtesy of the author, who has retained all other copyrights. For more information, please contact thinkir@louisville.edu. 
EMPLOYEES' PERCEPTIONS OF BARRIERS IN E-LEARNING:

THE RELATIONSHIP AMONG BARRIERS, DEMOGRAPHICS, AND

E-LEARNING SELF-EFFICACY

\title{
By
}

Penina Mungania

B.Ed., Kenyatta University, 1997

M.A., Eastern Kentucky University, 2000

Ph.D. University of Louisville, 2004

\author{
A Dissertation \\ Submitted to the Faculty of the \\ Graduate School of the University of Louisville \\ in Partial Fulfillment of the Requirements \\ for the Degree of
}

Doctor of Philosophy

Department of Leadership, Foundations, \& Human Resource Education University of Louisville

Louisville, Kentucky

May, 2004 
Copyright 2004 by Penina Mungania

All rights reserved 
EMPLOYEES' PERCEPTIONS OF BARRIERS IN E-LEARNING: THE RELATIONSHIP AMONG BARRIERS, DEMOGRAPHICS, AND E-LEARNING SELF-EFFICACY

By

\author{
Penina Mungania \\ B.Ed., Kenyatta University, 1997 \\ M.A., Eastern Kentucky University, 2000
}

A Dissertation Approved on

February 11, 2004

By the following Dissertation Committee:

Dissertation Directors 


\section{DEDICATION}

This dissertation is dedicated to my parents,

Josephine and Gilbert Mungania

for their love, trust, and support. 


\section{ACKNOWLEDGMENTS}

My heartfelt gratitude goes to my dissertation committee members: Dr. Tim Hatcher for being a wonderful mentor, professor, and Chair whose feedback and willingness to listen when the process overwhelmed me meant a lot. Dr. Petrosko, thank you for stepping in to co-chair this dissertation and for helping me to finally appreciate numbers. Dr. Lyle Sussman, Dr. Mike Boyle, and Dr. Tom Reio, for guiding me as I refined my rough ideas into this dissertation.

To my family: Both young and old from whom I always learn. Your love, support, and commitment to education are priceless.

The subject matter experts (Dr. Denzil Edge, Dr. Sharon Colton, Dr. Zane Berge, Dr. Simone Conceciao, Dr. Brad Cahoon, and Karen (Sam) Miller); to other researchers who allowed me to use their instruments and ideas; to my peers who motivated me to stay on task; to Marilyn, Penny, Nancy, Hugh, Capt. Lotring, Cdr. Gordon, Jana, Sitaramarao, and the Masie Center's E-learning Consortium. Your contributions made this study a success.

To hundreds of employees who voluntarily completed the survey Anonymous you remain but your experiences have informed us a lot about elearning!

Above all, I thank my God for granting me hope, strength, and wisdom through the years. 


\title{
ABSTRACT \\ EMPLOYEES' PERCEPTIONS OF BARRIERS IN E-LEARNING: THE RELATIONSHIP AMONG BARRIERS, DEMOGRAPHICS, AND E-LEARNING SELF-EFFICACY
}

\author{
Penina Mungania \\ February, 2004
}

The purpose of this empirical study was to examine the types of e-learning barriers and to establish the nature of relationships among (a) barriers perceived by employee e-learners in the process of starting, continuing, and completing online training; (b) demographic variables; (c) background characteristics; and (d) e-learning self-efficacy.

The population was comprised of employees $(N=4807 ; n=865)$ who had participated in Web-based training delivered 100 percent online. Convenient samples of employees were drawn from seven organizations representing (a) IT Manufacturing, (b) Oil Exploration \& Manufacturing, (c) Public School District, (d) Health Insurance, (e) Wholesale Distribution, (f) IT Consulting, and (g) US Military.

The social cognitive learning theory's dimension of self-efficacy examined e-learners' Internet and computer self-efficacy. Schilke's (2001) conceptual framework on e-learning barriers and ideas from various critics of the technological study guided the present study. 
The E-learning Barriers and Self-Efficacy (ELSE) survey was used to collect data from volunteer employees. This Web-based anonymous survey had 82 questions in three scales: (a) demographics and background characteristics; (b) Barriers in E-learning (BEL) scale (alpha = .9496) and one open-ended question; and (c) E-learning Self-Efficacy (ELSE) scale (alpha $=.9487)$. The instrument was validated using subject matter experts and a pilot study.

Response rates were $\mathbf{5 2 . 5 \%}$ (pilot study) and $\mathbf{1 8 \%}$ (main study). Data were analyzed using exploratory factor analysis, multiple regression, MANOVA, and Pearson correlation. Open coding was used for the open-ended responses.

Seven categories of barriers (factors) emerged: (1) Dispositional, (2) learning style, (3) instructional, (4) organizational, (5) situational, (6) contentsuitability, and (7) technological barriers. The barriers means ranged from 1.29 to 3.00 on a 5 -point scale $(1=$ weak and $5=$ strongest barrier $)$. Barrier ratings were weak on all categories. Personal barriers $(M=1.54)$ were the least common while situational barriers were the most prevalent $(M=2.81)$. The multidimensional nature of these barriers demands a systemic approach to reduce them. A MANOVA test indicated significant differences in barriers among the seven organizations.

The test of relationships using multiple regression revealed four predictors of e-learning barriers: (a) organization type, (b) computer competence, (c) computer training, and (d) e-learning self-efficacy.

Results, implications for practice, conclusions, and recommendations for further research are discussed. 


\section{TABLE OF CONTENTS}

\section{PAGE}

ACKNOWLEDGEMENTS

iv

ABSTRACT

LIST OF TABLES

v

ix

LIST OF FIGURES

INTRODUCTION

Theoretical framework.

Problem statement

Purpose

Research questions and hypotheses ......................... 10

Significance of the study ......................................... 14

Assumptions .................................................. 16

Limitations ........................................................ 17

Delimitations ................................................ 18

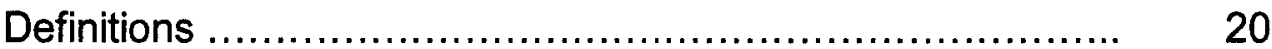

Conclusion ................................................ 25

LITERATURE REVIEW ................................................. 26

The technological society .................................... 26

Driving forces of change in e-learning ........................... $\quad 30$

Electronic learning (E-learning) ................................. 32

Barriers to participation in adult education ...................... 37

E-learning barriers ............................................. 38

Demographic variables ......................................... 42

Additional background variables ................................... 49

Types of Barriers ............................................... 55

Social Cognitive Theory and Self-efficacy ....................... 67

Conclusion.................................................... 80 
RESEARCH DESIGN AND METHODS .............................. 81

Instrument ................................................... 82

Validity and Reliability of the Instrument ........................ 89

Participants ...................................................... 92

Procedure........................................................ 97

Data Analysis.................................................... 103

Conclusion ................................................... 107

RESULTS ....................................................................... 110

Results of the pilot study ........................................ 112

Results of the main study.......................................... 116

Background characteristics ...................................... 123

Research question one ........................................ 129

Research question two ............................................... 145

Research question three .......................................... 158

Research question four ......................................... 162

Research question five........................................... 167

Conclusion ..................................................... 171

DISCUSSION, CONCLUSIONS, IMPLICATIONS, RECOMMENDATIONS

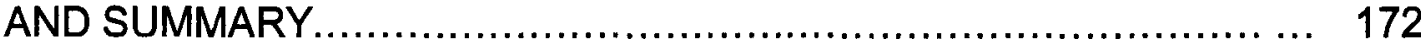

Research question one ....................................... 173

Research question two .......................................... 184

Research question three ........................................... 191

Research question four ......................................... 198

Research question five ........................................... 209

Implications for using web-based surveys for organizational research ................................................ 218

Limitations ........................................................ 221

Recommendations for future and further research ................ $\quad 227$

Conclusion ........................................................ 234

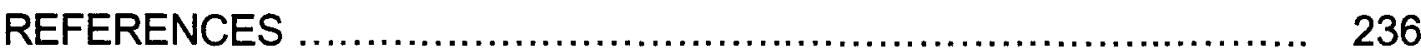

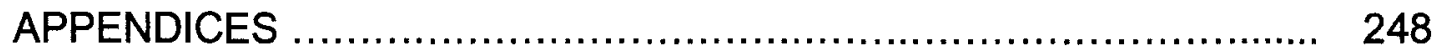

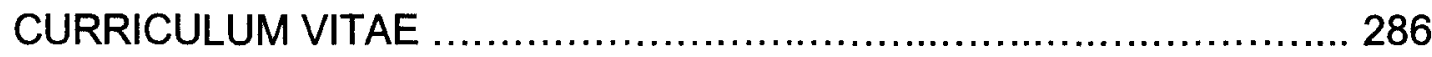




\section{LIST OF TABLES}

\section{TABLE}

1. Growth of the e-learning market in the US ...................... 2

2. Survey procedures used in the study .......................... 100

3. Research questions, variables, and statistical tests ............. 108

4. Pilot study reliability coefficients ............................. 115

5. Reliability coefficients for main study ....................... 116

6. Daily and weekly responses .............................. 117

7. Demographic characteristics of the respondents ............... 121

8. Three background characteristics of the respondents .......... 124

9. Prior e-learning experience of respondents ................... 126

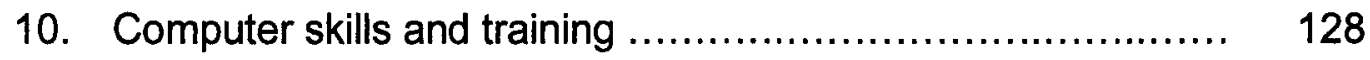

11. Barriers in E-learning (BEL) scale items, means, and standard 130 deviations

12. Kaiser-Meyer-Olkin (KMO) and Bartlett's tests for Barriers in E- 134 learning (BEL) scale .............................................

13. Components of Barriers in E-learning (BEL) scale with total variance explained.

14. Extracted factors from the Barriers in E-Learning (BEL) scale ... 137

15. Data on factors from the Barriers in E-Learning (BEL) scale... 138 
16. Descriptive statistics for dispositional and learning style barriers in organizations

17. Descriptive statistics for instructional and organizational barriers in organizations

18. Descriptive statistics for situational, content-suitability, and technological barriers in organizations

19. Model summary of variance explained by organization

20. Model summary of Relationships between barriers, job position, and study location

21. Model summary showing correlation between barriers predicted by computer skills and training

22. E-learning Self-Efficacy (ELSE) scale items, means, and standard deviations

23. Correlation between e-learning self-efficacy and barriers

24. Relationship between each type of barriers and e-learning selfefficacy 


\section{LIST OF FIGURES}

FIGURE

PAGE

1. Social cognitive theory ........................................ 6

2. Variables under study ........................................... 13

3. A model of barriers (Schilke, 2001) ............................ 41

4. Self-efficacy as a bridge between skills, action, and outcomes ...... 70

5. Line graph illustrating number of responses over 4 weeks .......... 118

6. Employee population and sample sizes in seven organizations ..... 120

7. Types of e-learning barriers.................................... 173

8. Triadic reciprocity between person, behavior, and the 215 environment. 


\section{CHAPTER I}

\section{INTRODUCTION}

The United States (US) corporate training market is worth over $\$ 100$ billion dollars (Moe, 2002), making e-learning the most rapidly growing segment of the training enterprise (Simmons, 2002; Taylor Nelson Sofres [TNS], 2001). Elearning is a trend that is engulfing the training industry in corporations and educational institutions (Schank, 2003). E-learning trends in the past five years and future predictions show exponential growth and investment as illustrated in Table 1 , with more than $60 \%$ of companies expecting to incorporate e-learning systems within two years (Simmons, 2002).

While continued investment in human, time, and financial resources for $e-$ learning is on the increase, the fact that $70 \%$ of e-learners do not complete scheduled online training (Meister, 2002 cited in O'Connor, Sceiford, Wang, Fourcar, Szocki, \& Griffin, 2003) is alarming. As companies quickly adopt e learning, they are facing unexpected barriers (Simmons, 2002). That is why the present research study investigated e-learning barriers that prevent learners from starting, continuing, and completing online training. 
Table 1

Growth of the E-learning Market in the US

\begin{tabular}{lll}
\hline Year & Growth in US \$ & Source \\
1997 & $\$ 197$ million & Moe (2002) \\
2001 & 1.2 billion & $\begin{array}{l}\text { American Society for Training and Development } \\
\text { (ASTD) and National Governors Association (NGA) } \\
(2001)\end{array}$ \\
2002 & $\$ 5.5$ billion & Moe (2002) \\
2003 & $\$ 7$ billion & ASTD and NGA (2001) \\
2005 & $\$ 18$ billion & Lord (2002) \\
\hline
\end{tabular}

An examination of the driving forces behind the growth of e-learning underscore e-learning' ability to reduce the two major traditional training barriers of time and money (Schank, 2002).

Secondly, in an effort to meet the changing demands of consumers and customers, organizations have turned to alternative forms of delivering instruction in order to improve their employee's performance. By 2005, it is projected that $85 \%$ of all jobs will require skilled workers (Moe, 2002). However, although people have become the key to success in today's highly competitive global economy (Kreitner \& Kinicki, 2002), over $75 \%$ of adults in the US do not have a bachelor's degree (Moe, 2002). Providing a lot of training is one of the key people-centered practices that is strongly associated with much higher profits and significantly lower employee turnover (Kreitner \& Kinicki, 2002). The Web 
has been commended for bringing human capital at the front and center where it belongs (Rossett, 2001).

Lastly, e-learning, has been adopted because it has the potential to provide access to high quality training content from multiple sources around the world among the other benefits (ASTD \& NGA, 2001; Kirk, 2001; Rosenberg, 2001). Consequently, many organizations have embraced e-learning and increasingly companies are adopting e-learning, but in this rush, they are encountering significant barriers to adoption (Simmons, 2002). Therefore, not all organizations are likely to implement this training strategy, because there are significant tradeoffs involved in terms of both costs and benefits (Nisar, 2002) and it brings with it new challenges to its users (Oblinger, Barone, \& Hawkins, 2001).

Apparently, "Like many other technologies, e-learning has its enthusiasts and skeptics. The enthusiastic view seems to dominate most of the e-learning literature, giving positive attributes of e-learning, high growth indicators, and lots of promises." (Mungania, 2003, p. 493). It is no wonder that the critics of the technological society Winner (1977), Postman (1993), Chidambaram and Zigurs (2001), Hatcher (2002), Schank (2003), and Webster, (2002) among others call for a critique of technology. They argue that technology has both good and bad impacts thus the intent and outcomes that technology has on individuals, organizations, and society in general demand questioning. Chidambaram and Zigurs (2001) argue that the losses brought by technology are typically less discussed and Schank (2003) warns that only a few have been able to 
understand the Web to leverage its value. While focusing on barriers might be construed as looking at obstacles brought by technology in the learning arena, it is not intended to dissuade organizations or individuals from using learning technologies. Rather, the purpose of the present study was to seek awareness of the nature of obstacles being faced by the learners. Such examination is critical considering the heavy investments and exponential growth associated with elearning.

E-learning is a major change and a recent addition to instructional delivery techniques that has brought with it unique issues that could impact e-learners' satisfaction (Schilke, 2001), learning (Garland, 1993), motivation to learn online (Kramarae, 2001), involvement, and even completion (Giles, 1999). Based on research conducted in higher education institutions, it is evident that innumerable barriers exist for adults engaged in distance learning (Garland, 1993; Schilke, 2001; Simmons, 2002). Like any other training delivery method, e-learning methods are sometimes flawed (Schank, 2002). This research study explored barriers faced by employee e-learners in seven organizations, populations that have not been addressed in previous studies on barriers such as research by Muilenberg and Berge (2001); Giles (1999) or Schilke (2001).

This was an exploratory study that aimed at promoting the understanding of e-learning barriers faced by employees in organizations. The examination of barriers was based on the social cognitive theory's dimension of self-efficacy, which influences choices about which behaviors to undertake, the effort, and persistence exerted in the face of obstacles to the performance of those 
behaviors (Campeau \& Higgins, 1995). The relationship between an individual's e-learning self-efficacy and perceived barriers was found to be significant.

To investigate the factors that employees consider as barriers to starting, continuing, and completing e-learning, this research study looked at several variables including demographics, type of organization, job position, computer ownership, computer training, location of study, and prior computer and elearning experience. The relationship between perceived barriers, employee's organization, computer skills and training emerged as significant.

\section{Theoretical Framework}

The theoretical foundation for the present study is grounded on the social cognitive theory. The dimension of social cognitive theory guiding this study was self-efficacy. Two aspects of self-efficacy are addressed (a) computer selfefficacy (CSE) and (b) Internet self-efficacy (ISE). This study is a synthesis of these two theories. The respondents' self-efficacy in e-learning were determined using the E-learning Self-Efficacy (ELSE) scale. This scale is the product of modifying and combining two instruments proposed by Eastin and LaRose (2000) and Cassidy and Eachus (2002).

Bandura (1986) indicates a triadic reciprocity occurs between a person, the environment, and behavior as illustrated in Figure 1. There is a reciprocal interchange between cognitive and personal factors like demographics and personality; environmental influences such as social pressures, and situational characteristics (Bandura, 1977; Campeau \& Higgins, 1995). Due to varied 
barriers, the present study examined barriers from a multi-dimensional perspective using Schilke's (2001) conceptual framework.

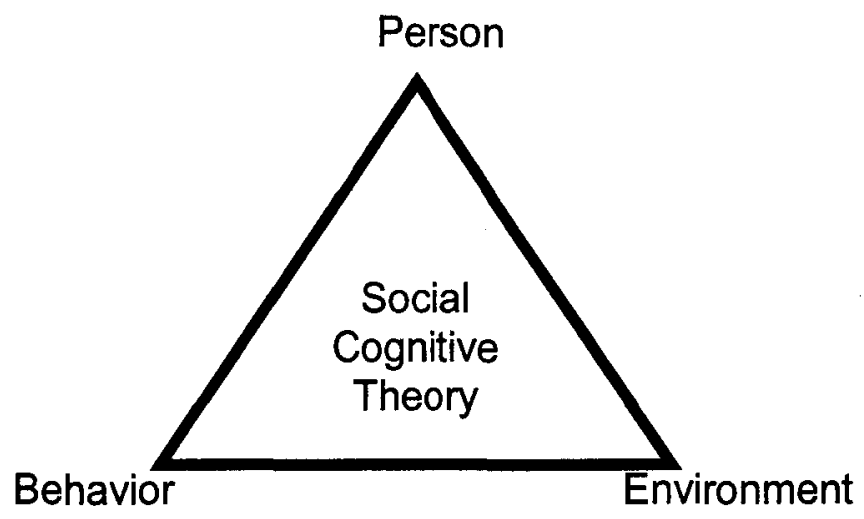

Figure 1. Social Cognitive Theory

\section{Problem Statement}

Distance learning is not a new phenomenon but the Internet is a relatively new learning technology. As a result, very little is known about the reasons for dropping out or persistence in online courses (Giles, 1999). To be able to address this challenge adequately, empirical research is necessary to enhance our understanding of this instructional technology.

The benefits brought by many of the latest technologies have been emphasized in the literature but little attention has been given to the barriers or obstacles faced by e-learners training online. Clearly, "The e-learning industry is currently facing growing pains as it matures from an innovative concept to an educational norm." (Kirk, 2002, p. 10). Biner (1993) suggests that in addition to assessing the levels of satisfaction both overall and with specific aspects of a course, and identifying facets of the course that predict overall course 
satisfaction, it also is important to identify areas of the program that are producing negative reactions. The latter point was the focus of this study.

The problem is that there has been a lack of a systematic analysis of barriers to organizational learning and most of the barriers that are referred to have been derived from theory and have not been empirically and systematically explored (Gieskes, Hyland, \& Magnusson, 2002).

Past research studies have highlighted the presence of learning barriers using other instructional delivery media such as Garland (1993) on college courses delivered through television broadcast, video, audio, slides and oncampus laboratory components. Others have looked at barriers in distance education using two-way interactive audio-video (Feldhaus, 1999); online computer-conference classrooms (Giles, 1999); college Web-based courses (Schilke, 2001). Clearly, research on barriers in organizations using e-learning to deliver instruction was found to be lacking.

In terms of the population, most of the existing literature on barriers perceived by distance learners is based on research conducted in college and university settings, that are different populations from that investigated in the present study (Garland, 1993; Giles, 1999; Feldhaus, 1999; Schilke, 2001). Garland (1993) and Schilke (2001) studied barriers experienced by students in college; and Simmons (2002) researched on barriers perceived by senior human resource and learning and development executives in corporate America. Most of these studies are mostly qualitative case studies or literature reviews. While these studies are useful, it would be inappropriate to generalize the results 
across all organizational settings. Berge (1998) and Berge and Muilenburg (2000) focused on barriers experienced by faculty when teaching online. Giles (1999) advocates "Researchers might want to be aware of the technical environment and context of their study so (that) appropriate variables can be identified for use in their study" (p.91). Berge, Muilenburg, and Haneghan (2002) recommended a study looking at barriers from a student's perspective and looking at other demographic variables. Organization was one of the variables investigated in this study. The population under study is made up of employees who have participated in e-learning in seven organizations, representing various organizational functions and job positions. The dearth of research that looks specifically at barriers experienced by this population is the gap that the present study sought to fill.

In a study by Schilke (2001) in higher education, most of the e-learners' decision to drop out was a result of a series of "individual small problems" and they could not identify one single factor that made them drop out. Another study by Galusha (1998) also reiterates that barriers experienced in DE are multidimensional with no single factor appearing to cause non-participation or non-completion. From a corporate standpoint, Simmons (2002) acknowledges that technology is only one of several barriers encountered. The present study's findings clearly enunciate the heterogeneous nature of barriers as discussed in Chapter 4.

Previous DL researchers have emphasized the need for further research pertaining to learning barriers particularly advocating for more research on 
attrition in Web-based instruction (Giles, 1999; Schilke, 2001) because attrition is indicative of obstacles in the learning process. The study of obstacles encountered in DE has been ignored and there is anecdotal information and speculation (Dean, Biner, \& Coehen, 1996; Feldhaus, 1999). Galusha (1998) noted a need for closer scrutiny of the intrinsic problems in DE facing learners and emphasized "further study of student demographics and motivators will help target the adult learner population and will help develop course materials and techniques appropriately" (Galusha, 1998, p.11). Berge (1998) argued that regardless of the advantages of online instruction, critical barriers to $D E$ specifically to online education at a distance do exist.

Literature on the utilization of theory to enhance the understanding of barriers seems limited. To fully understand barriers facing e-learners, it is fundamental to analyze them from a theoretical framework. A theory provides a conceptual framework that explains why something is occurring (Kreitner \& Kinicki, 2002). "Part of the challenge in researching obstacles in distance education is to identify a convenient framework for discussion and study" (Berge, Muilenburg, \& Haneghan, 2002, p.2). The present study used self-efficacy theory, a key dimension of the social cognitive theory that attests that one's beliefs can pave the way for success or failure (Kreitner \& Kinicki, 2002). A study by Kahl and Cropley (1986) of German distance students reported that distance learners demonstrated significantly less self-confidence than their conventional counterparts" (cited in Sheets, 1992, p. 9). This is indicative of the effect of a 
delivery media on the learner's confidence and perceptions and thus the relationship between e-learning barriers and self-efficacy was investigated.

\section{Purpose}

The purpose of this study was to investigate the factors that employees consider as barriers to starting, continuing, and completing online training. This study also determined the relationship between barriers and other variables including computer and Internet self-efficacy, demographics, type of organization, job position, computer ownership, computer competence, computer training, location of study, and prior e-learning experiences.

\section{Research Questions and Hypotheses}

Five research questions guided this study and several hypotheses were tested:

\section{Research Question 1}

What barriers do employees engaged in e-learning in organization face? Undisputedly, institutions and corporations face a number of challenges and opportunities in providing effective training (Christoph, Shoenfeld, \& Tansky, 1998; Colbrunn \& Tiem, 2000). Learners in turn experience challenges regardless of the medium used. Previous research clearly shows that distance learners experience multiple learning barriers (Galusha, 1998; Garland, 1993; Giles, 1999; Kramarae, 2001; Oblinger, Barone, \& Hawkins, 2001; Schilke, 2001; Simmons, 2002). 
Research Question 2

Are there differences in perceived barriers based on an employee's organization?

Hypothesis 1. There will be significant organizational differences in employees' perceptions of barriers. Organizational environments differ and so do their resources, nature of business, and services that they offer. Timura (1995) and Muilenburg and Berge (2001) found organizational differences in perceptions towards distance learning. Seven organizations offering online training to their employees were studied.

\section{Research Question 3}

What is the relationship between perceived barriers and demographic variables such as age, gender, ethnicity, marital status, level of education, and organization?

Hypothesis 2. Demographic variables of age, gender, marital status, ethnicity, level of education, and organization have significant relationships with barriers.

Studies differ on the effect of demographics on distance learners' perceptions with recent studies by Litchfield, Oakland, and Anderson (2002) and Feldhaus (1999) arguing that demographics do not have a significant impact on e-learner perceptions. The conflicting findings on the effect of demographics demand further study in addition to their relationship with e-learning barriers. 
Research Question 4

What is the relationship between perceived barriers and an employee's (a) job position, (b) study location, (c) computer ownership, (d) computer training, (e) computer competence, $(f)$ prior experiences with e-learning.

Hypothesis 3. There is a significant relationship between perceived barriers and an employee's (a) job position, (b) study location, (c) computer ownership, (d) computer training, (e) computer competence, (f) prior experiences with e-learning.

The participants of this study had varying levels of education and experience with computers and e-learning. This study examined the relationship between perceived barriers and these variables.

\section{Research Question 5}

What is the relationship between perceived barriers and an employee's selfefficacy?

Hypothesis 4. A significant relationship exists between an employee's selfefficacy and perceived barriers. Research indicates that individuals with a strong sense of efficacy do not get deterred by difficult problems and as a result of their continued persistence, they are more likely to overcome whatever obstacles are present (Campeau \& Higgins, 1995). Those with weak Internet self-efficacy tend to have little confidence in their ability to use it and are dissatisfied and uncomfortable with their Internet skills (Eastin \& LaRose, 2000). 
A graphic view of the variables under study and their relationship to barriers is shown in Figure 2.

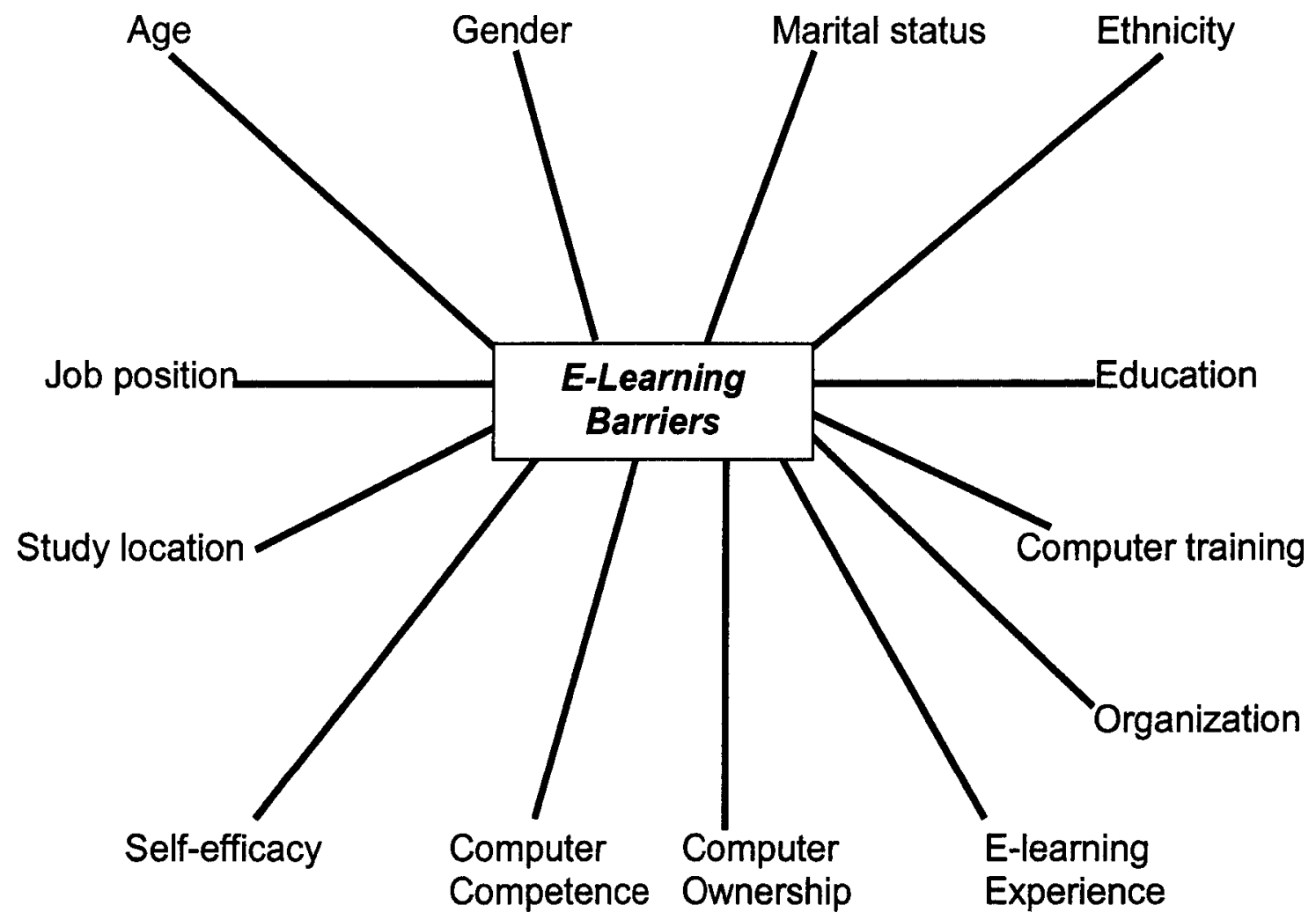

Figure 2: Variables under study

To answer these research questions, a survey was constructed and validated. The Barriers in E-learning and Self-efficacy (BELSE) survey instrument was used and it comprised of three scales made up of:

(a) Demographic questions. These questions established the demographic makeup and background characteristics of the e-learners.

(b) Barriers in E-learning scale (BELS). This scale was developed for the purpose of determining barriers faced by employees undertaking online 
courses. The reliability analysis found this survey to be highly reliable (alpha $=.9496)$.

(c) E-learning Self-Efficacy (ELSE) scale. This scale measured the employees' e-learning self-efficacy (Internet and Computer self-efficacy). It was also highly reliable $($ alpha $=.9487)$.

The instrument was validated using seven subject matter experts (SMEs). The SMEs found the instrument to have face and content validity. Feedback from SMEs and the pilot group was used to refine the instrument.

Both descriptive and inferential statistics were used to analyze the quantitative data. Descriptive statistics (means, standard deviations, and frequencies) were calculated. Inferential statistics such as multiple regression, multivariate analysis of variance (MANOVA), and a factor analysis were computed. Dependent variables emerged from a factor analysis. Chapter 3 presents a more in-depth look at the data analysis methods and Chapter 4 presents the results of these analyses.

\section{Significance of the Study}

The results of this study have multiple implications and significance to various stakeholders who include prospective and current employees, administrators, management, trainers, technical support staff, instructional designers, and community members such as family members, vendors, technology manufacturers, and service providers who are involved in the elearning business. It is intended that as a result of this research study: 
1. E-learning stakeholders have additional information concerning barriers that emerge with e-learning. The findings of this study are useful for assisting elearners and organizations to overcome barriers, and to aid in planning, implementation, and delivery; with a focus on continually improving the online learning environment.

2. This study attributes the nature of the relationship between an individual's elearning self-efficacy and barriers. Studies have been conducted that look separately at computer self-efficacy (Campeau \& Higgins, 1995, 1999) or the relationship between e-learning and Internet self-efficacy (Eastin \& LaRose, 2000) but not a combination of the two as evident in e-learning.

3. E-learning stakeholders now have a valid instrument for determining barriers in e-learning environments. The Barriers in E-learning and Self-Efficacy (BELSE) survey is a valid instrument for determining demographics, background characteristics, e-learning barriers, and self-efficacy.

4. The generalizability of this study's findings might be context-bound to organizations with similar e-learning populations. However, the present study's findings contribute to the empirical body of literature on e-learning and provides a foundation upon which future studies could be based.

5. Identification of barriers must come before barrier reduction strategies are implemented. Therefore, the findings will assist stakeholders in determining and implementing systems, support services, policies or products for solving problems encountered by e-learners. 
6. The findings reveal the threats that diffusion of technology has on organizational learning. This is necessary since most of the literature mostly focuses a lot on the benefits and promise of e-learning. A look at barriers is essential to determine what changes need to be made in order to make learning more effective.

\section{Assumptions}

At the beginning of the study, the researcher made several assumptions. The first assumption was that the chosen organizations would support the study by granting the researcher access to the targeted population. This would be accomplished by going through contact persons in each of the organizations who would forward requests (via email) concerning participation to the targeted employees. The contact persons supported this study thus meeting this assumption.

The second assumption was that the participants (employees) would be representative of employee e-learners in organizations and the emerging results would be transferable to other similar organizations, to the extent possible. Although a random sampling was not done, a purposive sample was selected from a wide variety of respondents. Babbie (1998) suggests that especially in the initial design of a questionnaire, the widest variety of respondents should be selected to test the broad applicability of questions. A purposive or judgmental sample is recommended especially on occasions when the researcher wants to select a sample on the basis of knowledge of the population, its elements and 
research aims (Babbie, 1998). This being an exploratory study, the participants were drawn from seven organizations representing manufacturing, military, service, sectors and a public school district.

The third assumption was that the participants would be willing to cooperate and give accurate data based on their e-learning experiences. Based on the response rate $(n=865)$, the cooperation assumption was met.

The fourth assumption was that the employees that have had an opportunity to engage in e-learning would be a significant source of information identifying barriers. This assumption was met considering the wealth of information they provided as discussed in Chapter 4.

The fifth assumption was that each individual employee's e-learning experiences somewhat differ and their responses would be independent of each other.

Since a Web-based questionnaire was used, there was an assumption that the respondents would be representative of the target population. Measures taken included using a password to limit access to the sampling frame as much as possible.

\section{Limitations}

This study just like any other had limitations. These are reviewed in more detail in Chapter 5. They included:

(a) A lack of a true random sample thus limiting the generalizability of the findings. A purposive sample of convenience was used. 
(b) Only a limited sample had access to the web survey. Those who responded had to have the access password, access to a computer, email, and the Internet at the time of data collection.

(c) The researcher was not able to ascertain the exact response rate in one organization due to communication problems.

(d) Limited access to participants since the researcher relied on the willingness and reliability of the contact persons in each participating organization to communicate with the respondents.

(e) Selection bias was a limitation because the researcher had access to a limited number of employees and in seven organizations only.

(f) The data had some elements of subjectivity to it since this study depended on self-reported data from the participants. "Every evaluation has some aspect of bias within it, ranging from choosing metrics to foregone conclusions" (Kidney, 2001, p.27).

(g) Lack of direct communication during the data collection process between the researcher and the employees resulted in misinterpretations of the instructions by some participants and anomalies in the procedures.

(h) Lack of specificity in the responses was a limitation. Some of the comments were not very specific enough to reveal the actual barrier faced, thus not revealing much about the exact nature of the problem encountered.

(i) The results might also have been skewed due to the disproportionate sample sizes in some of the organizations, ranging from 8 to 256 . 


\section{Delimitations}

This study is not about barriers faced by e-learning stakeholders in the process of designing, teaching or implementing e-learning. This study focused only on barriers faced from an e-learner's 'lens' and not from the administration or design perspective. Since some of the designers, teachers and administrators might also have participated in these online courses for professional development purposes and might be included in the population, they were specifically instructed to respond to the questionnaire from their experiences as e-learners.

This study targeted employees who have participated in e-learning courses offered by these organizations that are delivered $100 \%$ online. The present study excluded employees who had no experiences with e-learning.

The examination of barriers was not only restricted to e-learning technology but looked at multiple sources of barriers such as barriers relating to the individual, the environment, and instructional design, among others.

While the researcher acknowledges the existence of barriers that face elearners after they are trained in an effort to apply what they have learned, this was not a study of barriers to transfer of training.

The e-learning experiences under study were restricted to online courses that respondents had taken at their current place of employment. They were asked to limit their perceptions to e-learning barriers to their experiences in the current organizations. 
Lastly, this study was only a partial view of learners' perceptions but did not address how they see e-learning in its totality. The focus here was only on barriers to starting, continuing or completing courses and not other aspects of online training such as its effectiveness or deficiencies.

\section{Definitions}

Below is a list of terms as they are operationally defined and used in the present study. Due to the ever-changing nature of technology some of these terms have multiple applications.

Asynchronous Instruction not occurring in real time. The trainer and the trainee are not simultaneously engaged in the learning.

Attrition The process of dropping out of a class either through formal notification of withdrawal or without any form of notification of one's intent to drop a course (Giles, 1999). Non-completion, attrition, and dropout are used synonymously.

E-learning Barriers These are obstacles encountered in the process of learning online (when starting, continuing, and completing training) that could negatively impact one's learning experiences. This term is synonymous with obstacles, challenges or hindrances.

BELSE The acronym for the Barriers in E-Learning and Self-Efficacy scale, an instrument developed to determine e-learning barriers and self-efficacy among employees in organizations. 
Computer Self-Efficacy (CSE): Refers to the judgment of one's capability to use a computer (Campeau \& Higgins, 1995).

Diffusion

"The process by which an innovation is communicated through certain channels over time among the members of a social system." (Rogers, 1995, p. 10).

Digital divide The gap in access to computer technology among various populations (Williams, 2001).

Discussion board An electronic forum or message board on the Internet or an Intranet where users can post and read messages.

Declarative knowledge Refers to knowledge acquired from instruction, which is necessary but not sufficient for higher order learning (Martocchio \& Hertenstein, 2003).

Distance learning (DL): Involves the acquisition of knowledge and skills by learners who may be separated in time and space from their peers and the instructor, incorporating synchronous and/or asynchronous technologies.

Distance training (DT): Instruction delivered via technology where space and/or time separate an instructor (trainer) and learners (trainees). Such training is conducted for professional or personal development purposes in order to improve performance.

Dropouts Used as a noun to refer to learners who register for an online course but who voluntarily withdraw from a course. 
Education

E-Learners

E-learning

ELSE

End-user
Refers to the lifelong process of acquiring knowledge, skills, and values, formally through schooling or informally through social interactions and personal experiences (Ornstein \& Levine, 1987).

In this study, e-learners are employees who engage in mandatory and/or voluntary professional development training that is delivered $100 \%$ via the Internet or an Intranet. Refers to the delivery of educational content or learning experiences delivered or enabled by electronic technology via a Web browser, synchronously and/or asynchronously. This could be over the public Internet or a private Intranet, with or without interactive features such as e-mail, chats, bulletin boards, and discussion groups. It also may include links to other resources and/or an online facilitator(s). It is synonymous with Web-based training and online learning. Stands for the E-learning Self-Efficacy scale that was used in the present study to measure employees' self-efficacy, incorporating Internet and Computer Self-efficacy.

The person for whom a technology is designed or the individual who uses a technology for its designated purpose. In the present study, employee e-learners are an example of end-users of e-learning technologies. 
Firewall

Innovation

Internet

Intranet

Internet Self-Efficacy (ISE) Refers to the belief in one's capabilities to organize and execute Internet-related courses of actions in order to accomplish something (Eastin \& LaRose, 2000).

A private network that uses Internet-related technologies to provide services within an organization (Schreiber \& Berge, 1998).

Learning Management System (LMS): A platform, which deploys and manages learning content (Pollard \& Hillage, 2001). It is also referred to as Course Management System (CMS) or Virtual Learning Environment (VLE).

Locus of control A personality dimension, which determines how much responsibility an individual, takes for her/his behavior and its consequences (Kreitner \& Kinicki, 2001). 
Needs Assessment "A systematic set of procedures undertaken for the purpose of setting priorities and making decisions about program or organizational improvement and allocation of resources. The priorities are based on identified needs." (Witkin \& Altschuld, 1995, p.4).

Re-invention

"The degree to which an innovation is changed or modified by a user in the process of its adoption and implementation." (Rogers, 1995, p. 17).

Reliability

"The quality of measurement methods that suggests that the same data would have been collected each time in repeated observations of the same phenomenon" (Babbie, 1998, p. 378).

Sampling frame A list or quasi list of units composing a population from which a sample is selected (Babbie, 1998).

Self-efficacy

The belief in one's ability to successfully accomplish a specific task (Kreitner \& Kinicki, 2002). "It is not concerned with the skills one has but with judgments of what one can do with whatever skills one possesses" (Bandura, 1986, p. 391). In the present study, it is one's belief that one can be successful in e-learning.

Synchronous Instruction that occurs in real time. The trainer and trainees are engaged in the learning process simultaneously. 

as a tool (equipment), a network, or an organization, and as a technique (knowledge or skills) (Winner, 1977).

Theory

A 'story' that defines key terms, provides a conceptual framework (graphic model), and explains why something is occurring (Kreitner \& Kinicki, 2002).

Validity

"A term used to describe a measure that accurately reflects the concept it is intended to measure" (Babbie, 1998, p. 381).

Conclusion

This chapter presented an overview of the present study. The problem, theoretical framework, purpose, research questions, hypotheses, assumptions, limitations, delimitations, and the study's significance were discussed, although each of these facets are more detailed in Chapters 2 through 5. Chapter 2 presents a review of pertinent literature, Chapter 3 discusses the research methods, Chapter 4 reviews the results, and Chapter 5 discusses the results, drawing conclusions, implications, and recommendations. The ultimate goal of the researcher is to inform e-learning stakeholders so that they are better prepared before engaging in e-learning and to make improvements in already existing e-learning programs. 


\section{CHAPTER II}

\section{LITERATURE REVIEW}

This research study examined the barriers faced by employees engaged in e-learning in seven organizations. Barriers are defined as obstacles that learners are faced with that could negatively impact their starting, continuing or completion of e-learning courses. Learning barriers have been found to have effects on an individual's (a) learning, (b) levels of satisfaction, (c) persistence, and (d) propensity to dropout (Giles, 1999; Schilke, 2001).

To gain an understanding of e-learning and the related barriers, this chapter reviews literature pertaining to the driving forces behind the dramatic growth of e-learning in organizations, and barriers in traditional adult training, distance learning, and e-learning in particular. Additionally, this chapter describes the technological society and the social cognitive theory that guided this study.

\section{The Technological Society}

This section focuses on the impact of technology on society and especially on workplace learning. Barriers facing e-learners can best be understood by first looking at technology as the main change agent. E-learning is an example of the application of technology in today's organizations. 
Everyday, technology brings changes at work, play, and life in general (Chidambaram \& Zigurs, 2001). New technologies are revolutionizing work and transforming learning, creating a working-learning infrastructure (ASTD, 1998). The Internet is one of the key developments in learning technologies that is expected to have far reaching impact in the learning technology arena (ASTD, 1998). The Internet has already witnessed dramatic growth with tremendous impact on business, industry, and the community (ASTD, 1998).

"The virtual world increasingly challenges our traditional ways of dealing with one another" (Chidambaram \& Zigurs, 2001, p. ii) and technological innovations are especially changing training delivery in today's organizations. There are two schools of thought on whether it is technology that impacts society or vice versa.

Technological determinism. This theory is occasionally referred to as 'media determinism' and it is the most popular and influential theory of the relationship between technology and society (Chandler, 2003). Technological determinism theory seeks to explain social and historical phenomena in terms of one principal or determining factor (Chandler, 2003). Technological determinists hold the belief that technology impacts society and is the main enabling source of change in the virtual society (Chidambaram \& Zigurs, 2001). Technological determinists hold the belief that technology develops its own laws, that it realizes its own potential, it is limited only by material resources available, and is therefore autonomous (Heylighen, 2003; Winner, 1977); ultimately permeating all 
other subsystems of society (Heylighen, 2003). Technology has indeed penetrated all spheres of human life and especially education and its delivery.

Social determinism. Social determinism is the belief that society shapes technology and that any activity including technology, initiated by human beings must be a part of society (Hatcher, 2002). "Social determinism holds that society sculpts technology and thus technology can never be autonomous" (Hatcher, 2002, p. 139). It is the converse of technological determinism.

The technological determinism theory has been increasingly subject to critical review by scholars recently (Chandler, 2003). "Whether technology is autonomous or is governed by society, it is a fact that its development and implementation almost always causes unintended results. Actually, even sensible uses of a technology can sometimes have undesirable consequences some of which may show up decades later (National Academy of Engineering [NAE], 2001). Some of these results are good, others not so good" (Hatcher, 2002, p. 139). Winner (1977) also cautions that there is a "dark" side of technology that deserves criticism. Based on these premises, the present study investigated the side effects of technology by looking at barriers that technology brings to learning. What is critical is thoughtful consideration of the technological advantages and disadvantages. The National Academy of Engineering [NAE], 2001) cautions:

\footnotetext{
"If we perceive technology through the lens of technological determinism, we cannot weigh the risks or costs associated with a technology or its benefits. Certain technologies are used in ways that some people find objectionable or that result in unintended and sometimes undesirable consequences. And almost always, technologies are more advantageous
} 
for some people, animals, plants, generations, or purposes, than others. If one views technology as being outside human control, these considerations may never come up." National Academy of Engineering [NAE], 2001).

Various writers show that "The diffusion of technology into society and its subsystems is not without obstacles. Social, economic, physical and learning barriers exist in the workplace and schools" (Berge, Muilenburg, \& Haneghan, $2002, p .1)$. The technologies underlying the transformation to the virtual world may be viewed as a double-edged sword (Chidambaram \& Zigurs, 2001).

"Changes in technology always mix opportunity and threat" (Harry \& Peratton, 1999, p.5) of "gains and losses" (Chidambaram \& Zigurs, 2001). Belanger and Jordan (2000); Chidambaram and Zigurs (2001); Hatcher (2002); Postman (1993), and Winner (1977) among other researchers and critics of technology emphasize the need to look at both the advantages and disadvantages of each technology but according to Chidambaram and Zigurs (2001), the losses are typically less discussed. Why is this the case? Postman argues

"Because of its lengthy, intimate, and inevitable relationship with culture, technology does not invite a close examination of its own consequences. It is the kind of friend that asks for trust and obedience, which most people are inclined to give because its gifts are truly bountiful. But, of course, there is a dark side to this friend. Its gifts are not without a heavy cost...Technology, in sum, is both friend and enemy" (Postman, 1993, p. xii).

Chidambaram and Zigurs (2001) argue that technology fills gaps while creating new ones at the same time. "An awareness of the tradeoffs is the first step to managing them" Chidambaram and Zigurs $(2001, \mathrm{p}$. i ). This necessitates a critique of e-learning that is an important facet of this study because doing so 
will enable the organizations under study to examine what does not work in their e-learning system and to make improvements.

While the debate between technological determinism and social determinism continues, it is clear that technology is one of the major forces behind the recent trend in the growth of e-learning and below is an examination of other driving forces of change.

\section{Driving Forces of Change in E-learning}

Based on the literature reviewed, the reasons contributing to a changing educational culture are multifaceted to include globalization, social, cultural, economic, technological, ideological, political (Chidambaram \& Zigurs, 2001; Dhanarajan, 1998; O'Malley \& McCraw, 1999) and corporate development changes (Hatcher, 2002). These forces transcend national, regional, and international boundaries (Chidambaram \& Zigurs, 2001). Technological changes also represent "an evolutionary rather than revolutionary movement (Chidambaram \& Zigurs, 2001, p.11). These driving forces are demanding organizational changes in the way training and organizational learning is delivered. Driving forces of change in e-learning emerge from internal influences (such as the changing nature of work) and external environmental influences such as social, economic, and technological changes as discussed below.

Social forces. The demographic profile of the workforce is changing (Sheets, 1992; Ullrich, 1998) and an enlightened and diversified population is a major driving force of change (Chidambaram \& Zigurs, 2001). This has resulted 
in the need to adopt new instructional delivery systems (O'Malley \& McCraw, 1999), to broaden access, and to improve skills and knowledge through training and higher education (Moore, 2000).

Economic factors. Economic pressures are forcing businesses to shut down or to constantly layoff employees. Workers have to re-train for new careers (Sheets, 1992) in order to cope with organizations' reduced loyalty (O'Malley \& McCraw, 1999). This has resulted in a demand for lifelong learning, higher education, and professional development opportunities. Economic factors are calling for a reduction in training costs in order to increase profitability (Moore, 2000) and to successfully compete (Jackson, 2000; O'Malley \& McCraw, 1999; Schreiber \& Berge, 1998; Jackson, 2000; Moore, 2000).

Diminishing human and capital resources (ASTD \& NGA 2001; Schreiber \& Berge, 1998; Whalen, 1999) have led to an increasing training need and a demand for lifelong learning whereby people have to continuously update their knowledge and skills as well as learn new ones are perpetuating the trend. There is an insatiable demand for immediate needs for information referred to as "justin-time training" (Colbrunn \& Tiem, 2000) in order to remain competitive and upto-date.

Technological forces. The shift from the industrial revolution to an information revolution has resulted in new technologies. There has been a continued need to utilize new technologies for training purposes (Schreiber \& Berge, 1998) following emergence of the Internet in the 1990s and its growing popularity (Schilke, 2001). 
To respond to these demands, some organizations are moving on to using various approaches to deliver their training. A discussion of e-learning or Webbased delivery follows.

\section{Electronic Learning (E-learning)}

"While elements of e-learning have been around in some form or another for over ten years, the development of information and communication technologies have meant that e-learning has now come to mean much more than just learning from a computer" (Pollard \& Hillage, 2001, p.20). E-learning is usually associated with learning via a computer (Pollard \& Hillage, 2001), but this concept is increasingly broadening its focus to include a variety of learning options, administration of learning, and the provision of learning support (Pollard \& Hillage, 2001). Rossett (2002) supports this broad view in her definition of elearning which she refers to as the "big tent view" of e-learning that incorporates at least five functions: (a) learning; (b) information support and coaching; (c) knowledge management, (d) interaction and collaboration; and (e) guidance and tracking.

The Institute for Employment Studies [Pollard \& Hillage, 2001) defines elearning as "The delivery of learning opportunities and support via computer, networked and web-based technology to help individual performance and development." (p.20). They provide a three-level model that presents a more holistic view of e-learning. 
The first level is the provision of information: E-learning can be used to circulate information widely and to provide immediate information that enables individuals to refresh or extend their knowledge and for performance improvement (Pollard \& Hillage, 2001). This provides employees with online access to the organizations' mission statements or products or services that the organization offers (Pollard \& Hillage, 2001). This level is similar to Rossett's (2002) information support function of e-learning.

This is a more advanced level, information is provided through performance support in an interactive and immediate manner to support the individual in day-to-day work tasks (Pollard \& Hillage, 2001). E-learning at this level helps to simplify task complexity by providing information necessary for performing a task and by helping individuals to identify appropriate actions (Pollard \& Hillage, 2001). This may include the use of Electronic Performance Support Systems (EPSS), which allows users to learn while actually accomplishing a task (Pollard \& Hillage, 2001). Rossett (2002) calls this function information support and coaching, where the focus is "on building an external resource into which the individual dips at the moment of need" (p. 7). This aspect of e-learning has been acclaimed for its ability to provide just-in-time learning (Pollard \& Hillage, 2001).

The second level of e-learning provides interactive learning through materials that are designed to facilitate skills (Pollard \& Hillage, 2001). On this level, e-learning is used to provide a structured event intended to provide skills and knowledge (Pollard \& Hillage, 2001) in order to enhance an individual's 
capacity (Rossett, 2002). Various types of skills are taught via e-learning including but not limited to information technology (IT), (the most dominant), management training, induction programs, business applications, etc. (Pollard \& Hillage, 2001). This is the level that is commonly associated with the term 'elearning'.

The third level of e-learning is multi-dimensional, incorporating the first two levels into a wider performance support framework of knowledge management (KM), learner support, and learning administration (Pollard \& Hillage, 2001). Rossett's (2002) functions of knowledge management; interaction and collaboration; and guidance and tracking can be categorized under this level. Elearning is used to administer and monitor learning activities and outcomes, and to provide learners with various forms of support from experts and peers (Pollard \& Hillage, 2001).

There is debate about the merging of $\mathrm{KM}$ and e-learning since the two have different goals (Pollard \& Hillage, 2001). However, "e-learning can be seen as a way to share expertise by capturing, storing, and organizing the knowledge and experiences of staff, in order to make it available to others in the organization" (Pollard \& Hillage, 2001, p. 1). Online communities are another interactive form where learners are supported or coached by 'experts', not necessarily by skilled trainers but people with relevant experience or expertise, which they wish to share (Pollard \& Hillage, 2001). This aspect of e-learning is especially evident in the public school district under study where 'experts' among the staff members serve as content developers and online facilitators. 
Also included in this multi-dimensional aspect of e-learning are various forms of learner support (Pollard \& Hillage, 2001). Organizations provide facilities such as emails, online conferencing through which communities of practice (COPs) or collaborative learning communities (LCs) develop where peers share their experiences. Formal support between trainers and learners, more individual and informal learning opportunities through coaches or mentors and individual learners, are other learner support systems evident in organizations (Pollard \& Hillage, 2001).

Learning Management Systems (LMS)

To deliver content and to aid in the administration of e-learning, a learning management system (LMS) is usually used. LMS is also referred to as course management system (CMS) or virtual learning environment (VLE) (Pollard \& Hillage, 2001). Some of the platforms used by the organizations under study for deploying and managing e-learning content include Traccess $^{\mathrm{TM}}$, Mindleader ${ }^{\mathrm{TM}}$, Centra ${ }^{\mathrm{TM}}, \mathrm{Saba}^{\mathrm{TM}}$, and $\mathrm{ANGEL^{ \textrm {TM } }}$.

An LMS is a key ingredient of successful online learning (Epic, 1999 cited in Pollard \& Hillage, 2001) because it performs various functions. These include creation of course content, course management, course registration, information management, scheduling, administration, and provides access to learning. An LMS can also be used to track student registration, access, and progress; provide a learning environment; produce learning reports; assign students to groups; manage results; provide communication and collaboration tools; provide 
access to online help; and personal space for learners to store learning materials (Pollard \& Hillage, 2001). These capabilities of LMS indicate why e-learning has become popular among its other benefits.

E-learning has come to be associated with benefits such as flexibility because adult e-learners like the ability to control their time and coordinate their work, learning, and home responsibilities, and to do that at their convenience (Giles, 1999; Kramarae, 2001). "Adult students are looking to the online environment for providing educational opportunities they would not otherwise have sometimes due to circumstances beyond their control" (Giles, 1999, p. 77). E-learners also value the fact that they can learn at their own pace without schedule restrictions (Kramarae, 2001). Other advantages include the access to high quality content and to appropriate expertise irrespective of distance (ASTD \& NGA, 2001; Bonk, 2001; Furnell, Evans, Phippen, \& Abu-Rgheff, 1999). Elearning also has the ability to reach more learners; to broaden access to those who have been sidelined in the past (ASTD \& NGA, 2001; Bonk, 2001; Kirk, 2001); and the ability to improve efficiency in research and teaching, resource sharing, and to building partnerships (Bonk, 2001).

Online course materials have been credited for reinforcing classroom instruction, providing synchronous interaction and communication outside of the classroom, providing opportunities for self-paced remediation, and selfassessment among others. For the instructor, e-learning is acclaimed for providing multiple ways to communicate, monitor, track learners' progress unobtrusively provide feedback, and reward learners (Belanger \& Jordan, 2000). 
"Unfortunately, despite all the hype, not all learners and not all organizations benefit from e-learning" (Pollard \& Hillage, 2001, p.28). While the benefits have been highlighted in most of the literature, online learning also comes with some costs and/or obstacles. This realization resulted in the need for the present study on e-learning barriers.

\section{Barriers to Participation in Adult Education}

In his classic writings on departure from higher education institutions and from the system, Tinto (1993) argues that what research studies do not reveal are the processes leading to departure of students. Adult learning literature on traditional delivery methods reveals an interplay of forces (Sheets, 1992) and several barriers that interfere with participation of adults in educational and training activities. Charner and Fraser (1986) noted that the reasons for nonparticipation are related to socioeconomic status, race, and prior educational attainments. In addition, financial limitations, geographic restrictions, and personal preferences for self-paced learning, affect adult learners' attendance or progress (Fahy, 1991).

Tinto (1993, p. 37) argues, "...departure is a highly idiosyncratic event, one that can be fully understood only by referring to the understandings and experiences of each and every person..." However, there are some common themes among adult learners who depart. These fall under three categories: individual disposition, institutional, and external forces (Tinto, 1993) as discussed next. 
First is the disposition of individuals, that is, one's intention and commitment to learning (Tinto, 1993). The attributes, skills, and dispositions of individuals prior to entry affect the external forces on participation. According to Evans (1989) adult learners' motivation, fully formed ideas, values that are resistant to challenge, self-image, and reentry shock can be barriers to adult education.

On the institutional level, adjustment difficulty, incongruence between preentry expectations and experiences, isolation, and the nature of their interaction experiences within the institution determine one's persistence following entry (Tinto, 1993).

External forces such as obligations and finances shape persistence and sometimes influence individuals' behavior within the institutions (Tinto, 1993). These include an individual's contextual situation, family, work, and community roles, physical condition, personality, and earning ability (Knox, 1977 cited in Sheets 1992).

In addition to these barriers in traditional learning, a literature review found that learners involved in distance education are more likely to have insecurities (Galusha, 1998). The role of self-efficacy and its effect on e-learning is examined but first is an in-depth look at barriers encountered by adult distance learners.

\section{E-learning Barriers}

"Unfortunately, despite all the hype, not all learners and not all organizations benefit from e-learning" (Pollard \& Hillage, 2001, p.28). For 
example, the drop out rate is alarming, with some reports citing as high as $70 \%$ drop out rate (Meister, 2002 cited in O'Connor et al. (2003). O'Connor et al. (2003) study of e-learning abandonment in organizations collected data from 13 e-learning managers and 375 employee e-learners and the results show a major disparity between classroom training and e-learning dropout ( $3 \%$ vs. $26 \%$ ) respectively. It is no wonder that Belanger and Jordan (2000, p.181) remarked, "Technology insertion in the traditional classroom environment can have a tremendous impact on training quality, learning retention, and cost avoidance." That is why the present study took a proactive approach, identifying existing obstacles in e-learning, to provide a background for future efforts to reducing barriers.

This section identifies and discusses barriers from distance learning literature. Internal barriers often interfere with the success of learning at a distance (Cyrs \& Conway, 1997) and so do external barriers that may lie outside the organization. Most of the literature that mentions barriers faced by distance learners has been conducted in colleges and universities and focuses on attrition or persistence in distance education because dropouts have always been a major concern for colleges and universities (Garland, 1993; Giles, 1999; Schilke, 2001). Learners who do not participate in an online classroom or those who fail to complete a course are a source of concern for adult educators specializing in DE courses (Giles, 1999).

O'Connor, et al., (2003) found that during the last three years, e-learners that started 5.5 online courses completed 4; a much lower completion rate 
compared to that of classroom-based training ( 5.2 completed courses out of every 5.3 started). Dropouts do not only result in wasted resources but also feelings of frustration or rejection on the part of the learner (Giles, 1999). Although this is not a study on attrition, an understanding of barriers in e-learning could be insightful on how to keep e-learners engaged, motivated, satisfied, and willing to continue with online training programs. Consequently, this study investigated barriers in order to bring them to the limelight because it is only through addressing such problems that e-learning will be a successful innovation with positive returns on investment. Further, such research are a means toward improving the online learning environment (Schilke, 2001).

E-learning is not only affected by what is happening in an organization but also what is happening in the external environment. The external and internal environments of online learning seem rather complex and the reviewed literature agrees that there are myriad of challenges that online learners encounter (Giles, 1999; Schilke, 2001). This literature Giles (1999) citing Kember (1990) and Cookson (1990) stated that dropout in DE is multi-causal and complex. According to Coldeway (1986) success in distance learning is a combination of personal factors; contextual factors such as background and experience; institutional factors such as pacing and delivery methods; and lastly course factors such as design and delivery.

Rubenson (1986 cited in Garland 1993) classifies barriers in distance education as being situational, institutional, and dispositional. This model was updated by Garland (1993) to include epistemological barriers, and by Schilke 
(2001) to include technological factors. Giles (1999) research on online attrition and persistence classifies barriers into four categories of demographic, personal, institutional, and participative. Research by Berge (1998) classified barriers as being situational, epistemological, philosophical, pedagogical, technological, social, and/or cultural and psychological. These models emerged from studies in college settings thus limiting their generalizability to other organizations.

Schilke (2001) conducted a qualitative study to investigate why online students drop from community college online classes. Based on Schilke's (2001) study, the following categories of barriers facing e-learners emerged (a) dispositional barriers, (b) institutional barriers, (c) technological barriers, (d) epistemological, and (e) situational barriers. Under these five major categories making up this model are various items or variables that were incorporated in the instrument (see Appendix D). This model is illustrated in Figure 3 and this guided the review of literature.

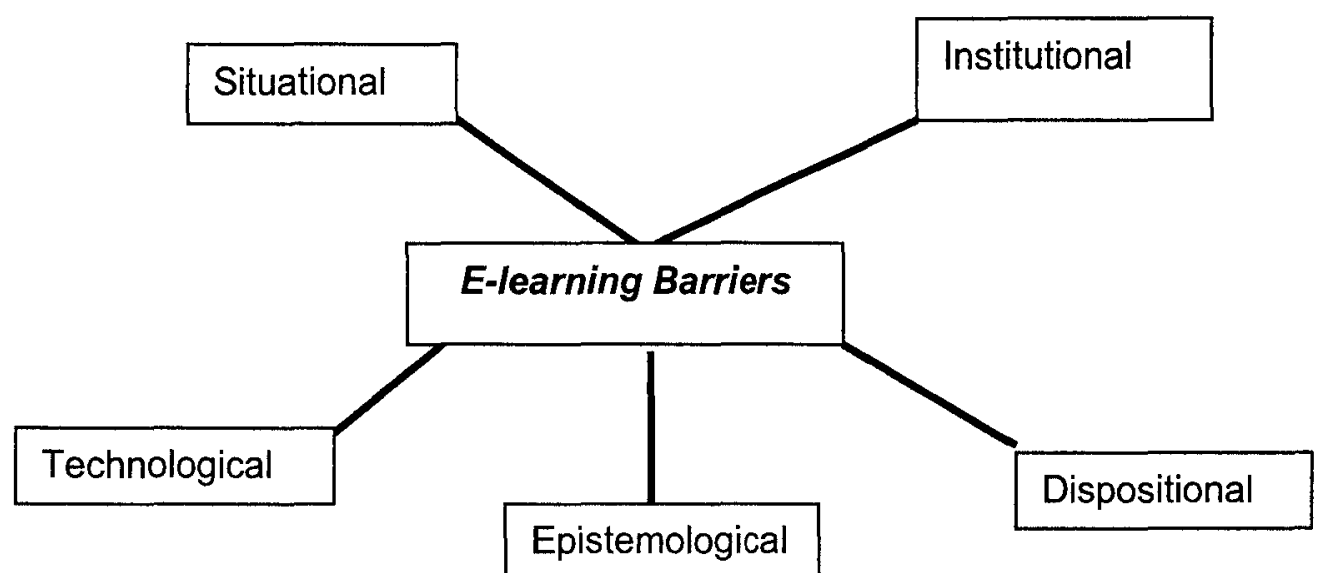

Figure 3: A model of barriers (Schilke, 2001) 
Compared to other studies on barriers, the population under study is unique since it is made up of adult employee e-learners, working in public education, manufacturing, service, and military sectors. To better understand this population, it is imperative to determine the demographic makeup and background characteristics.

\section{Demographic Variables}

In the reviewed literature, there has been an emphasis on the need to know learner characteristics or demographics (Feldhaus, 1999) for several reasons:

1. Learner characteristics could be predictors of learners' persistence or attrition in DE (Giles, 1999)

2. Demographic analyses are used to examine what kinds of learners are being served (Franklin, Yoakam \& Warren, 1996).

3. Planners of DE are concerned about student characteristics and their retention hence there is need for closer scrutiny of the intrinsic problems in DE facing students (Galusha, 1998; Keegan, 1996).

4. Understanding distance learners also gives indications for their reasons for involvement, outcomes, helps to explain and predict participation, and aids in program planning and policy formulation (Sheets, 1992).

"Distance education literature parallels much of the adult education literature generally in that it contains numerous studies of student characteristics as they pertain to participation" (Sheets, 1992, p.5). Distance learners have been 
described as being 'atypical' attracting working people with busy schedules, from mothers to executives (Timura, 1995). Adult e-learners are likely to be married with a full-time job (Schilke, 2001) and have other responsibilities that may take priority over course work (Timura, 1995). Such life situations can be barriers in starting and completing education (Giles, 1999; Schilke, 2001). In order to understand the learner population being addressed in this study, it was important to investigate their demographic makeup and any other factors that could be challenging their e-learning experiences.

Stanton (1998) indicates that the demographics of those with access to the World Wide Web (Web) vary from the population at large. Half of all Internet users are professionals or managers and nearly two-thirds possess college degrees (Stanton, 1998). Considering the continued trend of diversification of the work force, demographic characteristics cannot be ignored. Employees' age, gender, ethnicity, marital status, level of education, and organization were investigated.

It was hypothesized that the sample under study would be diverse thus leading to significant differences in perception of learning barriers for different demographic groups. Whether there is a relationship between demographic characteristics of the participants and their perception of the obstacles that they face was also determined. Below is a discussion of what previous studies have found in relation to these demographic characteristics. 
Ahn (1999) recommended that studies should look at personal characteristics such as age because age has been found to affect one's DL experience in some studies. In general, distance students tend to be older (Keegan, 1996) and age as a variable is very important because of digital divide issues (Kramarae, 2001).

The effect of age on distance learning indicates inconsistent findings on the effect of age on DL experiences. Giles (1999) found that age was not a significant predictor or persistence or dropout among a group of college students. This is similar to Feldhaus (1999) study of college students where a majority of the students felt that age does not make any difference in one's DL experiences. These studies contradict what Fjortoft (1995) found that age is a significant factor in determining persistence in DL.

Sixty percent $(60 \%)$ of distance or online learning are females over the age of 25 (Moe, 2002). According to Fjortoft (1995), older students (above middle age) were observed to have difficulty with $\mathrm{DL}$ although according to a review of literature by Sheets (1992), older students tend to have higher course completion rates. Kramarae (2001) indicated that older women e-learners have a preference for different learning methods compared to younger women because older women respondents students felt more comfortable online than on campus and welcome the relative anonymity that online courses offer. Online courses are more likely to be a good fit for older women who are more focused on goals and 
less on social interaction (Kramarae, 2001). Smith (1998) found that younger students were not consistently successful in DL because whenever they were unhappy with the instructor, they had a tendency to drop out of the class or cease trying to learn.

Feldhaus (1999) cautions however that although "age was not a barrier to the learning process, it is important to note that it is impossible to generalize these findings to other populations" (p. 154).

Gender

It is imperative to include gender as a variable in distance education (Ahn, 1999). Although women have outnumbered men on college campuses since 1979 (Moe, 2002), Kramarae (2001) argues that researchers often ignore gender and focus exclusively on race or ethnicity, class, or region. Gender disparities do exist in terms of family resources (Kramarae, 2001), which are not evenly divided; attitudes towards the Internet (Tsai, Lin, \& Tsai, 2001); and course completion (O'Connor, et al., 2003).

The effect of gender as a barrier is equivocal. O'Connor, et al. (2003) reported that females are more likely to complete an e-learning course than their male counterparts $(r=.13, p=.04)\left(O^{\prime}\right.$ Connor, et al., 2003). However, Kramarae (2001) noted that there are more barriers that are peculiar to women learning online. For example, while men in online courses usually study from 4 to 8 p.m., most women study later, perhaps because they have to fit in their course work after fulfilling other responsibilities. Women also tend to receive very little social 
or institutional support (Kramarae, 2001) but they also tend to place higher demands on themselves when pursuing education (Kramarae, 2001). These are indications that gender could play an important role in an e-learner's perception of barriers thus the relationship between gender and barriers were investigated in this study.

Feldhaus (1999) found that gender was not a barrier to the learning process and did not make any significant difference. This finding is similar to Giles (1999) and a review of literature by Sheets (1992) reported that gender has been found to be insignificant in persistence studies. Some studies have however indicated gender differences in the use of technology. For example, girls have been found to be more ambivalent about technology and are less likely to attempt to fix a broken piece of technology while boys are more excited about experiences with technology (particularly video games) than girls (Brunner \& Bennet, 1997 cited in Feldhaus, 1999, p. 101). Although "gender was not a barrier to the learning process, it is important to note that it is impossible to generalize these findings to other populations" (Feldhaus, 1999, p. 154). To determine the influence of gender on barriers, gender was included as a predictor variable in the regression analysis.

With regard to the influence of gender on one's self-efficacy, a study by Cassidy \& Eachus (2002) revealed that males showed significantly higher computer self-efficacy (CSE) than females. This finding is similar to Joo, Bong, and Choi's (2000) study with high school students in Korea that found stronger 
ISE among male students although the gender differences in Internet selfefficacy were not statistically significant.

Males have also been found to score higher than females on perceived relevance of computer skills to future career, interest and in knowing how computers work, and intentions to take computer courses (Cassidy \& Eachus, 2002). Tsai et al. (2001) in a study of Taiwanese high school students found that male students expressed more positive attitudes towards the Internet, showed lower anxiety, had higher confidence when using the Internet, and were also likely to use the Internet more frequently (Tsai et al., 2001).

\section{Race or Ethnicity}

The beneficiaries of DE tend to be white, the same population that has most benefited from traditional education (Gorard \& Selwyn, 2000). A study by Feldhaus (1999) on distance learning using the two-way interactive medium found that a majority of the participants who were white (males and females) felt that race made no difference in their ability to learn although the minorities felt that race was a barrier to the learning process. This finding is similar to Giles (1999) who found that ethnicity was not a significant predictor of persistence or dropout in college computer-conferenced courses. Considering the increasing diversity in the workforce, it is necessary to determine whether one's ethnicity has any effect on barriers. Consequently, the present study investigated this relationship. 


\section{Marital Status}

A review of literature by Sheets (1992) on characteristics of adult education students found that marital status has been found to be insignificant in persistence studies. However, Kramarae's (2001) study on women learning online indicates that marital status may impact online learning. For example, some women indicated that a spouse's approval and support for course taking is especially important and they needed to reassure their families that online studies would have minimal impact on family life. Many also admitted that their family responsibilities come first (Kramarae, 2001). Therefore, setting educational goals is a complex task especially for women with partners (Kramarae, 2001). One's marital status could have implications on time available for studying on line, support, and persistence (Kramarae, 2001) because DE brings learning activities into the home and can involve family members in a variety of ways (Kramarae, 2001). Marital status is a variable that deserves further attention with both genders since Kramarae's study involved only women learning online.

\section{Occupation}

In general, distance students tend to be employed (Keegan, 1996). According to a review of literature by Sheets (1992), occupational status of learners is not significantly related to program completion. The diversity of occupations represented in the present study would give an indication of the relationship between one's occupation and perceived barriers. 
While the significance of looking at demographic variables is common in many studies, Sheets (1992) noted that it is possible that less than $10 \%$ of the variance regarding the prediction of persistence in distance learning is accounted for by demographic variables. Sheets (1992) recommends that future studies should focus on other personal and situational factors that go beyond gender, age, and educational background. Consequently, this study looked beyond demographics to other factors that might influence one's perception of barriers as discussed next.

\section{Additional Background Variables}

\section{Level of Education}

"Throughout the world, the education background of distance students ranges from less than high school to completion of a university degree" (Sheets, 1992, p.8) and beyond. Feldhaus (1999) found that the diversity of educational background was the most significant factor causing barriers in this study of twoway audio-video courses. Differences among participants were most apparent in their level of education especially by participants who had a high school diploma and that barriers encountered from a lack of academic preparation were very apparent because lack of formal education impacted some participant's ability to learn (Feldhaus, 1999).

Lack of prior knowledge of the information being learned influenced the reading pace, level of understanding, and the amount of reading one required, and problems understanding words or terminology used (Feldhaus, 1999). 
However, some of the respondents who had learned the content before did not consider the educational diversity to be a barrier. They considered it boring or easy, frustrating, not challenging enough, considered it a review, normal, and less of a workload. The phrase "been there, done that" was common among the participants who had four year degrees and/or had been teaching for at least 15 years (Feldhaus, 1999, p. 110). Those without university level coursework thought that the content was more difficult (Feldhaus, 1999). This is similar to a review of literature done by Sheets (1992) that concluded that education level prior to enrollment in $\mathrm{DL}$ courses is significantly related to persistence.

Other research has also demonstrated relationships between demographic variables and computer anxiety (Igbaria \& Parasuraman, 1989 cited in Stanton, 1998). Those with greater levels of education tend to have lower computer anxiety (Stanton, 1998).

\section{Prior Experience with E-learning}

Sheets' (1992) literature review of DL studies reported that learners who had prior experience with nontraditional education were more likely to persist. ASTD \& Masie (2001) found that a learner's previous experiences with e-learning influences the level of satisfaction with technology and learners who reported having had negative e-learning experiences previously were significantly less satisfied with their current e-learning experience. ASTD \& Masie (2001) and TNS (2001) studies highlighted the importance of the participant's first-e-learning experience. They argue that one's initial experience determines a user's 
optimism about subsequent e-learning experience (cited in Rossett, 2002, p.5) with critical impressions being formed during one's first e-learning experience (Rossett, 2002). This indicated the need to include prior e-learning experience as a variable in the present study to determine its relationship to barriers.

\section{Type of Organization}

A study by Timura (1995) on the perceptions of human resource administrators regarding decisions to support employees' DL activities revealed that there were significant differences in responses according to the type of organization. Corporate officers specializing in finance, for example, insurance, investment, and banking were more supportive of $\mathrm{DL}$ and more concerned about its quality and cost effectiveness than other officers from other industries (Timura, 1995). Finance corporate officers' perceptions differed significantly from perceptions of officials in every other type of corporation (Timura, 1995). Similar studies with different samples of Fortune 500 companies that incorporate corporate workers' perceptions have been recommended (Timura, 1995). Muilenburg and Berge (2001) also determined that there are differences based on the type of organization one is in and the level of capability (stage of distance learning) that an organization has reached. These studies highlight the importance of including different organizations in order to determine the differences in their perceptions of barriers. 
A recent study by O'Connor, et al. (2003) found that employee e-learners with Intranet access are more likely to complete an online course $(r=.011$, $p=.031)$. The ability to access the Intranet frequently and from multiple locations can be affected by whether one owns a computer or not. Computer ownership has been found to increase one's computer self-efficacy according to a study by Cassidy \& Eachus (2002).

In a study by Kramarae (2001), computer related-costs present a problem because some e-learners either do not own a computer or they own one that is inadequate for e-learning. Ahn (1999) said that it is important to consider computer ownership or availability for optimum learning to occur because computer availability determines whether one can readily use it whenever it is needed. Owning a computer is not enough for e-learning, a learner must also have access to the Internet to access the course anytime from anywhere. Therefore, the relationship between barriers and whether or not an individual owns a computer with Internet connection was investigated.

\section{Computer Software Training}

Computer training has been reported to increase one's computer selfefficacy (Cassidy \& Eachus, 2002). Torkzadeh and Koufteros (1994) cited in Cassidy \& Eachus (2002) found that the CSE of a sample of 224 undergraduate students increased significantly following a computer training course. These studies however did not indicate what kind of training the students received. The 
present study examined the nature of the relationship between barriers and software training. Training in the instrument refers to software training because most of the e-learning activities require knowledge and use of software (such as the use of a word-processing application).

Experience with the Internet

Experience was the most important predictor of Computer Self-efficacy accounting for $63.5 \%$ of the variability $(R=.63509, F(1,196)=341.121, p<$ .00005) (Cassidy \& Eachus, 2002). Tsai et al. (2001) found that prior Internet experience impacts students' attitudes. Students with longer Internet exposure had more positive attitudes with the Internet (Tsai, et al., 2001), a finding that is similar to those with computer experience. Positive experiences may help learners have better attitudes towards the Internet especially those with high anxiety and low confidence in Internet use (Tsai, et al., 2001).

\section{Computer Competence or Experience with Computers}

Familiarity with software packages (Cassidy \& Eachus, 2002), experience, and positive attitudes are predictive of computer self-efficacy (Litchfield, Oakland \& Anderson, 2002 citing Delcourt \& Kinzie, 1993). Hill, Smith \& Mann (1987) cited in Cassidy \& Eachus (2002) found a significant positive correlation between one's CSE and previous computer experience within a sample of 133 female undergraduates. This finding is similar to the impact of computer experience on students' attitudes (Tsai, et al., 2001) and significant positive correlations found 
between CSE and computer experience and familiarity with computer software packages among university students (Cassidy \& Eachus, 2002). These two factors were significant predictors of CSE. The relationship between computer use and experience is rather indirect according to Hill, Smith \& Mann (1987) who found that computer experience influences behavioral intentions to use computers indirectly through self-efficacy beliefs. Similarly, Joo et al. (2000) found that previous experience working with computers showed a significant correlation with ISE ( $r=.396)$. Cassidy \& Eachus (2002) concluded that positive past experience with computers increases self-efficacy while negative experience reduces self-efficacy. The quality and not the quantity of one's computer experience is the critical factor in determining self-efficacy beliefs (Cassidy \& Eachus, 2002). A rather interesting finding regarding self-efficacy with the Web was documented by Litchfield, et al. (2002) study on interns in a dietetic training program utilizing online instruction, who found that significant improvement in self-efficacy with the Web occurred irrespective of the treatment. This finding should be reviewed with caution due to the limited sample size $(n=44)$.

Litchfield et al. (2002) also found out that previous computer experience was not predictive or self-efficacy and did not influence the use of online instruction. However, those with a preference for working with others reported using online instruction had a positive effect on their overall computer attitude and comfort using computers. These findings although somewhat similar in some way indicate the need for further study of this variable. 
This section has described the demographic and background variables under examination. These background factors were used as predictor variables with e-learning barriers as the dependent variable. A more in-depth discussion of barriers experienced by distance learners according follows.

\section{Types of E-learning Barriers}

\section{Situational Barriers}

Situational barriers are related to the situation or environment one is in (Schilke, 2001). Some of the variables that related literature has characterized as situational barriers include availability of time for study (Garland, 1993; Giles, 1999; Morgan \& Tam, 1999; O'Connor, et al, 2003), competing responsibilities (Kramarae, 2001; Bischoff, 2000) and changes in one's life circumstances (Giles, 1999; Morgan \& Tam, 1999). Other barriers include courses taking too much time than expected (Morgan \& Tam, 1999); condusiveness of the study environment (Morgan \& Tam, 1999); and cost or affordability (Chu \& Hinton, 2001; Kramarae, 2001; Morgan \& Tam, 1999; Whalen, 1999). Other situational barriers include:

Isolation. Barriers such as lack of socialization (ASTD \& Masie, 2001) leading to feelings of isolation (Bischoff, 2000) are often cited because "Nowhere is the challenge for student engagement greater than in the Web-based course" (Dereshiwsky \& Moan, 2000, p.1). The lack of face-to-face interaction in online courses deprives one of vital communication cues and feedback. E-learning has been said to be impersonal, frustrating, and lonely (Pollard \& Hillage, 2001). Distance learners feel isolated due to the fact that they are physically or 
geographically cut off from others hence limiting interactions. This takes away the opportunity to be a part of a scholarly community and this could lead to feelings of inadequacy and affect their perception of their abilities (Galusha, 1998). In college settings, DE students who are geographically isolated could have problems obtaining study materials and or library materials (Galusha, 1998). In an organizational setting, this would refer to those who work outdoors or who are constant away from their workstations, or are geographically dispersed in locations around the world.

Support. Good online learning requires adequate learner support (Pollard \& Hillage, 2001). Lack of support from employers, coworkers (ASTD \& Masie, 2001) and one's family (Chu \& Hinton; Morgan \& Tam, 1999) are often cited as barriers. Management support for e-learning is a key ingredient for e-learning (Rosenberg, 2001). "Lack of family support may come in the form of increasing demands for attention and help, destroying course materials, guilt-tripping, denying child care assistance, refusing to set aside time or space in the home for study, and refusing to spend family finances on women's education" (Kramarae, 2001).

Study environment. Not only do learners need the support to learn but also the space to learn without interruptions (Pollard \& Hillage, 2001). The most popular location for e-learning is the desktop but this is not the optimal place for learning (Pollard \& Hillage, 2001 citing Cross, 2000 and TechLearn Trends, 2001). This indicates that the environment a learner is in could present barriers in 
the learning process. Situational barriers were under study to determine the extent to which they were present among the respondents under study.

\section{Technological Barriers}

Due to the novelty of the Internet (Joo et al., 2000) accompanied by the ever-changing e-learning technologies, problems pertaining to technology require more investigation. "While technological change may be inevitable, the shape and character of the technology are molded by human beings who develop and use it for work, play, and life (Chidambaram \& Zigurs, 2001, p. 240). Therefore, for as long as new technology is being integrated into learning systems, further studies such as this one are essential to further investigate the technological barriers that exist in e-learning environments.

Access to computer technology has become a major issue in training and education (Williams, 2001). According to a literature review by Champagne, Wisher, Pawluk, \& Curnow (n.d.) nearly all the studies reviewed suggest that differences between the groups were solely due to the DL media used rather than to individual student differences such as learning style, self-efficacy, or motivation. Gorard \& Selwyn (2000) found out that virtual universities face major obstacles when registering populations who have been excluded in the past from learning because a majority of those people do not have computers or access to the Internet. This has emerged into the common phrase referred to as the "digital divide". The digital divide issue is one of the commonly expressed concerns about online learning today. Digital divide, may be defined as the gap in access 
to computer technology among various populations (Williams, 2001). Distance learners need to have access to e-mail, computers, Internet connection, and Web browsers (Porter, 1997). Yet, despite the incredible growth of the Internet since the early 1990s, many people in the United States still do not have easy access to technology including hardware, software, or the Internet itself. "Access is an issue that affects people at home, at school and in the community at large" (Digital Divide Network, 2003). Peratton (2000) argues that enrollment to DE programs is not a matter of geography but of access to the Internet and the ability to pay for the required technology. Clearly, access to technology is a universal issue and this study investigated whether it is an obstacle for employees. Owning a computer that has Internet connection and consistency of access were examined.

Magalhaes and Schiel (1997) suggest incorporating delivery issues such as technical problems, level of comfort with the use of the Internet as a delivery method. Other variables that previous literature has characterized as technological barriers include cost of computers and being online (Kramarae, 2001; Pollard \& Hillage, 2001); technical difficulties (Bischoff, 2000); access to technology (Schilke, 2001; Pollard \& Hillage, 2001; Williams, 2001); and reliability of technology, insufficient bandwidth (Pollard \& Hillage, 2001). Others include the quality of technology, inadequate technical assistance, lack of technical expertise, ease of use, changing technology, and logging-in problems (Schilke, 2001). Fear of technology is a major issue with "as many a one-third of college students in the US suffering from 'technophobia'" (Litchfield, Oakland \& 
Anderson, 2002, p. 24, citing DeLoughry, 1993). To determine the presence of these barriers in the sample under study, these variables were included in the instrument.

It is worth noting that a recent study by O'Connor et al. (2003) shows that technological factors such as Internet connection problems (4.5\%) and lack of access to a computer (1.1\%) seem to have minimal effect on e-learning drop out. While this communicates good news, the sample under study by O'Connor et al. (2003) had the necessary resources, with $87.7 \%$ having access to high-speed Internet resources via company Intranet or cable/DSL modem and $80 \%$ were highly computer competent.

\section{Institutional Barriers}

Sheets (1992) recommended that empirical studies be conducted with attention being paid to institutional interventions and other environmental factors that determine course completion and the success of participants.

Bonk (2001) notes that the primary institutional motives for online training are to increase profits and "...typically, many institutions begin a DE initiative encouraged by the many potential benefits, influenced by their competition, and prompted by the fear of not being involved in DE" (Broskoske \& Harvey, 2000, p.1). As a result, many are entering into e-learning initiatives without sufficient planning, without a clear mission for the program, and without realizing many of the challenges that will surface as they conduct their programs (Broskoske \& Harvey, 2000). This could result in tremendous challenges not only for the 
management but also in the learning system thereby affecting e-learners' experiences. Organizations with e-learning initiatives need to be aware of organizational barriers because this knowledge could lead to a review of existing systems and determine what is needed to support such a program (Cyrs \& Conway, 1997) experiences. This study aimed at bringing forth into the limelight some of the barriers that e-learners face that emerge from the organization/institution. As noted earlier, most of the research studies on barriers facing adult distance learners have been conducted in higher education settings (Garland, 1993; Giles, 1999; Schilke, 2001). Although differences do clearly exist between these higher education institutions and corporate, government, and nonprofit organizations, ultimately, they all are organizations.

Schilke's (2001) study on why online students in a community college drop out, institutional factors were the most commonly mentioned factors. These institutional concerns included two problems related to the instructor and instructional design (Schilke, 2001). Organizational support and instructional design-related factors influence dropout rate (O'Connor, et al., 2003).

Other studies have identified additional institutional-related problems that include:

- Procedural problems e.g. delay in registration or late arrival of course materials (Garland, 1993).

- Poor communication with one's institution (Garland, 1993).

- Scheduling restrictions (Whalen, 1999), course timing or when the course is offered (ASTD \& Masie, 2001).

- Lack of incentives (ASTD \& Masie, 2001; Rosenberg, 2001).

- Study location (ASTD \& Masie, 2001).

- Course duration (Giles, 1999).

- Reliability of support services.

- Communication (Sheets, 1992). 
- Access-related problems.

- Security.

- Program structure.

- Location of employees relative to accessibility to equipment and e-learning (Rosenberg, 2001).

- Pace on online courses (Bischoff, 2000).

- Costs associated with having to pay for training or accessing the Web for training and development purposes is another barrier to e-learning (Rosenberg, 2001).

Policy. Institutional DE policies and interventions may affect course completion (Sheets, 1992), and especially mandatory course completion policy (O'Connor, et al., 2003). Support for e-learning is also evident in the policies (O'Connor, et al., 2003) and procedures. In studies conducted in college settings, those with pacing techniques resulted in higher completion rates than in institutions that had open-ended enrollment (Sheets, 1992 citing Coldeway, 1986).

Institutional support. Support is critical in distance learning. Organizations could support e-learners by providing sufficient time and uninterrupted learning time (O'Connor, et al., 2003), provision of learning materials and facilities, emotional and financial support as well as access to experts (Sheets, 1992), availability of support services (Giles, 1999), and course workload are other influential factors. The ASTD \& Masie (2001) report noted that successful elearning courses are those that are well advertised, championed, those that give ample completion time, and those that provide support during work hours. This report further recommends providing support needed by e-learners by managers and coworkers in order to motivate e-learners. By virtue of the fact that the 
participants of this study work in different environments, it is vital to discover the different environment-related barriers facing employee e-learners.

Course management. Magalhaes and Schiel (1997) suggested incorporating course management issues in an evaluation. For example, the learners' level of comfort in the way in which the class is being conducted and in terms of course logistics, and amount of time given to complete assignments.

Instructor-related barriers. Distance learners also experience instructorrelated barriers such as instructor's knowledge, skills, and attitudes (KSAs), access to the instructor (Whalen, 1999), instructor availability (Magalhaes \& Schiel, 1997), instructor expectations, intimidating experiences (Magalhaes \& Schiel, 1997), and ambiguous instructions (Pollard \& Hillage, 2001).

Communication and feedback. Frequent contact between the instructor and students is highly correlated with learners' satisfaction ( $r=.54)$ according to Giles (1999). Poor and infrequent feedback (Magalhaes \& Schiel, 1997; Pollard \& Hillage, 2001; Schilke, 2001) and the absence of physical cues in communication with the facilitator can pose learning barriers (Dereshiwsky \& Moan, 2000; Pollard \& Hillage, 2001).

Instructional design barriers. In addition to instructor barriers are instructional design barriers. Instructional design-related factors influence dropout rate (O'Connor, et al., 2003) and they have been found to be "...the most common detractor of all... Frustration with the presentation of the material was possibly the single most deciding factor for attrition during this study" (Schilke, 
2001, p.71). "The degree to which a course is well-designed is directly related to the effectiveness of course delivery" (Belanger \& Jordan, 2000, p.38).

The quality of e-learning has often raised concern and this can be a major stumbling block (Mason, 1998 cited in Pollard \& Hillage, 2001; Masie, 2000). Masie (2000) said that there is a growing perception of an e-learning content deficit and often, e-learning content has been criticized of poor quality.

The instructional-design problems include quality of the course material, clarity of expectations, language barriers, unavailability of media used, "overwritten courses" (that is a course with large reading volumes required for each class), and style of materials (frustration with instruction limited to the written word and reading the lectures online), too much content, content taking too long to print, and information overload (Palloff \& Pratt, 1999; Schilke, 2001). Other barriers include boredom with repetitive nature of the course, need for other media, need for other learning resources, and poor use of the learning space (for example, constant need to scroll down) (Schilke, 2001).

The presence or absence of these barriers was examined in the present study. Since organizations differ in their e-learning offerings, policies, and procedures, this study examined the differences in barriers faced across the seven organizations. 


\section{Dispositional Barriers}

Dispositional or personal barriers have been known to contribute to student dropouts (Chu \& Hinton, 2001; Giles, 1999; Schilke, 2001; O'Connor, et al., 2003). These barriers result from:

Learning style differences. O'Connor, et al., (2003) found that $33 \%$ of employee e-learners cited learning style mismatch as a factor that influences dropout. Learning should be geared to the needs and interests of the individual learner (ASTD \& Masie, 2001) thus learning styles must be taken under consideration when launching an e-learning program (Kirk, 2002). "The success of e-learning systems is what comes naturally, the ways we learn on our own" (Masie, 2002, p. 58). One's preferred learning style such as a preference for structure can be a barrier. In a traditional classroom, most instructors realize that not all students learn best using the same method (Champagne et al., n.d.) and this recognition of individual differences in the traditional classroom should extend to the DL classroom (Champagne et al., n.d.).

Learner expectations. Learner expectations can also be a barrier because DE students tend not to have realistic expectations, which can lead to noncompletion (Timura, 1995).

Prior e-learning experiences. Personal barriers may include prior experiences with e-learning (ASTD \& Masie, 2001). It is imperative that learners' interests and their experiences are known in order to meet their needs in elearning environments. 
Resistance to change. The tendency to resist change and innovation (Baumgartner, 2000 cited in Dereshiwsky \& Moan, 2003) is a barrier to student engagement in Web-based courses.

Motivation. E-learning requires self-motivation (Pollard \& Hillage, 2001; Timura, 1995), dedication, and self-discipline than classroom training (Pollard \& Hillage, 2001). A learner's motivation level can be a learning barrier (ASTD \& Masie, 2001). O'Connor, et al. (2003) surveyed employee e-learners, $73 \%$ of whom said that personal motivation is a key factor leading to completion. The ability to work independently is essential (Timura, 1995) because learners are charged with completing learning at their own time and pace (Pollard \& Hillage, 2001). Active student involvement is crucial in Web-based courses because success is dependent upon motivation and initiative (Dereshiwsky \& Moan, 2000).

Time management. Since e-learning is usually self-paced, time management skills are essential. Lack of time management skills is a barrier (Garland, 1993). "DE is fertile ground for procrastination (Timura, 1995, p.22), making procrastination is one of the causes of non-completion (Timura, 1995). In addition, one's workload (O'Connor, et al., 2003) and time conflicts (Giles, 1999; Schilke, 2001) can inhibit learning.

Physical and psychological health. Stress resulting from multiple responsibilities at home, school and work (Garland, 1993; Giles, 1999) can be barriers to e-learning. Health issues (Giles, 1999) and anxiety (Palloff \& Pratt, 1999) also obstruct learning. 
Other barriers include privacy issues (Palloff \& Pratt, 1999), lack of appropriate communications skills, a course's relationship to one's job (Morgan \& Tam, 1999), one's attitude towards e-learning, and one's personality. Garland (1993) reported that adult pride and a lack of clear goals are barriers among college students. Due to the prevalence of personal barriers in the literature, their presence among employees under study was investigated.

\section{Epistemological Barriers}

"Epistemological barriers reflect a lack of congruence between the student's cognitive and affective characteristics and perceptions of knowledge, and the nature of the knowledge presented in the subject matter" (Garland, 1993, p.192). Epistemological barriers exist whenever a course's content or expectations are incompatible with one's cognitive stance. Questions concerning the kind of content needed and the usefulness of content (Magalhaes \& Schiel, 1997) need to be asked.

Garland's (1993) qualitative case study of college students found that epistemological barriers emerged if a course's epistemology differed from that of the student. Epistemological barriers exist whenever there was a gap between the presented content and expectations, when content lacked personal relevance or interest, and when prerequisite knowledge was lacking (Garland, 1993). Thus a lack of compatibility with a student's personal context and gaps in a learner's knowledge base can pose epistemological barriers (Garland, 1993). 
Epistemological barriers determine persistence or dropout (Schilke, 2001) thus deserved attention in the present study.

Content attracts considerable attention in e-learning (Pollard \& Hillage, 2001). "While there is a lot of interest in new tools for creating and delivering learning, the real interest is in the content (Masie, 1999 cited in Pollard \& Hillage, 2001). Content accounts for two thirds of the market (Urdan \& Weggen, 2000 cited in Pollard \& Hillage, 2001), making it the largest of the e-learning market segments (the others being technology and services). Content can be segmented into IT, business, and soft skills (Pollard \& Hillage, 2001). IT training accounts for one-third of all training delivered in US organizations (Pollard \& Hillage, 2001), and this is also characteristic of the organizations under study. While the availability of content is overwhelming, the issue that deserves attention is whether there is congruence between the courses offered and what the learners expect.

With the understanding of barriers that could exist in distance learning and specifically in online learning, it is now imperative to examine the theoretical underpinnings that could help to explain or predict why barriers occur and their relationship with an e-learner's self-efficacy (ELSE). The social cognitive theory is discussed next.

Social Cognitive Theory and Self-efficacy Theory

Social cognitive theory was the theoretical foundation for this study. Albert Bandura is credited for developing the social cognitive theory in the 1970 s. This 
is a widely accepted and empirically validated model of individual behavior

(Campeau \& Higgins, 1995). This theory is based on the premise that there is a triadic reciprocity between personal factors (demographics and personality), environmental influences (social pressures and situational characteristics), and behavior (Bandura, 1977, 1986, 1994; Campeau \& Higgins, 1995).

Social cognitive theory has many dimensions (Campeau \& Higgins, 1995). Within Bandura's social cognitive theory lies the concept of self-efficacy, a central facet of this theory (Cassidy \& Eachus, 2002). The present research study was particularly concerned about self-efficacy because self-efficacy influences activity (behavior), environment selection (Bandura, 1994), level of effort, and persistence exerted in the face of obstacles to the performance of those behaviors (Bandura, 1994; Campeau \& Higgins, 1995). Since e-learners are faced with obstacles, the nature of the relationship between an individual's elearning self-efficacy and barriers was under investigation.

\section{Self-Efficacy}

"There is a growing body of knowledge that human accomplishments and positive well-being require an optimistic sense of personal efficacy. This is because ordinary social realities are strewn with difficulties. They are full of impediments, adversities, setbacks, frustrations, and inequities. People must have a robust sense of personal efficacy to sustain the perserverant effort needed to succeed. In pursuits strewn with obstacles, realists either forsake them, abort their efforts prematurely when difficulties arise or become cynical about the prospects of effecting significant changes." (Bandura, 1994, Section III, П 1).

"Perceived self-efficacy is a judgment of one's capability to accomplish a certain level of performance" (Bandura, 1997, p.391). Kreitner and Kinicki (2001) 
define self-efficacy as the belief in one's ability to successfully accomplish a specific task. In this study, it is one's belief that s/he can be successful in elearning activities, since self-efficacy is domain specific (Joo, Bong, \& Choi, 2000).

"Self-efficacy is a form of self-evaluation that influence decisions about what behaviors to undertake, the amount of effort and persistence put forth when faced with obstacles, and finally, the mastery of the behavior. Self-efficacy is not a measure of skill; rather, it reflects what individuals believe they can do with the skills they possess." (Eastin \& LaRose, 2000, p.2). Self-efficacy beliefs may contribute to the success with which a task is completed (Cassidy \& Eachus, 2002).

Because psychological theories tend to focus on issues concerning knowledge acquisition or performance, the interrelationship between knowledge and action has been largely neglected (Bandura, 1986). Although knowledge and constituent skills are necessary, they are insufficient for accomplished performances (Bandura, 1986). Self-referent thought mediates between knowledge and action (Bandura, 1986) as illustrated in Figure 4. That is why it is important to be measure e-learners' self-efficacy. Awareness of their efficacy could help to bridge the gap between e-learners' knowledge and skills and to translate them into appropriate courses of action (in this case starting, continuing, and completing online training). 


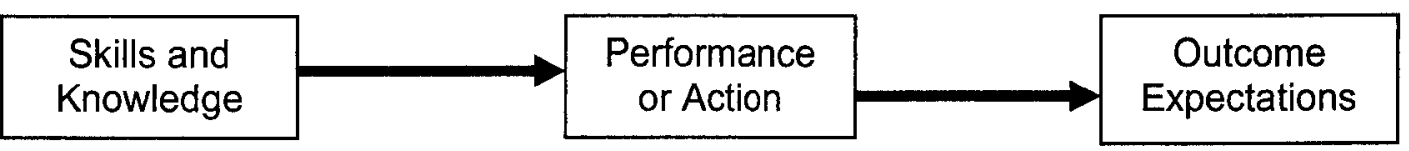

Figure 4. Self-efficacy as a bridge between skills, action, and outcomes

\section{Four Sources of Self-Efficacy Beliefs}

According to Bandura (1994), people's beliefs about their self-efficacy emerge from four sources of influence, namely:

1. Prior experiences. This is the most powerful source of self-efficacy and the most effective way of creating a strong sense of self-efficacy (Bandura, 1989, 1994; Campeau \& Higgins, 1995; Cassidy \& Eachus, 2002). Selfefficacy beliefs are deep convictions supported by experiences of success or failure (Kreitner \& Kinicki, 2001). While success builds self-efficacy, failures undermine it (Bandura, 1994). Experience overcoming obstacles through perseverant effort helps to build efficacy (Bandura, 1994).

2. Vicarious experiences. Vicarious experiences provided by social models is another way of creating and strengthening self-efficacy (Bandura, 1994). Self-efficacy emerges from observing the success or failure of models (Bandura, 1994; Campeau \& Higgins, 1995; Cassidy \& Eachus, 2002). The greater the perceived similarity between an individual and his/her model, the greater the impact of modeling on perceived self-efficacy, and the more persuasive are the models' successes or failures (Bandura, 1994). Success 
or failure of one's peers or models in doing similar tasks (in this case elearning) can strongly influence one's self-efficacy (Kreitner \& Kinicki, 2001). Modeling influence is more effective when models possess the aspired competencies (Bandura, 1994). Competent models transmit their knowledge through their behavior or teach their observers strategies for managing the environmental demands (Bandura, 1994). Learning effective means of coping with environmental demands raises perceived self-efficacy (Bandura, 1994).

3. Social persuasion. Social persuasion can be used to strengthen people's self-efficacy (Bandura, 1994). Self-efficacy is determined by verbal persuasion from others such as peers, colleagues or relatives (Campeau \& Higgins, 1995; Cassidy \& Eachus, 2002).

4. Physical and/or affective state. To some extent, somatic and emotional arousal influences one's self-efficacy (Bandura, 1994; Campeau \& Higgins, 1995; Cassidy \& Eachus, 2002; Kreitner \& Kinicki, 2001). Stress, tension, and depression are usually interpreted as signs of vulnerability to poor performance and are some of the affective characteristics of people with low self-efficacy (Bandura, 1994). Anxiety (Campeau \& Higgins, 1995; Cassidy \& Eachus, 2002), fatigue, pain, and aches are seen as signs of physical feebleness (Bandura, 1994), and could lead to negative frame of mind, which diminish self-efficacy (Bandura, 1994). Conversely, positive mood enhances perceived self-efficacy (Bandura, 1994). Therefore, reducing people's stress 
and altering negative dispositions can enhance self-efficacy (Bandura, 1994).

\section{Efficacy-Activated Processes}

Self-efficacy beliefs affect four major psychological processes (Bandura, 1994), namely:

Cognitive processes. Most courses of action are initially organized in thought (a cognitive function). Cognitive processes influence personal goal settings, which is in turn influenced by self-appraisal capabilities (Bandura, 1994). People with high self-efficacy, set challenging goals, have firm commitment to such goals, are task oriented, and are more likely to use good analytic thinking when faced with difficult environmental demands (Bandura, 1994). Thus a high sense of self-efficacy is essential in visualizing success, setting positive guides, and support for performance (Bandura, 1994). Further, strong self-efficacy requires one to remain task oriented when faced with obstacles or failure (Bandura, 1994) along the way. In the present study, such setbacks would entail the various forms of e-learning barriers.

Motivational processes. Motivation is related to cognitive functions and self-efficacy plays a fundamental role in regulating motivation. Motivation guides one's goals and courses of action (Bandura, 1994). There are three types of cognitive motivators.

Affective processes. As mentioned earlier, people rely on somatic and emotional arousal to judge their capability (Bandura, 1994; Campeau \& Higgins, 
1995; Cassidy \& Eachus, 2002; Kreitner \& Kinicki, 2001). Positive mood enhances perceived self-efficacy while negative moods diminish it (Bandura, 1994).

Selection processes. People not only influence the environment by they are partly a product of their environment. Self-efficacy affects one's choice of activities and environments (Bandura, 1994) and "People avoid activities and situations they believe exceed their coping abilities."(Bandura, 1994, p.6). Career development is one example of how self-efficacy beliefs affect one's choices. This study pertains to career development through e-learning, thus the relationship between e-learning barriers and self-efficacy was examined.

\section{Dimensions of Self-efficacy}

Self-efficacy judgments differ on three distinct, but interrelated dimensions: magnitude, strength, and generalizability.

Magnitude. The magnitude of self-efficacy refers to the level of task difficulty one believes is attainable. Individuals with a high magnitude of selfefficacy see themselves as being able to accomplish difficult tasks (Campeau \& Higgins, 1995).

Strength. This refers to the level of conviction about the judgment. Those with a weak sense of self-efficacy become more easily frustrated by obstacles to their performance and will respond by lowering their perceptions of their capability (Campeau \& Higgins, 1995). 
Generalizability. This dimension indicates the extent to which perceptions of self-efficacy are limited to particular situations (Campeau \& Higgins, 1995). While some individuals believe they can only perform some behavior under a particular set of circumstances, others might believe that they could execute some behavior under any circumstances and also perform behaviors that are slightly different (Campeau \& Higgins, 1995).

\section{Other Characteristics of Self-Efficacy}

Self-efficacy arises from the gradual acquisition of complex cognitive, social, linguistic, and/or physical skills through experience" (Gist, 1987 cited in Kreitner \& Kinicki, 2001).

"Self-efficacy determines how people feel, think, motivate themselves, and behave." (Bandura, 1994, p.1). Self-efficacy has been shown to be related to task choice, motivation level, effort, perseverance (Bandura, 1994; Cassidy \& Eachus, 2002), performance (Joo et al., 2000), and ultimately success (Kreitner \& Kinicki, 2001). One's cognitive evaluation of a situation yields a self-efficacy belief, which ranges from high to low expectations for success (Kreitner \& Kinicki, 2001). The perception that one has the capability to perform a task will increase the likelihood of that task being successfully completed (Cassidy \& Eachus, 2002).

The relationship between self-efficacy and performance is cyclical. Researchers have found a strong relationship between high self-efficacy expectations and a variety of physical and mental tasks (Kreitner \& Kinicki, 2001). People with low self-efficacy tend to have low success rates. Chronically 
low self-efficacy is associated with learned helplessness, a severely debilitating belief that one has no control over one's environment (Kreitner \& Kinicki, 2001). It is important to note that self-efficacy is domain sensitive or situation specific (Cassidy \& Eachus, 2002). In one situation, one may have high levels of selfefficacy while in another situation the individual may exhibit low levels of selfefficacy (Cassidy \& Eachus, 2002).

Kreitner and Kinicki (2002) adapted Bandura's (1986) social cognitive theory and constructed a model of how self-efficacy beliefs can pave the way for success or failure. These researchers argue "People program themselves for success or failure by enacting their self-efficacy expectations" (Kreitner \& Kinicki, 2001, p.143). One's self-efficacy beliefs can lead to either positive or negative feedback. High self-efficacy leads to positive feedback, which translates into behavioral patterns such as being active, selecting best opportunities, managing a situation, avoiding or neutralizing obstacles, setting goals to establish standards, planning, preparing, practicing, trying hard, persevering, creatively solving problems, limiting stress, learning from setbacks, and visualizing success. These behavioral patterns lead to success (Kreitner \& Kinicki, 2001). On the other hand, people with low self-efficacy get negative feedback, which causes them to be passive, to avoid difficult tasks, to develop weak aspirations. Low self-efficacy also leads to low commitment, focusing on personal deficiencies, putting little effort or not trying at all, quitting or becoming discouraged by setbacks, blaming setbacks on ability or bad luck, worrying, experiencing stress, becoming depressed, and thinking of excuses for failing. 
Such negative feedback and behavioral patterns lead to failure. Looking at the characteristics of people with low self-efficacy clearly indicates how one's selfefficacy can result to a perception of barriers and behavioral patterns, which lead to failure. Positive or negative results subsequently become feedback for one's base of personal experience (Kreitner \& Kinicki, 2001). Why is self-efficacy important to consider in relation to e-learning?

Organizational settings offering e-learning opportunities influence one's self-efficacy beliefs. Kreitner and Kinicki (2002) argue that it is important that workplaces and management nurture self-efficacy in their employees because research indicates significant positive correlation between self-efficacy and job performance (Kreitner \& Kinicki, 2001). Organizations offer e-learning as an intervention to increase job performance thus improving e-learning conditions could be beneficial to organizations. Therefore, it was hypothesized that there would be a significant relationship between one's self-efficacy and perceived barriers and the E-learning Self-Efficacy (ELSE) scale was used to determine this relationship.

Tsai, et al. (2001) noted that there is a difference between Internet literacy and computer literacy and Eastin and LaRose (2000) also noted the difference between Internet Self-Efficacy and Computer Self-Efficacy. Consequently, these two scales were modified and used to determine the employees' self-efficacy within an e-learning environment in the present study. The term "E-Learning SelfEfficacy" is used to refer to both Internet Self-Efficacy and Computer Self- 
Efficacy since both were applicable to this study. These two forms of self-efficacy are explained in more detail next.

\section{Computer Self-Efficacy (CSE)}

Campeau and Higgins (1995, p.192) define CSE as "a judgment of one's capability to use a computer." CSE is not concerned with what one has done in the past rather than with what could be done in the future (Campeau \& Higgins, 1995). CSE does not refer to one's ability to undertake simple component subskills (such as saving a file) rather it refers to one's judgment of the ability to apply those skills to broader tasks (Campeau \& Higgins, 1995).

CSE can ultimately influence the success or failure of online instruction (Litchfield et al., 2002) making it one of the critical variables determining the success of computer and Web-based instruction (Joo et al., 2000). CSE has been found to have a significant influence on frequency, intensity of computer use, and diversity of software packages used, (Joo et al., 2001), individuals' emotional reactions to computers such as their interest or anxiety; their expectations of the outcomes of using computers; and their actual computer use (Campeau \& Higgins, 1995). Stronger computer confidence led to more positive attitudes towards computers and higher levels of computer related-knowledge (Levine \& Donitsa-Schmidt, 1998 cited in Joo et al., 2000).

Encouragement by others at work and other people's use of computers positively influences one's CSE (Campeau \& Higgins, 1995). “Thus self-efficacy represents an important individual trait, which moderates organizational 
influences (such as encouragement and support) (Campeau \& Higgins, 1995, p.189). Once an individual's CSE level is identified, motivational and personal control issues can then be addressed (Cassidy \& Eachus, 2002). Clearly, understanding CSE is essential in the understanding of barriers.

When using computers for learning, one's CSE has implications to one's success in learning. "Self-efficacy beliefs have repeatedly been reported as a major factor in understanding the frequency and success with which individuals use computers" (Cassidy \& Eachus, 2002, p. 134). A study by Campeau \& Higgins (1995) indicated that individuals with high self-efficacy used computers more, enjoyed using computers more, and experienced less computer-related anxiety. One's level of enjoyment and anxiety are significant factors in computer use (Cassidy \& Eachus, 2002).

"An appropriate measure of computer self-efficacy may enable students 'at risk' to be identified at an early stage" (Cassidy \& Eachus, 2002, p.138). It is therefore important to measure students' CSE because "low self-efficacy may be a significantly limiting factor for students exploring new applications vital for academic progress - the Internet being a prime example" (Cassidy \& Eachus, 2002, p. 137). The issue of Internet self-efficacy is discussed next.

Internet Self-Efficacy (ISE)

Related to CSE is the issue of Internet self-efficacy. ISE is the belief in one's capabilities to organize and execute Internet-related courses of actions in 
order to attain something (Eastin \& LaRose, 2000). The literature on ISE is more limited compared to that of CSE, probably due to the novelty of the Internet.

Usually, new Internet users are less comfortable using the Internet and are less satisfied with their Internet skills and are more likely to encounter stressinducing situations (GVU 1999 cited in Eastin \& LaRose, 2000). New Internet users are faced with complexity, knowledge barriers to initial Internet adoption, discomfort, and dissatisfaction and these may be taken to indicate self-efficacy deficits (Eastin \& LaRose, 2000). Novice Internet users face psychological as well as socio-economic, and racial barriers (Eastin \& LaRose, 2000). People who are uncomfortable or have little confidence in their ability to use the Internet can be said to have low ISE (Eastin \& LaRose, 2000). According to Bandura's theory, people with low self-efficacy are usually less likely to perform related behaviors in the future.

Joo et al. (2000) found that learners' confidence varied across different tasks performed on the Internet. The importance of studying ISE is indicated by Joo et al., (2000) who argue that if teachers or instructors are aware of this variable, they can plan their instruction with an effort to strengthening weaker skills. They assert, “...trainers and instructional designers of Web-based instruction would benefit by being more attentive to students' percepts of efficacy".

Tsai, et al. (2001) found that Internet attitudes could influence one's motivation towards learning to use the Internet and may also have interactions with students' performance in employing Internet technology. Joo et al. (2000) 
confirmed this in their study that indicated that ISE significantly correlates with academic motivation, performance, and previous experience working with computers.

Learners' attitudes and preconceptions towards media affect their learning outcomes (Solomon, 1984 cited in Joo, et al., 2000). Since E-learning involves a lot of learner-technology interaction, it is imperative that a learners' comfort level with technology be known as this could determine his or her performance in a DL course (Williams, 2001). Eastin and LaRose's (2000) instrument to measure ISE was utilized.

In light of these findings, it is fundamental to examine the e-learning selfefficacy level of employees because this might reveal some indications towards their continued future participation and/or performance in online training.

\section{Conclusion}

This chapter synthesized the literature on adult learning, distance learning, and e-learning barriers. Demographics and background characteristics of elearners were highlighted. The social cognitive theory and specifically computer self-efficacy and Internet self-efficacy in addition to Schilke's (2001) conceptual framework were utilized. The review of literature also integrated the technological society's views of technological determinists and social determinists who assert the value of not only looking at the benefits of each technology but also the threats of technology to individuals, organizations, and society. Chapter 3 follows with details about the methods and procedures used in the present study. 


\section{CHAPTER III}

\section{RESEARCH METHODS}

This study was undertaken to gain a better understanding of e-learning barriers from the employees' perspective. Seven organizations were under study including a public school district, a division of the US military, and for-profit organizations comprising of a health insurance company, two consulting companies, and two manufacturing companies.

This chapter describes the research participants, the instrument that was used, the process of developing it and validating it, the data collection procedure, and how the data was analyzed. This being a quantitative study used both descriptive and inferential statistics to analyze the data. A factor analysis, multivariate analysis of variance (MANOVA), Pearson correlation, and multiple regression were used to address the following research questions.

1. What barriers do employees engaged in e-learning in organizations face?

2. Are there differences in perceived e-learning barriers based on the type of organization? 
3. What is the relationship between perceived barriers and demographic variables such as age, gender, ethnicity, marital status, and level of education?

4. What is the relationship between perceived barriers and an employee's background characteristics such as prior experience with e-learning, job position, location of study, computer ownership with Internet connection, computer competency, and computer training?

5. What is the relationship between an employee's e-learning self-efficacy and perceived barriers?

\section{Research Design and Methods}

This study is a correlation study that was exploratory in nature in order to determine relationships among a variety of independent variables and e-learning barriers (dependent variable). Its design was ex-post-facto and there was no manipulation of the independent variables.

Web surveys (also called e-surveys or Internet surveys) are receiving the most attention from researchers (Simsek \& Veiga, 2001). Web-based surveys could be extremely useful for conducting organizational surveys that are commonly used to assess attitudes and employees' perceptions (Simsek \& Veiga, 2001). A variety of approaches are used when collecting data on the Internet (Conway \& Thomas, 2003; Simsek \& Veiga, 2001). Conway and Thomas (2003) suggest three methods of e-questionnaires, namely: (a) email surveys, (b) an email invitation linked to a Web-based survey, and (c) Web surveys, which 
are surveys on a Website that are open to anyone who visits that particular Website (Conway \& Thomas, 2003; Simsek \& Veiga, 2001). These three categories involve computerized, self-administered questionnaires. A selfadministered Web-based survey was used to collect data. Self-administered surveys are the most widely used form of data collection in organizational studies This study used an email invitation linked to a Web-based survey. Simsek and Veiga (2001) reported that most Web-based organizational survey respondents are solicited through email. In this approach to data collection, a URL is embedded in the email message that is sent to the target population (Conway \& Thomas, 2003; Simsek \& Veiga, 2001). In the body of the email, the respondent is directed to click on the hypertext link (URL), which will bring up a Web browser that contains the survey (Simsek \& Veiga, 2001). A study by Shannon, Johnson, Searcy, and Lott (2002) to survey professionals indicated "Individuals would likely respond to a Web-based survey if all they had to do was click on the HTML address from an email message" (Shannon, et al., 2002, p. 1). "The value of any new surveying technique, in part, depends on its ability to offer new opportunities or handle issues that take advantage of its unique strengths" (Simsek \& Veiga, 2001, p.220). There are several benefits of using Internet self-administered surveys. Stanton (1998) collected data from individuals using a Web survey and mailed surveys and found that Web surveys had fewer missing values (cited in Simsek \& Veiga, 2001). Other positive elements of e-surveys are reduced cost, pre-notification and follow-up 
capabilities using email, and compatibility of data with existing software programs (Shannon, et al., 2002).

The other advantage of Web-based surveys is that respondents experience less evaluation anxiety than with other survey modalities because they convey little social information (Simsek \& Veiga, 2001). With Web surveys, there is limited need for data cleaning because data simply transfers from the form to the analysis software (Simsek \& Veiga, 2001). This is a major benefit especially when dealing with a large population like the present study. Internet surveys also reduce the cost incurred due to the reduced need for paper (Simsek \& Veiga, 2001) and time for data entry. Considering the size of this study's population (approximately 4807 respondents), the Web offered distinct advantages over a mailed survey. The data collection speed is another advantage of Internet surveys (Shannon, et al., 2002; Simsek \& Veiga, 2001). Speed can be "especially valuable at the pilot-testing stage of survey development, where pilot testing and instrument clarification are needed before the final survey can be launched" (Simsek \& Veiga, 2001, p.220). These were some of the reasons behind the use of a Web survey in this study.

Web-based surveys do have limitations too. Shannon, et al. (2002) found that some of the concerns with e-surveys have to do with the respondents' knowledge of and experience with technology. While this might be an unknown factor and a concern for some research studies, this study's participants were employee e-learners who must have had some experiences with computers and the Internet. 
Simsek and Veiga (2001) suggest using a combination of several approaches arguing, "No single survey approach can be judged effectively...because each is more appropriate under different circumstances" (Simsek \& Veiga, 2001, p. 219). Other researchers such as Shannon et al. (2002) acknowledge this reality and this study addressed this issue by using the pilot data to determine whether the population has a preference for mailed survey (MS) over Web surveys (WS). Two questions in the instrument sought this information from the pilot study respondents. The pilot group overwhelmingly agreed $(89.7 \%)$ that a Web-based survey was appropriate thus it was used to collect data in the main study.

\section{Instrument}

Closed-ended questions in the form of a Likert scale ranging from 1 to 5 as suggested by Magalhaes and Schiel (1997) were used. The use of openended questions to solicit further opinions and demographic questions is recommended by Biner (1993). Many researchers in the distance education arena support a multi-dimensional perspective whenever evaluations are conducted. For example, for the closed-ended questions, Magalhaes and Schiel (1997) suggested integrating various aspects such as the use of technology, technical support, training available, interaction between students, instructor or mentor, home page layout, and content. Biner (1993) also suggested including instructor or instructional aspects, technological aspects, and course management and coordination aspects in evaluations. Biner (1993) suggested 
that when developing an instrument to evaluate learner satisfaction, one should identify factors most closely related to course satisfaction in the minds of students. In this study, employee e-learners were the participants of interest and factors that were most closely related to their dissatisfaction were incorporated in the instrument. Biner (1993) also recommended generating an unrestricted list of possible items (factors that potentially could affect learners' attitudes) when developing an instrument. Following this advice, the instrument used 44 questions to determine e-learning barriers. These were reduced to 42 questions in the main study.

The survey instrument (see Appendix D) included a shortened version of an informed consent, instructions on how to complete the survey, and operational definitions of e-learning barriers. Completing and submitting the survey indicated an employee's willingness to participate. The instructions included how to respond and how to submit responses electronically. The instrument had three parts.

Part One

The first part of the instrument measured the employees' demographic and background characteristics and consisted of fifteen closed-ended, Likertscaled, multiple-choice questions. Various authors have noted the need to look at demographic variables (Franklin, Yoakam, \& Warren, 1996; Galusha, 1998), which were used as independent variables in this study. Demographic variables such as age (Feldhaus, 2001); gender (Kramarae, 2001; Robinson, 1992; 
O'Malley \& McCraw, 1999); ethnicity (Feldhaus, 2001); marital status (Feldhaus, 2001; Kramarae, 2001); and level of education (Giles, 1999; O'Malley \& McCraw, 1999) were included.

Other background questions were sought and used as independent variables. These included a respondent's prior experience with e-learning (Giles, 1999; O'Malley \& McCraw, 1999; Schilke, 2001); occupation or job position held in the organization (Campeau \& Higgins, 1995; computer competency; computer ownership (Cassidy \& Eachus, 2002); and computer training (Cassidy \& Eachus, 2002). Their overall rating of e-learning experiences was also determined.

\section{Part Two}

Part two consisted of 44 closed-ended, five-point Likert-scaled questions, addressing e-learning barriers. The instrument featured items reflecting multiple sources of barriers using the Schilke (2001) model of situational, institutional, dispositional, epistemological, and technological barriers. Since the researcher had not identified any one particular instrument for determining barriers perceived by employee e-learners in organizations, the instrument was comprised of barriers cited in other instruments and variables from the literature. These items on barriers were extracted from previous literature on barriers in adult, distance, and e-learning including ASTD and Masie (2001), Berge (1998, 2000), Feldhaus (1999), Galusha (1998), Garland (1993), Gilpin (2000), Keegan (1986), Kramarae (2001), Muilenburg and Berge (2001), Oblinger, Barone, and Hawkins (2001), Peratton (2000), and Schilke (2001). 
Most of the available instruments did not fit the population under study.

For example, Berge and Muilenburg (2000) developed a questionnaire that looked at barriers across e-learning stakeholders, such as administrators, trainers, and students. Since some of the items were applicable to the present study, those that specifically addressed barriers that exist in organizational settings were extracted, modified, and used. For example, being a full-time student or paying tuition was not applicable to this study's population; therefore such barriers were excluded. Permission to modify and use these instruments and/or items was sought and granted.

On a Likert scale ranging from 1 to 5 , the participants rated the items based on how they weighed the strength of a particular barrier to one's e-learning experiences. The intent was not to determine course-specific barriers but the general perception of all online experiences (across multiple courses if applicable). Checking 5 would indicate a "very strong barrier", that it was a major learning obstacle. Checking 1 "no barrier" means that one did not perceive that item to be an obstacle to starting, continuing and completing e-learning.

Situational barriers. Items pertaining to an employee's situation, environment or circumstances were asked. These included "Lack of support by family, friends, or significant others" or "Lack of free time to study" (Berge, 2001; Garland, 1993; Kramarae, 2001; O'Malley \& McCraw, 1999; Schilke, 2001).

Technological barriers. Under technological barriers were items such as "Technical assistance or support services" or "Consistent access to the course" (Campeau \& Higgins, 1995 \& 1999; Franklin, Yoakam, \& Warren; Schilke, 2001). 
Institutional barriers. Under institutional barriers were items such as "support by employer, supervisor or coworkers" (ASTD \& Masie, 2001; Garland, 1993; Campeau \& Higgins, 1995; Schilke, 2001) and the quality of the learning materials (Garland, 1993; Oblinger, Barone \& Hawkins, 2001; Schilke, 2001).

Epistemological barriers. Under epistemological barriers were items such as the difficulty of the content (Garland, 1993; Morgan \& Tam, 1999; Schilke, 2001) and the course's relationship to one's job or interest (Schilke, 2001).

Personal barriers. Items were included under personal barriers including one's resistance to change and motivation towards e-learning (Conway \& Ross, 1990; Franklin, Yoakam \& Warren, 1996; Garland, 1993; Schilke, 2001).

\section{Part Three}

Part three of the main study's instrument consisted of 24 items addressing the participants' e-learning self-efficacy. The nature of self-efficacy is an egocentric construct that demands that it be measured directly using self-report scales (Cassidy \& Eachus, 2002). Therefore, items from Cassidy and Eachus' (2002) Computer User Self-Efficacy (CUSE) scale and Eastin and LaRose (2000) instrument to measure Internet Self-Efficacy were modified and used. Some of the items that were included were "I can use the Internet to gather data" (Eastin \& LaRose, 2000); "I can turn to an online discussion group when help is needed" (Eastin \& LaRose, 2000); and "Computers frighten me" (Cassidy \& Eachus, 2002) among others. 
This CUSE scale was designed to measure general computer self-efficacy in an adult student population (Cassidy \& Eachus, 2002). "The scale may be used to identify individuals, in particular students, who will find it difficult to exploit a learning environment, which relies heavily on computer technologies" (Cassidy \& Eachus, 2002, p. 133). The items on this scale seem relevant to the employee population under study, but it was tested and validated through the pilot and main study.

\section{Validity and Reliability of the Instrument}

\section{Validity}

Content validity was established by seeking feedback from subject matter experts about the instrument's validity. Content validity is the extent to which a set of items on a test are relevant and a representative sample of the full domain of content (Biner, 1993). The subject matter experts (SMEs) were chosen based on their experience with e-learning. The selection criteria included those who had conducted e-learning research, published articles on e-learning, learned, designed, developed, or taught online courses, and their willingness to participate. Other researchers such as Timura (1995) and Colton (2001) have used SMEs for validity tests. Content validity analysis for each of the items assists in determining which items should be included in the final version of the instrument (Biner, 1993). The feedback from the SMEs was valuable in this determination. 
The researcher emailed pre-identified SMEs to first seek their approval to review the instrument before it was piloted. The instrument was emailed to seven volunteers, giving them clear directions of what to do. The researcher sought both verbal and written feedback from the SMEs. Specifically, they were required to do an item-by-item analysis and below each item, space for feedback was provided. They were asked to comment on the overall structure, content, and wording. Some were interviewed over the phone and probed on their responses to the questionnaire items. Their suggestions were incorporated in the instrument revisions.

Reliability

The instrument was piloted using a random sample of e-learners from the participating organizations. The pilot served two purposes: to detect any technological problems since a Web-based instrument was used and to gain additional feedback about the questionnaire instrument. According to Babbie (1998), the pilot-study sample should be selected in the same manner as that of the final survey. Clearly, the entire population of e-learners cannot be used for the pilot study so ten e-learners were randomly chosen from each organization.

The researcher sought written feedback from the pilot group. They were asked to time themselves during the completion of the questionnaire to determine how long it took them to complete the questionnaire. They were also asked to give their feedback pertaining to the clarity of the items. This was accomplished by integrating an open-ended question as an additional question in 
the instrument. Babbie (1998) noted that it is reasonable for the pilot-study instrument to contain more questions than the final survey. Based on their feedback and reliability analysis, revisions were made to the instrument. The main study was conducted after the pilot study.

Data from both the pilot and main study were entered into an SPSS data file for statistical analysis. The SPSS procedure Reliability was employed to perform item analysis and to calculate Chronbach's alpha internal consistency reliability coefficient for sub-scales in the questionnaire. The purpose of reliability analysis is to establish that the instrument contains scales having minimally acceptable internal consistency reliability.

For the pilot test, e-learning barriers and e-learning self-efficacy subscales were analyzed. For each scale, the goal was to obtain a scale with a reliability coefficient of at least .70 (Nunnally \& Bernstein, 1994) although already validated scales were used to measure e-learning self-efficacy. Cassidy and Eachus (2002) developed the Computer User Self-Efficacy Scale (CUSE) comprising of 30 items and tested it with university students $(N=184)$. The CUSE 30 -item scale was found to have high levels of internal reliability (alpha $=.97$ ) and high levels of external validity with a test-retest reliability conducted over a one month period being high and statistically significant (alpha $=.86$ ) (Cassidy \& Eachus, 2002). Similarly, the Internet Self-efficacy scale was validated through a factor analysis that yielded "substantial factor loadings" and obtained a Cronbach's alpha of .93 (Eastin \& LaRose, 2000). This study undertook further 
efforts to validate a combination of these two scales with the target population through reliability analysis.

\section{Participants}

The participants of this study were employees in seven organizations that had participated in e-learning. Employees in an Information Technology (IT) manufacturing company, an Oil Exploration and Manufacturing company, a health insurance company, a division of the US military, an IT Consulting company, a Wholesale Distribution company, and a public school district were represented.

These participants had engaged in voluntary or mandatory e-learning opportunities offered by these organizations dating back to 2001. This period was limited to two years (2001 to 2003) to ensure that the participants have recent memories of their online learning experiences.

The sampling frame for this study was made up of databases of employee e-learners (similar to student rosters) in each of the participating organizations. Babbie (1998) suggested selecting the widest variety of respondents especially in the initial design of a questionnaire, to test the broad applicability of questions. Therefore, purposive or judgmental sampling was used, with a sample size of ( $n$ $=4807$ ) drawn from the seven organizations. Respondents were comprised of all job levels ranging from senior management, middle level staff, to clerical staff. In the public school district, they included administrators, teachers, and support 
staff; while in the military, both commissioned and non-commissioned officers were included.

Franklin, Yoakam, and Warren (1996) cautioned that some types of information may be sensitive and people are not always comfortable providing personal information. Other researchers (Biner, 1993; Magalhaes \& Schiel, 1997) have emphasized that a questionnaire should seek voluntary and anonymous responses. Following this caution, the survey was anonymous and voluntary.

Shannon et al. (2002) indicated that respondents need to be protected in terms of their authenticity, confidentiality, and privacy and access to the surveys must be limited to the targeted sample only. This was accomplished by requiring the respondents to enter a password to gain entry to the web survey as recommended by Shannon et al. (2002). The password was sent to them via an email. Confidentiality was ensured to the extent possible and the raw data was accessible only by the researcher and the Web administrator assisting with technological issues.

Context

Seven organizations were involved and below are brief descriptions of each one of them.

Organization 1 is an international Information technology (IT) productmanufacturing firm that provides networking infrastructure and connectivity solutions and technologies. It has over 5,000 employees who have access to Web-based courses delivered via Webex ${ }^{\mathrm{TM}}$ learning management system (LMS). 
For the last four years this organization has offered to its employees voluntary and mandatory courses, covering technical and soft-skills, mostly asynchronous in nature. A total of 867 employees in this organization were invited to participate in the main study.

Organization 2 is a Global 500 oil and gas manufacturing company with over 100,000 employees. It is a company with a long history in oil and natural gas, petrochemicals and more recently in renewable energy technologies. The division under study has been offering online courses for the since 2002 using TRACCESS ${ }^{\mathrm{TM}}$ LMS. The employees under study participated in one voluntary soft-skills course that was applicable and available to approximately 1,000 employees in this division. A total of 10 employees in this organization were invited to participate in the main study.

Organization 3 is a Fortune 500 offers health insurance coverage and related services nationally with approximately 13,000 employees. It has been offering both voluntary and mandatory e-learning courses using SkillSoft ${ }^{\mathrm{TM}}$ and Mindleader ${ }^{\mathrm{TM}}$ for the last 5 years. This organization has 13,000 employees and online training spans across all job levels to deliver various courses, which are asynchronous. A total of 500 employees in this organization were invited to participate in the main study.

Organization 4 is a public school district that has been offering e-learning for the last 1 year. Their training targets its administrators, teachers and clerical staff using ANGEL ${ }^{\mathrm{TM}}$ as their Learning Management System (LMS). This organization's e-learning is voluntary although participants can use the credits 
earned towards professional development hours required by their professions.

The courses are both technical and soft skill courses.

Organization 5 is the largest wholesale distribution company in North America with approximately 15,000 employees. It sells wholesale products in Canada, Mexico and the United States. Approximately three-fourths of all training courses in this organization are delivered electronically with its e-learning program targeting all employees. Several LMS' are used including SmartForce, Skillsoft, Saba, and an internal LMS to deliver asynchronous technical and softskills training across all levels. The e-learning history in this company dates back to the last five years. A total of 1200 employees in this organization were invited to participate in the main study.

Organization 6 is a leading global consulting and IT services company with approximately 10,000 employees. Its services range from strategy consulting to implementing IT solutions for clients. This organization serves over 270 global companies and its marketing network spans 45 countries across five continents. E-learning is offered across all job positions and targets all employees. Both mandatory and voluntary are available with most being asynchronous. An in-house authoring tool called eSLC is used to deliver elearning. A total of 1600 employees in this organization, most of whom were located outside the United States were invited to participate in the main study.

Organization 7 is a division of the US military that delivers Web-based training to its commissioned and non-commissioned officers located both on land and at sea. This particular division has approximately 1700 employees. E- 
learning has been offered for the last three years using NET $\mathrm{G}^{\mathrm{TM}}$. The technical and soft-skill courses offered are mostly asynchronous, both mandatory and voluntary. Approximately 130 employees in this organization were invited to participate in the main study.

It is evident that there are similarities in most of these organizations in the way they use e-learning as a training tool. Most of these organizations are diverse, targeting international and geographically dispersed employees. Most courses target internal employees, are asynchronous, and offer both mandatory and voluntary training. Differences do occur within and among these organizations in terms of courses offered, LMS' used, and nature of delivery (asynchronous vs. synchronous) among others.

\section{Subject Selection}

The subjects under study were samples of convenience, from seven organizations that volunteered to participate. Researchers using Internet surveys have reported extremes in response rates (Simsek \& Veiga, 2001).

Communication with the contact persons in the organizations under study also indicated that typical response rates to surveys they have conducted in the past ranged from $10 \%$ to $100 \%$. The size of the target population to which the researcher has access varies across these organizations with one of them having only 80 employees who had participated in e-learning. Therefore, considering this uncertainty on the response rate and the varied sizes, the 
researcher invited as many employee e-learners as possible to respond to the survey.

\section{Procedure}

Prior to any data collection, the proposed study was submitted to the Human Subjects Committee for review and approval. Appendix A accompanied the application material in order to comply with the research standards for human subjects' protection. Upon approval, the SMEs were contacted to review the instrument and provided the researcher with feedback (Appendix B).

The data collection procedures for both the pilot-study group and the main study were very similar. All communication (email messages) originated from the researcher but went through the contact person in each organization, since they had direct access to employees' email addresses. The contact persons had already volunteered do this.

The pilot study was done in early May 2003. The email to the pilot group (Appendix C) to complete the survey only went out to ten pre-selected individuals in each organization. The contact persons did the random pre-selection. Once the pilot study was completed and the revisions made, the main study commenced on June 2, 2003, lasting for one month. The Web-based survey remained open during this time period (June $2-31,2003$ ) to give the participants ample time to respond. Regular correspondence with the respondents occurred during this period as described below. 
Week 1: A pre-notification email (see Appendix E) was sent to the target population in each of the participating organizations. This was intended to initiate contact with the respondents informing them of the upcoming research study in which their contribution was sought. Some of the contact persons (championing the study) customized the email message to fit their organizational communication procedures and culture.

Following the pre-notification email, the researcher sent another email to the entire targeted population, through the contact person, asking them to complete the survey. This email (see Appendix F) gave more details about the purpose of the study; included an informed subject consent; the researcher's contact information; a password to access the survey; and a Web site address (URL) that hosted the questionnaire. One password was used across all organizations. Upon gaining entry using the prescribed password, they completed and submitted their responses electronically.

Week 2 and 3: Reminder emails were sent, one in the second and another during the third week of the study (see Appendix G). These are intended to increase the response rate.

Week 4: At the end of the fourth week, data collection was completed. An email was sent to the respondents, thanking them for their participation in the study (Appendix H). This email included the researcher's email (in case they had questions or concerns or were interested in receiving the results of the study).

This was an additional measure of protecting their privacy so that they would not have to contact their employer. This procedure is illustrated in Table 2. 
Table 2

Survey Procedures Used in the Study

\begin{tabular}{lll}
\hline Activity & Tentative Dates & Appendix \\
Human Studies Committee review & April 2003 & Appendix A + forms \\
SME survey review & May & Appendix B \\
Survey revisions (by researcher) & May & \\
Pilot group pre-notification & & Appendix E \\
Pilot group review & May & Appendix C \\
Survey revisions (by researcher) & May & \\
Pre-notification & $1^{\text {st }}$ week of June & Appendix E \\
Main study (all e-learners) & $1^{\text {st }}$ week & Appendix F \\
$1^{\text {st }}$ reminder & End of $2^{\text {nd }}$ week & Appendix $\mathrm{G}$ \\
$2^{\text {nd }}$ reminder & End of $3^{\text {rd }}$ week & Appendix $\mathrm{G}$ \\
Thank you note & End of $4^{\text {th }}$ week & Appendix $\mathrm{H}$ \\
Close survey & End of $4^{\text {th }}$ week & \\
\hline
\end{tabular}

There are some procedural issues that are unique to Web-surveys that deserve further description and these issues were addressed in the present study. Some of the most problematic and controversial aspects of Internet surveys include representativeness of samples, sampling frames, response rates, anonymity, and confidentiality (Simsek \& Veiga, 2001). Below is a description of how this study addressed these concerns. 
Anonymity. According to Simsek and Veiga (2001), the extent to which a survey modality affords the respondent anonymity is a major factor contributing to measurement error in Internet surveys. Magalhaes and Schiel (1997) also emphasized on the use of anonymous questionnaires. "A respondent is anonymous when nobody, including the researcher can associate a given response with that respondent" (Simsek \& Veiga, 2001, p. 225). Anonymity is especially important in the Internet environment, which can be lost when responses are sent by emails and when "cookies" are used (Simsek \& Veiga, 2001). To alleviate these concerns in Web surveys, three measures were taken: respondents were directed to an alternative Website (other than that of their employer), a measure that has been suggested by (Simsek \& Veiga, 2001). Secondly, cookies and email responses was not used either. Complete anonymity "is not possible with Internet surveys (Simsek \& Veiga, 2001, p. 231) just as in regular mailed surveys. The researcher therefore did not make any promise of complete anonymity.

Confidentiality. This is a critical issue when using e-surveys (Shannon et al., 2002; Simsek \& Veiga, 2001). Passwords are likely to invoke perceived levels of confidentiality (Shannon et al., 2002; Simsek \& Veiga, 2001). The researcher made assurance of efforts to maintain confidentiality to be best extent possible in the pre-notification email as recommended by Shannon et al. (2002). Passwords were used for several purposes.

1. To limit access only to the target samples 
2. To alleviate respondents' suspicions about confidentiality (Simsek \& Veiga, 2001)

3. To gain entry into the survey although they too do not ensure total confidentiality (Simsek \& Veiga, 2001, p. 231), and

4. For data analysis purposes.

Representativeness of samples. Shannon, et al. (2002) recommended that measures must be taken to reduce sampling error and samples must be clearly defined and authenticated. Therefore a password was used to limit access to the survey to the targeted sample. Representativeness of samples, sampling frames, and representativeness of the sample are issues that deserve attention when dealing with Internet self-administered surveys (Simsek \& Veiga, 2001). Concerns over representativeness vary considerably depending on who or what is being researched (Simsek \& Veiga, 2001). For example, "Internet users may be exactly the individuals that the researcher is targeting if one is seeking opinions related to a new software program" (Simsek \& Veiga, 2001, p.222). The focus of this study was employees who had used the Internet for learning purposes.

Organizational surveys normally involve all members of the organization (Simsek \& Veiga, 2001). Ensuring that the sample represents the population from which it is drawn is currently difficult to achieve with Internet surveys because Internet surveys can only be conducted with those who can and do use the Internet (Simsek \& Veiga, 2001). It is important to note that "Organizational research has traditionally relied on designs that are vulnerable to sample 
selection bias; hence, a strict application of the representativeness issue will mean ruling out a vast portion of fruitful organizational research" (Simsek \& Veiga, 2001, p.222). To address these issues, this study used the entire population of employees who had been engaged in online training dating back to 2001 in each of the participating organizations.

Response rates: Internet surveys have been reported response rates ranging from $7 \%$ to $76 \%$ (Simsek \& Veiga, 2001). Personalized pre-notification and number of contacts have been found to influence response rate (Shannon, et al., 2002). Consequently, the contact person in each participating organization sent a pre-notification email to the target audience. Further, the contact persons were requested to place a link (URL) of the survey on each organization's Website that is most frequented by target employees. Reminders were also sent, two weeks after the first email to help boost the response rate.

The researcher was unable to predict beforehand what the response rate would be. Based on communication with the contact persons in each organization about their previous research response rates in previous surveys, response rates varied, ranging from $10 \%$ to $100 \%$. This uncertainty on response rate is a limitation that other researchers have encountered. For example, Koresdoski (2001) was unable to formulate an exact survey response rate because she had to the use third parties (human resource professionals) to forward the survey request to colleagues and was unable to control the return of surveys from all participants. 
Non-response error occurs when some members of the targeted group do not respond to the survey (Simsek \& Veiga, 2001). Internet surveys are not exempt from non-response error but there has been no theoretical work that addresses non-response in Internet surveys (Simsek \& Veiga, 2001). Contacting non-respondents in this study was not a possibility because their participation was not tracked and their responses were anonymous.

\section{Data Analysis}

Data collection was followed by analysis using Version 11 of the Statistical Package for Social Sciences (SPSS). Descriptive and inferential statistics were used. Descriptives of the data such as means, frequencies, mode, median, and standard deviations were computed. Inferences were made using an alpha level of .05, which is used in most educational studies (Glanz, 1998).

Inferential statistics. The instrument was further validated through an exploratory factor analysis. According to Biner (1993) it is important to identify the major dimensions underlying groupings of specific items because the identification of such groupings/dimensions helps to format the questionnaire in which related questions are clustered together. In addition, the factors emerging from the factor analysis were labeled as the types of barriers and used as the dependent variables. Multivariate statistical tests were utilized including multiple regression and factorial MANOVA due to multiple e-learning barriers.

Research question one. This question addressed barriers that employee e-learners faced. To answer these questions, descriptive statistics were 
calculated on each questionnaire item to report what percentage of respondents selected the options from no barrier (1) to very strong barrier (5).

The open-ended response question addressing additional barriers that employees might have perceived were analyzed following steps recommended by Creswell (2003). The first step involved organizing and preparing the data for analysis. This included downloaded data from the server and saving it in a secondary location.

Step two involved reading through all the data to obtain a general sense of information. The third step followed with a more thorough reading and analysis of each comment, chunking it into sub-headings or terms that best described them. The fourth step involved summarizing or paraphrasing each comment briefly and looking for any major themes emerging from those comments. Step five involved presenting these seven themes through the use of tables. Creswell (2003) notes that tables can be used as adjuncts to narrative discussions. The themes were followed by sub-themes (sub-headings) and in some cases, actual comments were quoted or paraphrased. The final step involved interpreting and presenting the results.

Research question two. This question investigated whether significant differences exist between perceived barriers and type of organization. A multivariate analysis of variance (MANOVA) was used to determine the differences among the seven organizations (independent variables) and the dependent variables (categories of barriers emerging from a factor analysis). 
Research question three. This question investigated the nature of relationship between perceived barriers and each one of these demographic variables (age, gender, ethnicity, marital status, level of education, and organization). "Survey researchers very often find that a given dependent variable is affected simultaneously by several independent variables. Multiple regression analysis provides a means of analyzing such situations" (Babbie, 1998 , p. 308). Thus multiple regression was used to make this determination. Forward entry of variables was done since there was no theoretical ordering of the variables under consideration. In this method, "the first predictor that has an opportunity to enter the equation is the one which has the largest simple correlation with the dependent variable (y) (Stevens, 2002, p.96).

Research question four. This question's purpose was to identify the relationship between perceived barriers and background characteristics (job position, prior experience with e-learning, computer ownership with Internet connection, study location, computer competence, and computer training). Multiple regression with forward entry was used since there was no theoretical ordering of these variables.

Research question five. This question established the nature of the relationship between perceived barriers and an employee's e-learning selfefficacy. Pearson correlation was used to make this determination. Each correlation involved (a) the overall score of the barriers scale and (b) the overall score of e-learning self-efficacy scale. 
Assumptions Tested

Independence assumption: MANOVA assumptions and regression model assumptions were put under consideration during the data analysis. The linear regression model assumes that errors are independent. "The independence assumption implies that the subjects are responding independently of one another" (Stevens, 2002, p. 110). Based on a description by Glass and Hopkins (1984), "Whenever the treatment is individually administered, the observations are independent..." (cited in Stevens, 2002, p. 259). The respondents were involved in e-learning, which is self-directed and self-paced hence their responses were also independent of each other.

Normality assumption: The linear regression model also assumes that errors follow a normal distribution with constant variance (Stevens, 2002). The normality assumption was checked through the use of histograms of residual plots as recommended by Stevens (2002).

\section{Conclusion}

This chapter details the research methods and procedures that were followed to collect and analyze data including the subjects, instrumentation, validation process, data collection, and analysis procedures. Upon completion of the data collection, the data was analyzed as illustrated under Table 3. The results of the present study are discussed in Chapter 4. 
Table 3

Research Questions, Variables, and Statistical Tests

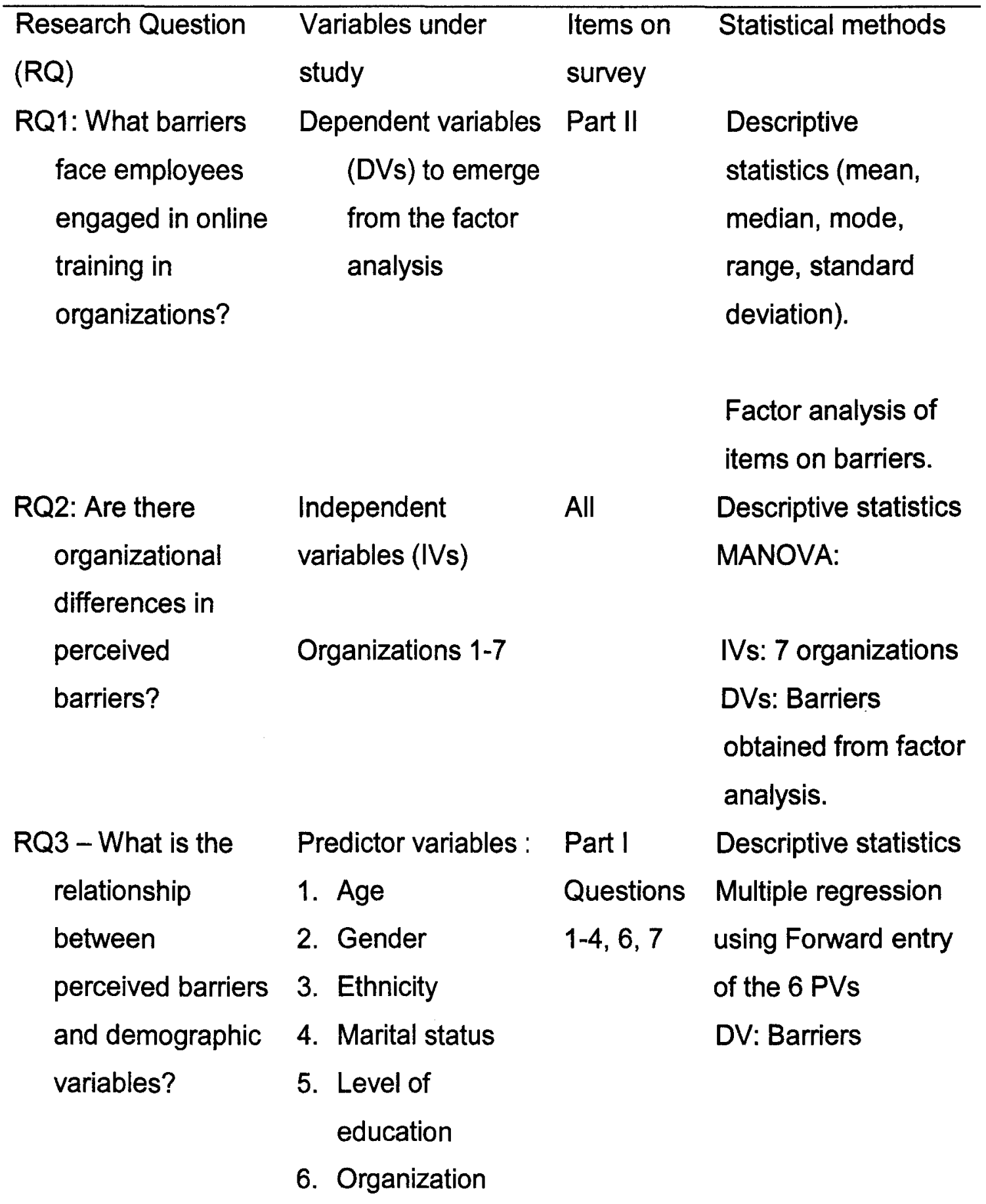


Table 3 (continued)

\begin{tabular}{|c|c|c|c|}
\hline $\begin{array}{l}\text { Research Question } \\
(R Q)\end{array}$ & $\begin{array}{l}\text { Variables under } \\
\text { study }\end{array}$ & $\begin{array}{l}\text { Items on } \\
\text { survey }\end{array}$ & Statistical methods \\
\hline $\begin{array}{l}\text { RQ4: What is the } \\
\text { relationship } \\
\text { between perceived } \\
\text { barriers and an } \\
\text { employee's prior } \\
\text { experience with e- } \\
\text { learning, job } \\
\text { position, location of } \\
\text { study, computer } \\
\text { ownership, } \\
\text { computer } \\
\text { competency, and } \\
\text { computer training? }\end{array}$ & $\begin{array}{l}\text { Predictor variables } \\
\text { (PVs) } \\
\text { 1. Job position } \\
\text { 2. Prior e-learning } \\
\text { experience } \\
\text { 3. Computer } \\
\text { competence } \\
\text { 4. Study location } \\
\text { 5. Computer } \\
\text { ownership with } \\
\text { Internet } \\
\text { connection } \\
\text { 6. Computer } \\
\text { training }\end{array}$ & $\begin{array}{l}\text { Part I } \\
\text { Questions } \\
5,8-14\end{array}$ & $\begin{array}{l}\text { Descriptive } \\
\text { statistics } \\
\text { Multiple regression } \\
\text { PVs: Background } \\
\text { DVs: Barriers }\end{array}$ \\
\hline $\begin{array}{l}\text { RQ5: What is the } \\
\text { relationship } \\
\text { between perceived } \\
\text { barriers and an } \\
\text { employee's self- } \\
\text { efficacy? }\end{array}$ & $\begin{array}{l}\text { Predictor variable } \\
\text { Self-efficacy }\end{array}$ & Part III & $\begin{array}{l}\text { Descriptive } \\
\text { statistics } \\
\text { Pearson } \\
\text { correlation } \\
\text { PV: Self-efficacy } \\
\text { DVs: Barriers }\end{array}$ \\
\hline
\end{tabular}




\section{CHAPTER IV}

\section{RESULTS}

The current study, recognizing the value of e-learning, explored the barriers facing employee e-learners in organizations and their self-efficacy. A number of studies have underscored the value of continued research in these areas (Christoph, Shoenfeld, \& Tansky, 1998).

The current study involved a survey measuring (a) demographic characteristics of e-learners, (b) barriers faced by employees engaged in elearning, and (c) e-learning self-efficacy (Appendix D). The specific details about these constructs are covered in more detail under Chapter Three. The items in the demographics section and Barriers in E-learning Scale (BELS) were developed based on suggested issues in the literature and refined through a pilot study. Items in the E-learning Self-Efficacy Scale (ELSES) were a modification of the Eastin and LaRose (2000) and Cassidy and Eachus (2002) instruments. Individual items were all measured on a 5-point Likert scale, reflecting the respondents' perception of their Internet and computer self-efficacy; with the scale ranging from strongly disagree (1) to strongly agree (5). 
Since the researcher did not identify any developed and validated instrument, one was designed, and validated through a pilot study and a review by subject matter experts (SME) to determine its psychometric properties prior to its use. The results of the pilot will be discussed first, followed by results from the main study. This is consistent with Creswell (1994) who recommended presenting the data analysis in sequential steps.

This chapter presents an analysis of the main study's findings and is organized following the five research questions leading this study. The research questions were:

1. What barriers do employees engaged in e-learning in organizations face?

2. Are there differences in perceived e-learning barriers based on an employee's organization?

3. What is the relationship between perceived barriers and demographic variables such as age, gender, ethnicity, marital status, and level of education?

4. What is the relationship between perceived barriers and an employee's prior experience with e-learning and computers, job position, location of study, computer ownership, and computer training?

5. What is the relationship between an employee's e-learning self-efficacy and perceived barriers?

To analyze the data the researcher used the Statistical Package for Social Sciences (SPSS). Descriptive and inferential statistical techniques used included 
Factor analysis, multiple regression, MANOVA, and Pearson Correlation. The level of significance used for data analysis was .05.

\section{Results of the Pilot Study}

Response Rate

The pilot study was conducted in all the seven organizations. Originally a total of 70 potential respondents were randomly chosen and contacted in each of the seven organizations. The contact person was asked to pick at random any 10 employees although in one of the organizations, 20 people were contacted, leading to a total pilot sample size of 80 . There were 42 responses yielding a response rate of $52.5 \%$. One email reminder was sent to the pilot group. The average time taken by each of the respondents in the pilot group to complete the survey was 14 minutes.

Data were collected using a Web-based survey and the respondents were given two weeks to respond. The researcher decided to extend the deadline for four days for several reasons. First, one of the organization's fiscal year was ending around the same time period that the data was being collected. Timing also a factor in the Public School District whose employees were in their last week of the academic year. Secondly, some of the contact persons delayed in notifying their employees. Therefore, a reminder was sent and six additional participants completed the survey after the initial deadline.

The comments emerging from the pilot study were valuable to the study and aided in the refinement of the instrument. Four open-ended questions 
seeking respondents' feedback helped in making the final revisions. The respondents also gave indications on the appropriateness of the Web-survey. Changes were made to the survey based on the feedback from the pilot study and the comments from the subject matter experts. For example, they indicated a need for an open-ended question addressing barriers faced that were not included in the survey. In addition, "Rank one" was one of the choices given under level of education. Because this was not a nationally recognized level of education, it was changed to "Specialist Degree". Several SMEs indicated the need to clarify the use of the terms "learning style" and "learning community" which might not be understood by the audience, and this was done. Some of the questions that had been repeated were eliminated and revisions were made to the instrument. A discussion of the reliability and validity of the instruments and the results from the pilot study follows.

\section{Validity and Reliability}

Instrument Validity

Seven subject matter experts (SMEs) reviewed the survey for validity. The SME selection process is discussed in depth in Chapter Three. The survey was attached to an email to seven SMEs as an editable document. After reviewing the survey, some sent their comments via email and in some cases the researcher contacted them by phone for feedback and to clarify their comments. They indicated that the survey was well constructed with face validity and construct validity. They gave suggestions concerning how to improve content 
validity, clarity, and appropriateness of each one of the items. For example, to capture as many barriers as possible, SMEs recommended the inclusion of an open-ended question that would capture other barriers not addressed in the survey. Another example was the need to modify some of the closed-ended questions such as job position to be more inclusive and specific, by including positions such as managers and administrators. Their feedback was incorporated in the revised survey before it was sent out to the pilot group.

\section{Instrument Reliability}

Reliability analysis procedure provides information about the relationships between individual items in the scale. The internal consistency of the two scales (BEL and ELSE) used in this study was calculated using SPSS. Cronbach's alpha, a measure of internal consistency based on the average inter-item correlation, was used. The results indicated that both scales had very high reliability. This scale was made up of 44 items whose alpha coefficient was .9605 as depicted on Table 4.

E-learning self-efficacy scale (ELSE). This scale was made up of a combination of two instruments with a total of 34 questions. The resulting reliability of these 34 items in the ELSE scale was an alpha coefficient of .9570 . However, due to the redundancy in some of the questions, in the CUSE scale, 9 items were eliminated, resulting in a 24-item scale with an alpha coefficient of .9438 as illustrated in Table 4. These changes emanated from the pilot group's 
comments and the reliability of the scale was barely affected by the removal of these 9 items.

Table 4

Pilot Study Reliability Coefficients

\begin{tabular}{|c|c|c|}
\hline Scale & Number of items & Coefficient alpha \\
\hline Barriers in e-learning scale (BELS) & 44 & .9605 \\
\hline $\begin{array}{l}\text { E-learning self-efficacy scale } \\
\text { (ELSES) (long form) }\end{array}$ & 34 & .9570 \\
\hline $\begin{array}{l}\text { E-learning self-efficacy scale } \\
\text { (ELSES) (short form) }\end{array}$ & 24 & .9438 \\
\hline
\end{tabular}

The pilot study survey consisted of four additional questions that were eliminated in the main study. Instructions relating to these questions were removed or modified to suit the main study. These questions sought feedback concerning the (a) clarity and appropriateness of the questions, (b) the appropriateness of a Web-based survey (Internet-based) for this kind of study on e-learning barriers, (c) problems encountered in the process of accessing and completing the survey, and (d) how long it took to respond to the survey (Appendix D).

The modifications of the survey resulted in a total of 15 questions under the demographic section. An additional question was added asking for an overall rating of their e-learning experiences. Due to redundancies (pointed out by the pilot group), two items were deleted from the BELS leaving 42 Likert-scaled 
items plus an open-ended question asking about other perceived barriers. Ten questions were deleted from the ELSE scale leaving 24 Likert-scaled items. This resulted in a total of 82 questions (see survey in Appendix D).

\section{Results of the Main Study}

Following the pilot study, the instrument was revised and sent to potential respondents in seven organizations. The target population consisted of employees who had had e-learning courses in the last two years. More details about the population are discussed in Chapter 3. The following is a discussion of the main study's findings.

\section{Instrument Reliability}

Table 5 indicates the three scales, reliability (alpha coefficients) and number of items in three-scaled instrument used to determine demographics, perceived e-learning barriers, and e-learning self-efficacy.

Table 5

Reliability Coefficients for Main Study

\begin{tabular}{llll}
\hline Parts of the Survey & Scale & $\begin{array}{l}\text { Number } \\
\text { of Items }\end{array}$ & $\begin{array}{l}\text { Alpha } \\
\text { Coefficient }\end{array}$ \\
\hline $\begin{array}{l}\text { Part 1 } \\
\text { Questions 1-15 }\end{array}$ & $\begin{array}{l}\text { Demographics and background } \\
\text { characteristics }\end{array}$ & 15 & \\
$\begin{array}{l}\text { Part 2 } \\
\text { Questions 16-57 }\end{array}$ & $\begin{array}{l}\text { Barriers in E-Learning Scale } \\
\text { (BELS) }\end{array}$ & 42 & .9496 \\
$\begin{array}{l}\text { Part 3 } \\
\text { Questions 58-81 }\end{array}$ & $\begin{array}{l}\text { E-learning Self-Efficacy Scale } \\
\text { (ELSE) }\end{array}$ & 24 & .9487 \\
\hline
\end{tabular}


Response Rate

The overall response rate was $18 \%$. Table 6 shows the percentage response rates by organization. Table 7 shows that daily and weekly responses were steady during the first week. However, the responses reduced to 150 by the end of the second week. A reminder was sent during the end of the second week, leading to a substantial increase (from 150 in the second week to 310 in the third week). A second email reminder was sent during the end of the third week. Responses fell to 129 during the fourth and last week of the data collection process. In some organizations, some of the contact persons were unavailable to send the second reminder email, thus some respondents did not get the reminder. Figure 4 shows the fluctuation of responses during the data collection process.

Table 6

Daily and Weekly Total Responses

\begin{tabular}{llll}
\hline Week 1 & Week 2 & Week 3 & Week 4 \\
\hline Monday June 2 & $1^{\text {st }}$ reminder & $2^{\text {nd }}$ reminder & Monday June 30 \\
286 & 150 & 310 & 129 \\
\hline
\end{tabular}




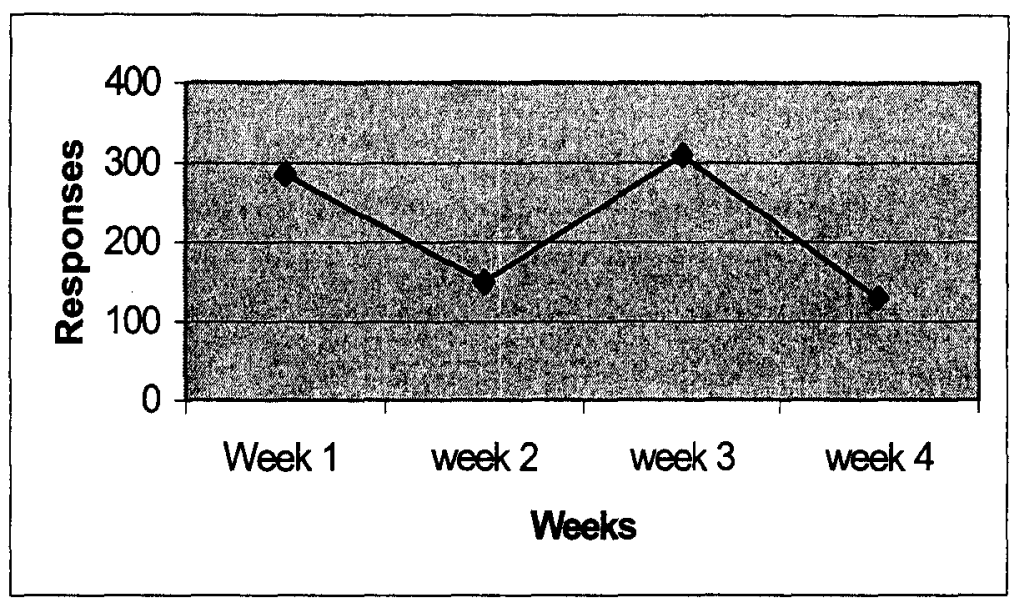

Figure 4. Line Graph Illustrating Number of Responses over 4 Weeks

Some of the reasons regarding participation and non-response were evident in the comments made by some potential participants, such fear of evaluation. One of the organizations contacted was unwilling to participate because they were afraid that research would expose information about their organization especially at a time when consulting organizations were in the public eye. Lack of commitment to participate in a research study and lack of time were other limitations. One respondent said, "Stuff like this that takes time away from my other online duties." This subject actually left most items blank. The timing of the study was another limitation because the public school district employees were out on summer break while the other organizations were closing their fiscal year, a peak period for most organizations. The length of survey could have affected the response rate as well as the framing of the survey questions, which were written in a positive mode and others in a negative mode. According to some participants, this was rather confusing. 


\section{Demographics}

Descriptive Statistics

A description of the demographic variables including the population size, percentages, means, and standard deviations for each of the variables measured is presented next. A discussion of each one of the variables is presented thereafter. Figure 5 indicates the population and sample sizes of the respondents in the seven participating organizations. The researcher contacted approximately 15 organizations initially inviting them to participate in the survey. However, most were either unwilling to do so or their distance learning programs did not meet the criteria required for the present study ( $100 \%$ online courses).

In an effort to understand the demographic make up and background characteristics of the employees under study, descriptive statistics were used to analyze the data whose results are discussed next.

Age

The results indicate that the age group that was represented by most of the employees participating in the study was between 32 and 38 years old $(31 \%)$. Approximately $19 \%$ are over 45 years of age while $80 \%$ are below 45 years of age as illustrated in Table 7. 


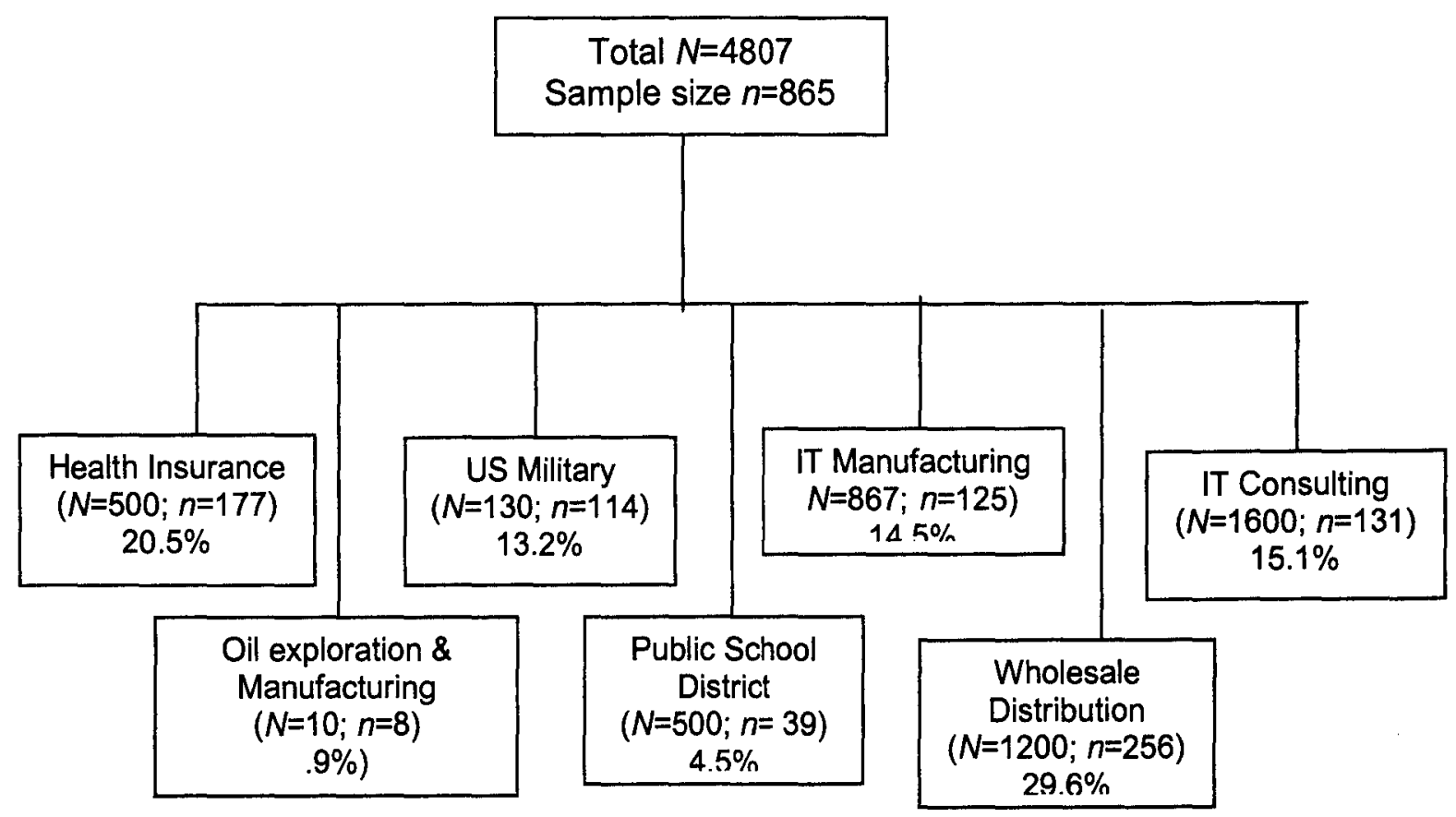

Figure 5. Employee population and sample sizes in seven organizations

Percentages represent how much of the entire sample $(n=865)$ was represented by each group.

Gender

The majority of employees who participated in the study were male (62\%) compared to $36 \%$ females as illustrated in Table 7.

Ethnicity

The results indicate ethnic diversity encompassing Asian, Indian, African, European, Hispanic, Native American, and other ethnicities. Persons of European descent consisted $48.9 \%$ of the employees participating in the study, but other groups were significantly represented as shown in Table 7. 
Marital Status

The results indicate that the majority of employees participating in the study were married $(68.7 \%)$ as shown in Table 7.

\section{Work Position}

The results indicate that the respondents work in various capacities in management and support levels (see Table 7). Support staff made up $43.7 \%$ of the employees while $32.8 \%$ were managers or administrators.

Table 7

Demographic Characteristics of the Respondents

Demographic Variable Frequency $(\mathrm{N}) \%$

Age in Years

18-24

32

3.7

25-31

194

22.4

$32-38$

268

31.0

$39-45$

201

23.2

46-52

97

11.2

53 and above

67

7.7

Gender

Female

314

36.3

Male

542

62.7 
Table 7 (continued)

Demographic Variable

N

$\%$

Ethnicity

African descent

40

4.6

Asian descent

28

3.2

European descent

423

48.9

Hispanic descent

43

5.0

Indian

61

7.1

Native-American

51

5.9

Other

195

22.5

Pacific-Islander

5

.6

Marital Status

Married

594

68.7

Single

254

29.4

Work Position

Commissioned officer $\quad 34$

Manager or administrator $\quad 284 \quad 32.8$

Non-commissioned officer 37

4.3

Support staff

378

43.7

Teacher or instructor

105

12.1

Total

865

100.0 


\section{Background Characteristics}

Level of Education

These results indicate that the $36.8 \%$ of the respondents had a Bachelor's degree closely followed by those with a high school diploma (36.5\%) as shown in Table 8.

Location of Study

These results indicate that the majority of the respondents took their elearning courses while in the office $(55.8 \%)$ and other locations as shown in Table 8.

Ownership of a Computer with Internet Connectivity

Ownership of a computer that has Internet connectivity was reported by $88 \%$ of the respondents. Table 8 shows the results. 
Table 8

Three Background Characteristics of the Respondents

Variable

$\mathrm{N}$

$\%$

Level of Education

Doctorate

7

.8

Specialist degree

57

6.6

Master's degree

153

17.7

Bachelor's degree

318

36.8

High school diploma or GED

316

36.5

No high school diploma

10

1.2

Location of Study

At home

136

15.7

Both (home \& office)

228

26.4

In the office

483

55.8

Other locations

13

1.5

Ownership of a Computer with Internet Connectivity

Own computer with Internet

No

97

11.2

Yes

761

88.0 


\section{E-Learning Experience}

Prior E-learning Experience

The respondents differed in the amount of e-learning courses they have had over the years. Although a majority had taken online courses before $(83 \%)$ there were some newcomers, accounting for $17 \%$ of the sample. Table 9 illustrates this.

Prior E-learning Experience in Other Organizations

When asked about prior e-learning experiences prior to current employer, $64 \%$ answered no while $34 \%$ said that they had had prior experiences as shown on Table 9.

Total number of Online Courses Taken

The respondents were asked to indicate the total number of courses taken online. Table 9 below illustrates the results, with a majority $(61 \%)$ having had between 1 and 5 online courses. Approximately $31 \%$ had taken between 6 and 20 courses. Respondents were asked to count any courses they were enrolled in at the time these data were collected. 
Table 9

Prior E-learning Experience of Respondents

Background Variable

$\mathrm{N}$

$\%$

E-learning Experience

Took online course(s) before 2001

200

23.1

Enrolled in an online course(s) in 2001

118

13.6

Enrolled in an online course(s) in 2002

393

45.4

First online course

148

17.1

Prior E-learning Experience Outside Current Organization

No (experience with current employer only) $\quad 556$

64.3

Yes (e-learning experience from elsewhere) 294

34.0

Total Number of Online Courses Taken

$1-5$

530

61.3

$6-10$

168

19.4

$11-15$

62

7.2

$16-20$

39

4.5

$21-25$

14

1.6

26-30

9

1.0

Over 30

43

5.0 
Computer Skills or Competence

With regard to the employees' computer skills, $54.3 \%$ claimed to be average and $41.2 \%$ as expert computer users. A few rated themselves as novices (only 4.3\%) as illustrated in Table 10.

Computer Training

This question sought to determine whether the respondents had gone through face-to-face or online computer software training targeted to improve their computer skills. A majority of the respondents (almost 58\%) had received training while $41 \%$ had not, as illustrated in Table 10.

Overall Rating of E-learning Experiences

The respondents where asked if overall they were pleased with their elearning experiences. A great majority reported positive experiences (86.5\%) compared to $10 \%$ who rated their experiences as negative as shown on Table 10. 
Table 10

Computer Skills and Training

Variable

N

$\%$

Level of Computer Competence/Skill

Average (intermediate knowledge and experience with $\quad 470 \quad 54.3$ computers)

Expert (advanced user with a lot of computer experience) $356 \quad 41.2$

$\begin{array}{lll}\text { Novice (very limited knowledge and experience with } & 37 & 4.3\end{array}$ computers)

Received Computer Training

No

357

41.3

Yes

499

57.7

Overall Rating of E-learning Experiences

Negative experiences

10.1

Positive experiences

86.5

\section{Section Summary}

This section discussed the results of the pilot study and the main study. The response rates, reliability, and validity of the instruments were discussed as well as the demographic characteristics of the population. The results indicate that a majority of the employees were in their thirties, predominantly male, 
married, and of European descent. Further, most employees were in supportlevel positions, held a Bachelor's degree, studied in the office, owned a computer with Internet connectivity, had been enrolled in less than ten online courses, and had participated in e-learning for the last three years. For most employees, they had had no outside e-learning experiences other than with their current employer. Most were intermediate and advanced computer users who have received computer training. Overall, these employees were positive about their elearning experiences. The next section presents the results of each of the five research questions under study.

\section{Research Question One}

\section{E-learning Barriers}

The first research question asked employee e-learners to identify the barriers they faced in starting, continuing and completing online training. To answer this question, a survey made up of 42 items was constructed to determine the barriers. This scale is referred to as the Barriers in E-learning Scale (BELS). The mean (M) and standard deviations (SD) of each of the 42 items making up the BELS are presented in Table 11. Response options ranged from 1 (not a barrier) to 5 (very strong barrier) scale. The higher the mean score (closer to 5), the more the item was perceived as a barrier. 
Table 11

Barriers in E-learning Scale (BEL) Items, Means, and Standard Deviations

Items

M SD

16. Awareness of online course availability

$2.35 \quad 1.163$

17. Over commitment to multiple roles and responsibilities

$3.10 \quad 1.224$

18. Concerns about the legitimacy of e-learning certificates or $2.39 \quad 1.267$ diplomas

19. Content difficulty

$1.99 \quad .917$

20. Content's relationship to job requirements or career plans $2.25 \quad 1.096$

21. Courses offered were not those I desired

$2.37 \quad 1.190$

22. Difficulty contacting administrative and support staff

$2.17 \quad 1.218$

23. Difficulty obtaining reference materials

$2.23 \quad 1.181$

24. Discomfort with the technology

$1.74 \quad .988$

25. Fit between my learning style (i.e. the way I prefer to

$2.18 \quad 1.154$ learn) and e-learning

26. E-learning seems impersonal

$2.06 \quad 1.192$

27. Fear of failure

$1.56 \quad .897$

28. Fear or insecurity regarding a loss of privacy or confidentiality online

$1.65 \quad .942$

29. Feeling isolated due to lack of interaction with other

1.92

1.136 students and instructor

30. Gap between presented content and my expectations $\quad \begin{array}{lll}2.24 & 1.111\end{array}$

31. High cost of hardware, software, repairs, or a service $\quad 1.72 \quad 1.029$ provider

32. Consistency of access to the course (e.g. access to computer hardware, software or connectivity) 
Table 11 (continued)

Items

M SD

33. Information overload due to too much learning material

2.051 .022

34. Instructor's knowledge, skills, and attitudes

1.811 .009

35. Insufficient support from my family, friends, or significant others

1.39 .755

36. Interruptions at work, home or wherever I study

2.881 .313

37. Lack of confidence in my ability to participate in e-learning

1.52 .846

38. Motivation to learn online

1.951 .102

39. Lack of prerequisite knowledge

1.72 .907

40. Insufficient support from coworkers to engage in e-learning

1.721 .004

41. Lack of support from my employer and supervisor for e-learning

1.931 .174

42. Unreliable technical support or support services

43. Lack of technical expertise or my unfamiliarity with e-learning

1.70 .949 technology

44. Lack of time to study

2.991 .295

45. Lack of training on how to learn online

1.891 .098

46. Limited access or communication with the instructor

2.151 .200

47. My resistance to change

1.53 .887

48. Physical health barriers such as eye strain, carpal tunnel

1.54 .922 syndrome, or physical immobility

49. Poor communication skills required for e-learning such as using 1.63 .957 email or discussion boards

50. Problems with language (reading level) used in course materials 1.43 .839 
Table 11 (continued)

\begin{tabular}{ll}
\hline Items & $M$ SD
\end{tabular}

51. Procrastination or time management problems

2.281 .160

52. Psychological barriers such as anxiety or stress

1.55 .900

53. Quality of the learning materials

2.091 .135

54. Slow speed of Internet connection

2.451 .426

55. Timeliness or frequency of feedback from the instructor 1.871 .092

56. Clarity of course expectations

2.011 .083

57. Unclear instructions from instructor(s)

1.881 .044

The scale used to determine the level of perceived barriers to e-learning was $1=$ not a barrier, $2=$ =weak barrier, $3=$ =moderate barrier, 4=strong barrier, $5=$ very strong barrier). The means ranged from 1.43 (lowest) to 3.10 (highest). Overall employees rated barriers from weak to moderate. The top five barriers were:

1. Over commitment to multiple roles and responsibilities $(M=3.10)$

2. Lack of time to study $(M=2.99)$

3. Interruptions at work, home or wherever one studies $(M=2.88)$

4. Slow speed of Internet connection $(M=2.45)$

5. Awareness of online course availability $(M=2.35)$

The five least rated barriers (lowest mean scores) were:

1. Problems with language (reading level) used in course materials $(M=1.43)$

2. Lack of confidence in my ability to participate in e-learning $(M=1.52)$ 
3. My resistance to change $(M=1.53)$

4. Physical health barriers such as eye strain, carpal tunnel syndrome of physical immobility $(M=1.54)$

5. Psychological barriers such as anxiety or stress $(M=1.55)$

The overall score of all the 42 items on the BELS was 83.33 [out of a possible total score of $210(42 \times 5)]$. Thus the cumulative mean was $1.98(83.33 / 42$ items), an indicator that employees perceived weak barriers in the course of starting, continuing, and completing online courses.

\section{Identification of Dependent Variables Using Factor analysis}

The purpose of computing a factor analysis was to reduce the complexity of the data collected in order to understand the underlying factors that exist in a collection of variables and to develop dependent variables needed to answer the other research questions. The factor analysis helps in understanding the underlying relationships that could explain the correlation among a number of variables. The researcher used an exploratory factor analysis to find the underlying factors that exist among the variables under study in the BEL scale. Stevens (2002) explains its use: "The purpose of a exploratory factor analysis is to identify the factor structure or model for a set of variables. This often involves determining how many factors exist, as well as the pattern of the factor loadings." (p. 411).

To determine the factorability of the data, the Kaiser-Meyer-Olkin (KMO) measure of sampling adequacy was checked. Table 12 presents the Kaiser- 
Meyer-Olkin (KMO) and Bartlett's tests indicating good "factorability" of the data. These two tests indicated that a factor analysis can be done for these variables because first, the KMO measure was .950 , which exceeded the value of .60 , which is considered an acceptable minimum value (Stevens, 2002). Second, The Bartlett's test of sphericity indicated significant correlations $(p<.05)$, leading to a rejection of the null hypothesis that the correlation matrix was an identity matrix, meaning that the variables in this data set are correlated with one another, another indication that a factor analysis is appropriate (Stevens, 2002).

Table 12

Kaiser-Meyer-Olkin (KMO) and Bartlett's Tests for Barriers in E-learning (BEL) Scale

Kaiser-Meyer-Olkin Measure of Sampling

.950 Adequacy

Bartlett's Test of Sphericity Approx. Chi-Square 16809.505 df 861

Sig. .000

To interpret the meaning of the factors, the factors were rotated using Varimax with Kaiser Normalization. This approach is used in order to yield a situation in which most variables will load on one factor only (Stevens, 2002) and being an orthogonal rotation, the factors are mathematically independent of one another (uncorrelated). To determine how many principal components to retain and interpreted as factors, the Kaiser criterion, which is the SPSS default, was 
used. Factors with an eigenvalue of $>1.00$ or greater were retained for interpretation. Seven factors had an eigenvalue of $>1.00$ and accounted for $58.65 \%$ (cumulative percentage) of the variance in rating scale data. The factors had eigenvalues ranging from 14.671 to .168 .

A Principal Component Analysis extraction method was used and Table 13 indicates the seven components (factors) that emerged. Stevens (2002) recommends the use of principal components analysis as a preliminary data reduction method before the use of MANOVA.

Table 13

Components of Barriers in E-learning (BEL) Scale with Total Variance Explained Initial Eigenvalues Rotation Sums of Squared Loadings

\begin{tabular}{lllllll}
\hline \multicolumn{2}{l}{ ComponentTotal } & $\begin{array}{l}\text { \% of } \\
\text { Variance }\end{array}$ & $\begin{array}{l}\text { Cumulative } \\
1\end{array}$ & Total & $\begin{array}{l}\% \text { of } \\
\text { Variance }\end{array}$ & $\begin{array}{l}\text { Cumulative } \\
\%\end{array}$ \\
2 & 14.67 & 34.93 & 34.93 & 6.02 & 14.34 & 14.34 \\
3 & 2.33 & 5.55 & 40.48 & 3.93 & 9.36 & 23.71 \\
4 & 2.11 & 5.02 & 45.50 & 3.89 & 9.25 & 32.96 \\
5 & 1.76 & 4.19 & 49.69 & 3.32 & 7.92 & 40.87 \\
6 & 1.42 & 3.38 & 53.07 & 2.71 & 6.44 & 47.31 \\
7 & 1.21 & 2.89 & 55.96 & 2.51 & 5.99 & 53.30 \\
\hline
\end{tabular}

Extraction Method: Principal Component Analysis. 
To determine the factors to extract, a multi-step process was used. Stevens (2002) suggests that to determine which items to extract from the factor loadings, one should calculate the critical value (based on the $n$ ), which acts as a base line. This helped in determining how high a factor loading needs to be for it to be interpreted. Consequently, Stevens (2002) table of critical values (CV) was used in the calculation. To calculate this, the formula $\mathrm{n} \times \mathrm{CV}$ was used. The sample size in this study was 865 and the absolute value for a significant factor loading in this analysis was .196. Therefore, only factor loadings for each item loading with an absolute value that exceeded .196 were selected from the "Rotated Component Matrix" and interpreted. However, this criterion resulted in duplication and many items loading on different factors as illustrated in Table 14, the last column on the right). Statisticians have suggested using higher criteria. Consequently, the criterion was raised to $>.50$ to reduce duplication. Column three on the table below indicates the 32 items that loaded under each factor with the .50 criterion. These are the items that were used in naming the factors.

Guided by the item loading, the researcher identified the common theme or name that represented the items under each factor. For example, the three items that loaded under technological factors were item number 31 (high cost of hardware, software, repairs or service provider), 32 (consistency of access to the course), and 54 (slow speed of Internet connection). These three items represent technological issues, hence the name. 
Table 14

Extracted Factors from the Barriers in E-Learning (BEL) Scale

\begin{tabular}{|c|c|c|c|}
\hline Factor & Name of factor & $\begin{array}{l}\text { Items on survey with } \\
\text { critical value of }>.50^{*}\end{array}$ & $\begin{array}{l}\text { Items on survey with } \\
\text { critical value of }>\text {. } \\
196\end{array}$ \\
\hline Factor 1 & $\begin{array}{l}\text { Dispositional } \\
\text { barriers }\end{array}$ & $\begin{array}{l}27,35,37,39,47,48 \\
49,50,52\end{array}$ & $\begin{array}{l}19,24,26,27,28 \\
29,31,32,33,34 \\
35,37,38,39,40 \\
41,43,45,47,48 \\
49,50,51,52,55 \\
56,57\end{array}$ \\
\hline Factor 2 & Learning Style & $24,25,26,29,46$ & $\begin{array}{l}18,19,23,24,25 \\
26,27,28,29,30 \\
33,34,37,38,39 \\
43,45,46,47,49\end{array}$ \\
\hline Factor 3 & $\begin{array}{l}\text { Instructional } \\
\text { barriers }\end{array}$ & $53,55,56,57$ & $\begin{array}{l}18,21,22,23,29 \\
30,34,41,42,46 \\
48,49,50,51,52 \\
53,54,55,56,57\end{array}$ \\
\hline Factor 4 & $\begin{array}{l}\text { Organizational } \\
\text { barriers }\end{array}$ & $40,41,42,43,45$ & $\begin{array}{l}16,22,23,24,27 \\
32,35,37,39,40 \\
41,42,43,45,46, \\
49,56,57\end{array}$ \\
\hline Factor 5 & $\begin{array}{l}\text { Situational } \\
\text { barriers }\end{array}$ & $17,36,44,51$ & $\begin{array}{l}17,36,38,40,41 \\
44,45,51,52,54\end{array}$ \\
\hline Factor 6 & $\begin{array}{l}\text { Content } \\
\text { suitability } \\
\text { barriers }\end{array}$ & 20,21 & $\begin{array}{l}16,17,18,19,20 \\
21,22,23,24,25 \\
30,33,34,53\end{array}$ \\
\hline Factor 7 & $\begin{array}{l}\text { Technological } \\
\text { barriers }\end{array}$ & $31,32,54$ & $\begin{array}{l}18,22,23,28,31 \\
32,33,42,43,46 \\
48,54,55\end{array}$ \\
\hline
\end{tabular}

* The loadings with a critical value of $>.50$ was used. 
The reliability of each of the factors was determined using the reliability function in SPSS. Table 15 indicates the seven factors identified with their respective item loadings, alpha reliability, and mean.

In the remainder of this study, the term factor will refer to the average of the items derived from the factor analysis that were used to create a scale. For example, Factor 1 (dispositional barriers) was the average over the nine items derived from the factor analysis that dealt with barriers due to disposition of an employee.

\section{Table 15}

Data on Factors used to Create Seven Scales from the Barriers in E-Learning (BEL) Scale

\begin{tabular}{lllll}
\hline $\begin{array}{l}\text { Dependent } \\
\text { Variables or }\end{array}$ & Type of barriers & $\begin{array}{c}\text { Item number } \\
\text { and its Factor } \\
\text { loading }\end{array}$ & $\begin{array}{l}\text { Alpha } \\
\text { reliability }\end{array}$ & Mean \\
Factors & & &
\end{tabular}

\begin{tabular}{lllll}
\hline Factor 1 & Dispositional & $27(.626)$ & .8860 & 1.54 \\
barriers & $35(.629)$ & & \\
& $37(.709)$ & & \\
& $39(.583)$ & & \\
& $47(.623)$ & & \\
& $48(.605)$ & & \\
& $49(.559)$ & & \\
& $50(.653)$ & & \\
Factor 2 & $52(.695)$ & & \\
& & & \\
& & & \\
& & & \\
& Learning Style & $24(.528)$ & & \\
& barriers & $25(.724)$ & & \\
& & $26(.786)$ & & \\
& & $29(.679)$ & & \\
& & $46(.508)$ & & \\
& &
\end{tabular}


Table 15 (continued)

\begin{tabular}{|c|c|c|c|c|}
\hline $\begin{array}{l}\text { Dependent } \\
\text { Variables or } \\
\text { Factors }\end{array}$ & Type of barriers & $\begin{array}{l}\text { Item number } \\
\text { and its Factor } \\
\text { loading }\end{array}$ & $\begin{array}{l}\text { Alpha } \\
\text { reliability }\end{array}$ & Mean \\
\hline Factor 3 & $\begin{array}{l}\text { Instructional } \\
\text { barriers }\end{array}$ & $\begin{array}{l}53(.673) \\
55(.677) \\
56(.706) \\
57(.720)\end{array}$ & .8608 & 1.96 \\
\hline Factor 4 & $\begin{array}{l}\text { Organizational } \\
\text { barriers }\end{array}$ & $\begin{array}{l}40(.561) \\
41(.514) \\
42(.607) \\
43(.593) \\
45(.591)\end{array}$ & .8309 & 1.84 \\
\hline Factor 5 & $\begin{array}{l}\text { Situational } \\
\text { barriers }\end{array}$ & $\begin{array}{l}17(.665) \\
36(.751) \\
44(.751) \\
51(.567)\end{array}$ & .7274 & 2.81 \\
\hline Factor 6 & $\begin{array}{l}\text { Content } \\
\text { suitability barriers }\end{array}$ & $\begin{array}{l}20(.720) \\
21(.796)\end{array}$ & .6463 & 2.31 \\
\hline Factor 7 & $\begin{array}{l}\text { Technological } \\
\text { barriers }\end{array}$ & $\begin{array}{l}31(.602) \\
32(.669) \\
54(.661)\end{array}$ & .6929 & 2.05 \\
\hline Overall & & 32 items & .9364 & \\
\hline
\end{tabular}

*The 32 items had a loading of $>.50$ on each factor

Besides the quantitative data, there was one open-ended question that asked the participants to document any other barriers that they experienced in the process of taking Web-based courses that were not captured in the survey. A large amount of data emerged from this question, and it was coded using the open-coding procedure. Open-coding involves generating categories of information from collected data (Creswell, 2003). These categories and actual 
comments are captured and tabulated in summary form in Appendix I (Tables A1-A7).

The researcher compiled the summaries on the basis of free response comments offered by respondents. The process that lead to these conclusions followed steps recommended by Creswell (2003) as discussed in Chapter 3.

First, the data were organized and prepared for analysis. This included downloading all the data regardless of organization and compiling all the comments into one electronic file using Microsoft Word. Step two involved reading through all the data to obtain a general sense of information. The third step followed with a more thorough reading and analysis of each comment. The data was put into "chunks" and these were recorded electronically in subheadings or terms that best described them.

The fourth step involved summarizing or paraphrasing each comment briefly and looking for any major themes emerging from those comments. The comments were sorted and category names (themes) were constructed. When the open-ended responses were coded, seven themes emerged: (a) personal barriers, (b) learning style barriers, (c) instructional design-barriers, (d) instructorrelated barriers, (e) organizational, (f) content-related barriers, and (g) technological barriers.

Step five involved presenting these seven themes through the use of tables. Creswell (2003) noted that tables could be used as adjuncts to narrative discussions. The themes were followed by sub-themes (sub-headings) and in some cases, actual comments were quoted or paraphrased. 
The final step involved interpreting the data and as indicated in conjunction with the quantitative results in the section above. A discussion of these results and the researcher's interpretations appears in Appendix I and under Chapter 5.

Description of the Seven Factors or Types of Barriers

1. Dispositional barriers. The items that loaded under this factor indicated the perception of barriers emerging from employee e-learners' personal characteristics and attitudes towards e-learning. Dispositional barriers are also referred to as personal barriers. Items under this factor had to do with:

- fear of failure

- confidence in one's ability to participate in e-learning

- prerequisite knowledge,

- resistance to change,

- physical or psychological health,

- communication skills

- adult pride

A more in-depth discussion of the types of dispositional barriers and some of the employees' comments are presented in Appendix I Table 1. Although the Learning Style barriers (see number 2) emerged as a separate category in the factor analysis, during the analysis of the open-ended responses, the researcher categorized it under personal barriers.

2. Learning style barriers. The items that loaded under this factor had to do with barriers pertaining to the employee e-learners' comfort with technology and the fit between e-learning and individual learning styles or preferences. The 
researcher coded learning style barriers under personal discussion of the types of dispositional barriers and some of the employees' comments are presented in Appendix I Table 1. Specific barriers cited were:

- Discomfort with technology.

- Lack of fit with one's preferred learning style.

- Isolation or lack of interaction.

- Preference for instructor-led training.

- Limited access to the instructor.

- Impersonal nature of e-learning.

3. Instructional barriers. The barrier items that loaded under this factor had to do with the online instructor, instructional design, and instructional materials. Specifically, respondents cited:

- Poor quality of materials.

- Timeliness and frequency of feedback.

- Clarity of course expectations and instructions.

- Lack of progress reports.

- Limited learner engagement or interaction.

- Poor instructional design.

- Limited reference materials.

- $\quad$ Access and navigation problems.

- Information overload.

- Limited opportunities for transfer of learning or skills learned online.

- Too many links within a course.

- Changes in the course titles while a course was in progress.

- Poorly constructed assessments.

- Course materials not being printable or downloadable.

A detailed description appears under Appendix I Table 2. In addition to these barriers, employees identified instructor-related barriers, which were grouped in a separate category as presented in Appendix I Table 3.

4. Organizational barriers. The items that loaded under this factor communicated barriers that had to do with the organization an employee 
worked in. Appendix I Table 4 presents more details and comments about

barriers in this category but some examples cited included:

- Limited support from coworkers, supervisor, or employer to engage in e-learning.

- Reliability of technical support.

- Level of technical expertise or familiarity with e-learning technologies.

- Lack of training on how to learn online.

- Long waiting lists before one could enroll in an online course.

- Organizational culture that did not support e-learning.

- Lack of credibility of e-learning in some organizations.

- Registration problems.

- Lack of awareness of online course availability.

- Lack of credit or certification after completion of online training.

- Non-involvement in decision-making concerning e-learning.

- Course management problems.

5. Situational barriers. The items that loaded under this factor had to do with life circumstances or situations that limited study opportunities. Appendix I Table 5 presents a description of the nature of barriers faced classified under this category. Some examples cited were:

- Commitment to other roles and responsibilities.

- Interruptions during study.

- Lack of time for study.

- Time management problems.

6. Content suitability barriers. The items that loaded under this factor had to do with the fit between one's career plans or job requirements and courses offered. Appendix I Table 6 presents more details and employees' comments about barriers in this category.

- Course(s) was/were not audience-specific.

- Poor quality courses.

- Courses were not rigorous enough (especially for "seasoned" employees). 
7. Technological barriers. The items that loaded under this factor had to do with learning technologies. Appendix I Table 7 presents more details and comments about barriers in this category.

- Affordability (cost of hardware, software or services).

- Access to the course (consistency).

- Slow Internet connection (speed).

- Poorly designed Learning Management Systems (LMS).

- Poor navigation.

- Inability to save or transfer data leading to loss of data.

Among these seven factors, situational barriers $(M=2.81)$ were the most common barriers. These had to do with lack of time for study, time management problems, over commitment to multiple roles and responsibilities, interruptions during study. These items were also ranked as the top three barriers.

\section{Section Summary}

The open-ended responses elaborate the findings emerging from the factor analysis. The employees' comments provided a richer and in-depth view of the kinds of barriers they are faced with when they engage in e-learning. Elearning barriers are heterogeneous in nature encompassing personal, instructor, organizational, content, situational, instructional design, and technological barriers. There were some similarities across the seven organizations in terms of the barriers mentioned. The organization-specific barriers and recommendations for each organization are covered in Chapter Five. The next question will address how barriers differed among organizations. 


\section{Research Question Two}

\section{E-learning Barriers and Differences among Organizations}

\section{Multivariate Analysis of Variance (MANOVA)}

Research question two tested whether there are differences in perceived barriers based on the employee's type of organization. The researcher hypothesized that there would be significant differences in employees' perceptions of barriers depending on the type of organization. This hypothesis was tested by a multivariate analysis of variance (MANOVA).

This test involved an independent variable with seven levels (organizations) and seven dependent variables (types of barriers). The purpose of conducting a MANOVA test was to determine if organizational differences exist on the seven dependent variables identified in the factor analysis. MANOVA is a technique for simultaneously assessing group differences across multiple dependent variables.

Several statistics were calculated to determine the appropriateness of MANOVA and to ensure that MANOVA assumptions were met. Below are some of the tests that were examined that the readers should be aware of when interpreting the results.

The equality of covariance matrices assumption was tested. To test this assumption, the Box's Test was used. This test determines whether the observed covariance matrices of the dependent variables are equal across groups. The 
test was Box $M=334.36, F(168,6759)=1.78, p<.000$. Hence the equality of covariance assumption of MANOVA was not supported.

Levene's test of equality of error variances was conducted on each factor (see Appendix J). The null hypothesis that the error variance of the dependent variable is equal across groups was rejected for the following factors: (a) Factor 1 (dispositional barriers), (b) Factor 3 (instructional barriers), (c) Factor 4 (organizational barriers), and (d) Factor 7 (technological barriers).

Taken together, results from Box' test and Levene's test showed violations of the equal variances assumption of MANOVA. Thus results could be biased due to this violation.

\section{Multivariate Test Results}

The results indicate significant differences among organizations on perceived barriers, Hotelling's Trace $=.212, F(42,4994)=4.20, p<.001$. Stevens (2002) notes "Wilk's $\wedge$, Pillai-Bartlett trace, and Hotelling Lawley statistics are equally robust (for equal or approximately equal group sizes)" ( $p$. 248). Since the power differences among these four statistics are quite small $(<.06)$, any one of them can be used.

Effect size. The eta squared value $\left(\eta^{2}\right)$ was .034 for the multivariate test. Eta square is a measure of the importance or magnitude of the effect. Using Cohen's rule of determining effect size (Stevens, 2002), the effect size was small to moderate $.01<.034<.06$. This sample data's effect size gives an indication of the practical significance of the statistical results. 
Using a method suggested by Stevens (2002), the researcher performed pairwise multivariate comparison to determine how organizations differed from one another on the factors. Following Stevens (2002) the significance level was adjusted downward to reduce Type I errors. The significance level used for each test was $.15 / 21=.007$. Appendix K gives details of pairwise comparisons. In narrative, the results were as follows.

1. IT Manufacturing Company. E-learning barriers perceived by employees in this organization were significantly different from the other organizations other than with the Oil Company, which is also a manufacturing company.

2. Oil Exploration and Manufacturing Company. E-learning barriers perceived by employees in this organization were not significantly different from any of the other organizations. However, it should be noted that the sample size was very small $(n=8)$.

3. Public School District. E-learning barriers perceived by employees in this organization were significantly different from the Manufacturing and the IT Consulting company.

4. Heath Insurance Company. E-learning barriers perceived by employees in this organization were significantly different from IT Manufacturing, Wholesale, IT Consulting, and the Military.

5. Wholesale Company. E-learning barriers perceived by employees in this organization were significantly different from IT Manufacturing, Health Insurance, and IT Consulting. This indicates differences even among organizations in the service sector. 
6. IT Consulting Company. E-learning barriers perceived by employees in this organization were significantly different from those perceived by employees in Public School District, IT Manufacturing, Health Insurance, and Wholesale company.

7. Military. E-learning barriers perceived by employees in this organization were significantly different from those perceived by employees in the IT Manufacturing and Health Insurance companies. There were no significant differences between the public school district, which is also a governmentsupported institution.

\section{Post Hoc Tests}

Since there were significant differences among the groups, post hoc tests were done to determine the differences further. For those multivariate-paired comparisons that were significant, the differences were further explored using Tukey test comparisons. The Tukey confidence interval technique is applied "to determine which of the individual variables are contributing each pairwise significant multivariate result" (Stevens, 2002, p.217). This procedure provides protection against Type I errors (Stevens, 2002). The post hoc tests revealed differences in barriers on some factors, although not on all factors as discussed below.

\section{Organizational Differences on Dispositional Barriers}

The IT consulting company had the highest mean $(M=1.73)$, indicating that the employees perceived more dispositional barriers, while the oil 
exploration and manufacturing company had the least barriers. Overall, personal barriers in e-learning in these organizations were few $(M=1.54$ on a 5-point scale for the total sample).

There were significant organizational differences in terms of dispositional barriers. Mean differences are presented in parenthesis. Four comparisons that had significant differences (alpha $=.05$ ) were:

1. IT Manufacturing significantly lower than IT Consulting (.25)

2. Health Insurance significantly lower than Wholesale (.26)

3. Health Insurance significantly lower than IT consulting (.39)

4. Health Insurance significantly lower than Military (.30)

Based on these results, the Health Insurance Company seemed to be most distinctive from others on this factor.

\section{Organizational Differences on Learning Style Barriers}

The IT consulting company had the highest mean $(M=2.28)$, indicating that the employees perceived more learning style barriers. Overall, learning style barriers in e-learning in these organizations are few $(M=2.00$ on a 5-point scale for the total sample).

There were significant organizational differences between the IT Consulting company, which was significantly lower than the Public school district (.49) and between the IT Consulting and Health Insurance (.50). 
Table 16 presents means, standard deviations, and total number of respondents in each organization with regard to dispositional and learning style barriers.

Table 16

Descriptive Statistics for Dispositional and Learning Style Barriers in Organizations

Type of Barrier Organization $\quad$ Mean SD $\mathrm{N}$

$\begin{array}{llllll}\text { 1. Dispositional 1. IT Manufacturing } & 1.48 & .580 & 125\end{array}$

2. Oil E \& M $\quad 1.29 \quad .325 \quad 8$

3. Public School District $\quad 1.40 \quad .617 \quad 39$

4. Health Insurance $\quad 1.34 \quad .451 \quad 177$

$\begin{array}{llll}\text { 5. Wholesale } & 1.59 & .634 & 256\end{array}$

$\begin{array}{lllll}\text { 6. } & \text { IT Consulting } & 1.73 & .752 & 128\end{array}$

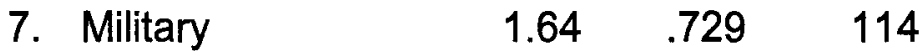

$\begin{array}{llll}\text { Total } & 1.54 & .636 & 847\end{array}$

$\begin{array}{lllll}\text { 2. Learning Style } & \text { 1. IT Manufacturing } & 2.00 & .948 & 125\end{array}$

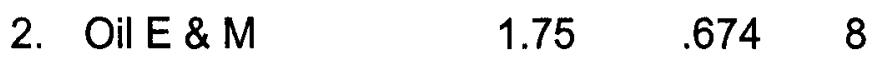

3. Public School District $\quad 1.79 \quad .795 \quad 39$

4. Health Insurance $\quad 1.78 \quad .845 \quad 177$

$\begin{array}{llll}\text { 5. Wholesale } & 2.02 & .835 & 256\end{array}$

$\begin{array}{lllll}\text { 6. } & \text { IT Consulting } & 2.28 & .938 & 128\end{array}$

$\begin{array}{llll}\text { 7. Military } & 2.06 & .917 & 114\end{array}$

$\begin{array}{llll}\text { Total } & 2.00 & .890 & 847\end{array}$ 
Organizational Differences on Instructional Barriers

The IT consulting company had the highest mean $(M=2.47)$, indicating that the employees perceived more instructional barriers. Overall, employees in these organizations perceived fewer barriers $(M=1.96$ on a 5 -point scale) compared to other than organizational and dispositional factors.

There were significant organizational differences among:

- IT Manufacturing significantly lower than Healthcare (.44)

- Health Insurance significantly lower than Military (.34)

- IT Consulting was significantly different from (lower than) all the six organizations on this factor.

\section{Organizational Differences on Organizational Barriers}

The post hoc test revealed that the IT consulting company $(M=1.99)$ and the wholesale company $(M=1.98)$ had the highest means, indicating that the employees perceived more organizational barriers. Overall, employees in these organizations perceived few organizational barriers ( $M=1.84$ on a 5-point scale). Under organizational barriers, there were more similarities than differences across organizations. There were significant differences in these organizations:

- IT Manufacturing significantly lower than Wholesale (.27);

- Health Insurance significantly lower than Wholesale (.34);

- Health Insurance significantly lower than IT consulting (.35). 
Table 17 presents means and standard deviations in each organization with regard to instructional and organizational barriers.

Table 17

Descriptive Statistics for Instructional and Organizational Barriers in Organizations

Type of Barrier

Organization

Mean

$\mathrm{N}$

3. Instructional

1. IT Manufacturing

$2.11 \quad .960$

125

2. Oil Exp. \& Manufacturing

$\begin{array}{lll}1.44 & .458 \quad 8\end{array}$

3. Public school district

$\begin{array}{lll}1.74 & .745 & 39\end{array}$

4. Health Insurance

$1.67 \quad .800 \quad 177$

5. Wholesale

$\begin{array}{lll}1.87 & .832 \quad 256\end{array}$

6. IT Consulting

$2.47 \quad 1.005 \quad 128$

7. Military

$\begin{array}{lll}2.01 & .911 \quad 114\end{array}$

Total

$\begin{array}{lll}1.96 & .913 & 847\end{array}$

4. Organizational

1. IT Manufacturing

$\begin{array}{lll}1.72 & .749 & 125\end{array}$

2. Oil Exp. \& Manufacturing

1.55

$.487 \quad 8$

3. Public School District

$\begin{array}{lll}1.58 & .629 \quad 39\end{array}$

4. Health Insurance

$\begin{array}{lll}1.65 & .726 & 177\end{array}$

5. Wholesale

$\begin{array}{lll}1.98 & .887 & 256\end{array}$

6. IT Consulting

$\begin{array}{lll}1.99 & .865 \quad 128\end{array}$

7. Military

$\begin{array}{lll}1.85 & .834 & 114\end{array}$

Total

$1.84 \quad .823$

847 
Organizational Differences on Situational Barriers

The Oil Exploration and Manufacturing Company had the highest mean ( $M$ $=3.00$ ), indicating that the employees perceived more situational barriers. Compared to other e-learning barriers, situational barriers seem to be the most prevalent yielding the highest mean of 2.81 .

Under situational barriers, there were more similarities than differences across organizations evident among:

- Health Insurance significantly lower than IT Manufacturing (.34)

- Health Insurance significantly lower than IT Consulting (.36).

Organizational Differences on Content Suitability Barriers

The IT Consulting Company had the highest mean $(M=2.65)$, indicating that the IT consulting employees seem to experience more content-related barriers compared to other organizations. IT Consulting significantly differed with four other organizations on this factor.

The post hoc test revealed significant differences between:

- IT Manufacturing significantly lower than Public school district (.54)

- IT Manufacturing significantly lower than Health insurance (.48)

- IT Consulting significantly lower than Public school district (.67)

- IT Consulting significantly lower than Health Insurance (.61)

- IT Consulting significantly lower than Wholesale (.35)

- IT Consulting significantly lower than Military (.42) 


\section{Organizational Differences on Technological Barriers}

Similar to the types of barriers discussed above, the post hoc test revealed that the IT Consulting Company had the highest mean $(M=2.38)$, indicating that its employees seemed to experience more technological barriers or were at least more aware of them. Overall, technological barriers were weak $(M=2.05$ on a 5 -point Likert scale).

The post hoc test revealed significant differences between:

- IT Manufacturing significantly lower than Wholesale (.35)

- IT Manufacturing significantly lower than IT Consulting (.56)

- Health Insurance significantly lower than Wholesale (.44)

- Health Insurance significantly lower than IT Consulting (.65)

- Health Insurance significantly lower than Military (.40).

Table 18 presents means, standard deviations, and total number of respondents in each organization for situational, content-suitability, and technological barriers respectively. 
Table 18

Descriptive Statistics for Situational, Content-Suitability, and Technological Barriers in Organizations

Type of Barrier Organization

5. Situational 1. IT Manufacturing

2. Oil $E \& M$

3. Public School District

4. Health Insurance

5. Wholesale

6. IT Consulting

7. Military

Total
Mean SD $\mathrm{N}$

$\begin{array}{lll}2.94 & .959 \quad 125\end{array}$

$3.00 \quad .096 \quad 8$

$\begin{array}{lll}2.54 & .921 \quad 39\end{array}$

$\begin{array}{lll}2.61 & .929 & 177\end{array}$

$\begin{array}{lll}2.84 & .939 \quad 256\end{array}$

$\begin{array}{lll}2.96 & .868 & 128\end{array}$

$\begin{array}{lll}2.80 & .926 & 114\end{array}$

$\begin{array}{lll}2.81 & .933 \quad 847\end{array}$
6. Content Suitability
1. IT Manufacturing

2. Oil Exp. \& Manufacturing

3. Public School District

4. Health Insurance

5. Wholesale

6. IT Consulting

7. Military

Total $\begin{array}{lll}2.53 & 1.078 \quad 125\end{array}$

$.791 \quad 8$

$\begin{array}{lll}1.99 & .847 \quad 39\end{array}$

$\begin{array}{lll}2.05 & .928 & 177\end{array}$

$2.30 \quad .941 \quad 256$

$\begin{array}{lll}2.65 & 1.021 & 128\end{array}$

$\begin{array}{lll}2.24 & .932 & 114\end{array}$

$\begin{array}{lll}2.31 & .986 \quad 847\end{array}$ 
Table 18 (continued)

\begin{tabular}{lllll}
\hline Type of Barrier & Organization & Mean & SD & $\mathrm{N}$ \\
\hline 7. Technological & 1. IT Manufacturing & 1.82 & .879 & 125 \\
& 2. Oil Exp. \& Manufacturing & 1.92 & 1.179 & 8 \\
& 3. Public School District & 2.05 & .916 & 39 \\
& 4. Health Insurance & 1.74 & .795 & 177 \\
& 5. Wholesale & 2.17 & .955 & 256 \\
& 6. IT Consulting & 2.38 & 1.062 & 128 \\
& 7. Military & 2.14 & .992 & 114 \\
& Total & 2.05 & .959 & 847 \\
\hline
\end{tabular}

Sector Differences

Since there were organizational differences, the organizations were combined into three sectors to establish differences: (a) manufacturing sector, (b) service sector, and (c) government sector.

Manufacturing sector. Across all the categories of barriers, there were no significant differences between the IT Manufacturing Company and the Oil Exploration and Manufacturing Company.

Government sector. On all categories of barriers, there were no significant differences between the Public School District and the Military.

Service sector. There were significant differences among the organizations that make up the service sector (health insurance, wholesale, and 
IT consulting). On all categories of barriers, the IT Consulting Company significantly differed from the Health Insurance Company.

\section{Section Summary}

Based on these results, the respondents in the seven organizations surveyed perceived various types of e-learning barriers with means ranging from 1.29 to 3.00 on a 5-point scale. These ratings are low indicating that employees in these organizations experienced few barriers on all categories of barriers. Personal barriers $(M=1.54)$ were the least common barriers while situational barriers were the most common barriers $(M=2.81)$.

Overall, employees of the IT consulting company (organization 6) perceived more barriers in all categories other than situational barriers where the Oil Exploration and Manufacturing company (organization 2) perceived the most barriers $(M=3.00)$. On all categories of barriers, the IT Consulting Company significantly differed from other organizations.

On almost all factors other than under instructional and instructor barriers, the Oil Exploration and Manufacturing company did not significantly differ from the other organizations. Caution should be exercised when interpreting the results of this organization due to the small sample size $(n=8)$ because standard error of the statistic increases with a small sample size (Hinkle, Wiersma, \& Jurs, 1994). In other words, "Statistical precision is enhanced when sample size is increased, other conditions remaining constant" (Hinkle, Wiersma, \& Jurs, 1994, p. 223). 
The MANOVA test indicates significant differences across organizations in terms of perceived barriers to e-learning. Compared to other e-learning barriers, situational barriers seem to be the most prevalent yielding the highest mean of 2.81. Employees of the IT Consulting company seem to experience the most barriers across six categories of barriers. The Oil Exploration and Manufacturing Company employees perceived the most situational barriers. There are significant sector differences in terms of perceived barriers.

\section{Research Question Three}

Research question three addressed the relationship between perceived barriers and six variables (a) organization, (b) age, (c) gender, (d) ethnicity, (e) marital status, and (f) level of education. The researcher hypothesized that there would be significant relationships between demographic characteristics and elearning barriers.

\section{Multiple Regression}

Multiple regression was used to determine the nature of relationships between and among the DV (perceived barriers) and these six predictor variables. Some variables had to be recoded before analysis. For example, Gender and marital status were dichotomous variables: gender (male, female) and marital status (single, married). Age and education level yielded continuous data, coded so that the higher the value, the higher the age or education level. 
Some of the ethnic groups had small sizes therefore the ethnicity variable was recoded into two groups. Respondents who were of European descent were kept intact since they had many cases $(n=423)$ and the remaining ethnic groups, were combined into one ethnic group, non-European ( $n=442)$.

The variable organization had seven categories. Using procedures described in Pedhazur (1997), six dummy variables were created to represent each organization. Multiple regression was performed by first entering the six dummy codes for organization as a block. Then forward entry method (Stevens, 2002) was used to determine if the remaining predictors could account for any significant variance.

It was found that the six dummy variables significantly predicted average barriers score. However, no remaining variables were added to the regression equation. Table 19 summarizes the regression results. 
Table 19

Model Summary of Variance Explained by Organization

$\begin{array}{llll}\mathrm{R} & \mathrm{R} & \text { Adjusted Std. Error } & \text { Change Statistics } \\ & \text { Square R } & \text { of the } & \\ & \text { Square } & \text { Estimate } & \end{array}$

\begin{tabular}{lll}
\hline Model & $\begin{array}{l}\text { R Square } \\
\text { Change }\end{array}$ & Change \\
& & $\begin{array}{l}\text { df1 } \\
\text { Chan } \\
\text { ge }\end{array}$
\end{tabular}

$\begin{array}{llllllll}\text { Organization } .250 & .062 & .055 & 25.21 & .062 & 8.98 & 6 & 809.000\end{array}$

Note: No other predictors entered the regression equation after six dummy variables for organization.

Testing Multiple Regression Assumptions

Assumption of independence. The method of data collection implies that this assumption was met due to the fact that each of the scores came from individual separate persons in different organizations and their ratings were independent of each other.

Independent errors. The Standardized residuals had only three values that were less than -3.00 or greater than 3.00 . The maximum value for Cooks' distance was $.029<1$ indicating that there were no influential points affecting the regression coefficient (Stevens, 2002). Using Stevens (2002) formula for determining the centered leverage value $3(k+1) / n$, the threshold value was .026 . The maximum centered leverage value was .124 , which exceeded the threshold. So at least one case was an outlier on the predictors. 
Multicollinearity. To Variance Inflation Factor (VIF) indicated limited multicollinearity among the predictors which is an ideal situation for multiple regression. The VIFs for all predictors were less than 10.

Test of normality and homoscedasticity. The normal distribution and constant variance assumptions were checked. A histogram plot indicated normality was a reasonable assumption for the data.

A scatterplot involving studentized residuals plotted by standardized predicted values indicated random scatter, that the homoscedasticity assumption of multiple regression was met.

Multiple regression with dummy codes as predictors is equivalent to one-way analysis of variance (ANOVA) (Pedhazur, 1997). Therefore, as an additional analysis, one-way ANOVA was performed with organization as the independent variable and barriers as the dependent variable. The ANOVA was significant $F$ $(6,842)=9.08, p<.001$. Tukey multiple comparisons revealed that the means for IT Manufacturing $(M=83.62)$, Public School District $(M=74.00)$, Health Insurance $(M=73.75)$, were lower than IT Consulting $(M=93.44)$. In addition, the mean of Health Insurance, $(M=73.75)$ was significantly lower than IT Manufacturing $(M=83.62)$, Wholesale Distribution $(M=84.48)$, and US Military $(M=86.24)$.

\section{Section Summary}

The hypothesis that there would be significant differences in perception of barriers for different groups was confirmed. Significant relationships emerged 
between e-learning barriers and an employee's organization. Other demographic variables were not significant predictors.

\section{Research Question Four}

\section{Multiple Regression}

Multiple regression was used to determine the nature of relationships between perceived barriers (DV) and eight predictor variables, namely

1. Job position

2. Location of study

3. Owns a computer that has Internet connectivity

4. Prior e-learning experience in present organization

5. Prior experience in another organization

6. Total number of online courses taken

7. Computer competence or skills

8. Computer training

Hypothesis

The researcher hypothesized that there would be significant differences in barriers based on these variables. Stevens (2002) cautions that "F tests are positively biased, and the greater the number of predictors, the larger the bias" (p. 107). Thus to reduce the amount of bias, two separate multiple regression calculations were done and each one will be discussed separately below. This follows Steven's (2002) recommendation of carefully selecting predictors "using 
substantive knowledge and/or any previous related literature" (p.109). Prior elearning experience in present organization, prior experience in another organization, total number of online courses taken, computer competence, and computer training represent one's e-learning and computer experiences so they were put together under regression equation two.

\section{Regression Part 1}

The first regression involved three predictor variables (a) job position (b) location of study, and (c) ownership of a computer that has Internet connectivity. To ensure cross-validation or generalization of the regression equation, the researcher had a sufficient sample size $(n=865)$ and adequate subjects (more than 15) per predictor variable $(k=5)$, as recommended by (Stevens, 2002).

Three dummy code variables were created to represent the variable job position and three dummy code variables were created to represent the variable study location. These sets of variables were both entered into a regression equation first. Then, forward entry was used with the variable ownership of a computer than has Internet connectivity. The sets of dummy code variables for job position and for study location accounted for less than $1 \%$ of the variance, a statistically insignificant amount. The variable ownership of a computer that has Internet connectivity did not enter the equation as a significant predictor. Table 20 summarizes the results of this analysis. 
$\overline{\text { Table } 20}$

Model Summary of Relationships between Barriers, Job Position, and Study Location

\begin{tabular}{|c|c|c|c|c|c|c|c|c|c|}
\hline & $\mathbf{R}$ & $\begin{array}{l}\mathrm{R} \\
\text { Square }\end{array}$ & $\begin{array}{l}\text { Adjusted } \\
\text { R Square }\end{array}$ & $\begin{array}{l}\text { Std. Error of } \\
\text { the Estimate }\end{array}$ & & Change & Stat & tistics & \\
\hline Model & & & & & $\begin{array}{l}\text { R Square } \\
\text { Change }\end{array}$ & $\begin{array}{l}\mathrm{F} \\
\text { Change }\end{array}$ & df1 & df2 & $\begin{array}{l}\text { Sig. } \mathrm{F} \\
\text { Change }\end{array}$ \\
\hline 1 & .065 & .004 & .000 & 25.857 & .004 & 1.125 & 3 & 793 & .338 \\
\hline 2 & .075 & .006 & -.002 & 25.888 & .001 & .372 & 3 & 790 & .773 \\
\hline
\end{tabular}

Model 1 has dummy codes for job

Model 2 has dummy codes for both job and study location

Dependent variable: Mean score on BARRIERS

\section{Section Summary}

There was no association between job position and barriers or study location and perceived barriers.

\section{Regression Part 2}

The second regression equation involved variables that had to do with computer and e-learning experiences. Five predictor variables were used in the equation predicting barriers. These were the following:

1. Prior e-learning experience in current organization

2. Prior experience with e-learning in another organization

3. Total number of e-learning courses taken

4. Computer competence

5. Computer training 
The forward entry method (Stevens, 2002) was used. Of these five variables, only two variables entered the regression equation: level of computer competency or skill and whether the employee had gone through computer training. These two variables accounted for $1.7 \%$ of the variance. Employees were asked to indicate their level of computer knowledge and skills (novice, intermediate, or advanced). The question of whether or not one had gone through computer training was dichotomized (yes=0, no=1). The Table 21 below indicates the model summary.

\section{Table 21}

Model Summary Showing Correlations Barriers Predicted by Computer Skill and Training

\begin{tabular}{|c|c|c|c|c|c|c|c|c|c|}
\hline & $\mathrm{R}$ & R Square & $\begin{array}{l}\text { Adjus- } \\
\text { ted R } \\
\text { Square }\end{array}$ & $\begin{array}{l}\text { Std. Error } \\
\text { of the } \\
\text { Estimate }\end{array}$ & $\begin{array}{l}\text { Change } \\
\text { Statistics }\end{array}$ & & & & \\
\hline$\overline{\text { Model }}$ & & & & & $\begin{array}{l}\text { R Square } \\
\text { Change }\end{array}$ & $\begin{array}{l}\text { F } \\
\text { Change }\end{array}$ & df1 & df2 & $\begin{array}{l}\text { Sig. F } \\
\text { Change }\end{array}$ \\
\hline 1 & .120 & .014 & .013 & 25.854 & .014 & 12.217 & 1 & 836 & .000 \\
\hline 2 & .138 & .019 & .017 & 25.810 & .005 & 3.855 & 1 & 835 & .050 \\
\hline
\end{tabular}

a Predictors: (Constant), Computer skill

b Predictors: (Constant), Computer skill, Computer training

c Dependent Variable: Barriers 
Testing Multiple Regression Assumptions

Assumption of independence. The method of data collection implies that this assumption was met due to the fact that each of the scores came from individual separate persons in different organizations and their scores were independent of each other.

Independent errors. There were 29 cases of the 838 that had standardized residuals greater than 2 or less than -2 . This is $3.5 \%$ of the total and not unusual, in that the normal distribution predicts $5 \%$ of cases to exceed 131 .

Multicollinearity. To Variance Inflation Factor (VIF) indicated little multicollinearity among the predictors, which is an ideal situation for multiple regression. The VIFs for both predictors that entered was $1.014<10$.

Test of normality and homoscedasticity. Normal distribution and constant variance were checked. The histogram for standardized residuals was close to bell-shape. A scatterplot involving studentized residuals plotted by standardized predicted values indicated that the homoscedasticity assumption was met.

\section{Section Summary}

The relationships indicate multicollinearity among all the predictor variables. Only two variables were significant predictors of barriers, namely:

- Computer competency or skill $(F(1,836)=12.217, p<.000)$

- Computer training

Computer skill has an inverse relationship to barriers. This meant the persons who rated themselves lowest in skill were those who reported the most 
barriers. Computer training was coded Yes $=0$ and No $=1$. Therefore, the positive correlation between training and barriers meant that persons who reported not being trained had the most barriers.

\section{Research Question Five}

\section{Relationship between Barriers and Self-Efficacy}

The research question five was to determine the relationship between perceived barriers and an employee's self-efficacy. To answer this question, two scales were modified and combined to determine the employees e-learning selfefficacy. More details about these scales are discussed in Chapter 3. The Elearning Self-Efficacy (ELSE) scale consisted of 24 items, whose means and standard deviations are presented in Table 22. Nine of the items were negative (indicated by an asterisk) and therefore they were reverse scored.

Table 22

E-Learning Self-Efficacy (ELSE) Scale Items, Means, and Standard Deviations

Items

M SD

58.I understand terms/words relating to Internet

$4.20 \quad .959$

59.I have the necessary skills for using e-learning software

60.I can turn to an online discussion group when help is needed

61. I can use the Internet to gather data

62.I can troubleshoot Internet problems 
Table 22 (continued)

\begin{tabular}{lll}
\hline Items & $M \quad S D$
\end{tabular}

63.I can usually deal with most difficulties that I encounter when $\quad \begin{array}{lll}3.79 & 1.049\end{array}$ learning online

64.I find working with computers easy

$4.08 \quad .988$

65.I seem to have difficulties with most of the software

$2.01 \quad 1.055$ applications I have tried to use *

66. Computers frighten $\mathrm{me}^{*}$

$1.48 \quad .996$

67.I enjoy working with computers

$4.16 \quad 1.008$

68. Computers make me much more productive

$4.14 \quad 950$

69.I am confident in my abilities to make use of computers in learning

$\begin{array}{ll}4.16 & .959\end{array}$

70.1 find it difficult to get computers to do what I want them to*

1.941 .076

71.I find working with computers confusing*

$1.73 \quad .983$

72. I would rather that we did not have to learn how to use

$1.51 \quad .951$ computers*

73.I usually find it easy to learn how to use a new software application

74. Using computers makes learning more interesting

75.I always seem to have problems when trying to use

$1.72 \quad .959$ computers*

76. Some computer packages definitely make learning easier

77. Computer jargon baffles $\mathrm{me}^{*}$

$2.08 \quad 1.102$

78. Computers are good aids to learning

$4.07 \quad .993$

79. Computers help me to save a lot of time

$4.10 \quad 998$

80.I find working with computers very frustrating*

$1.76 \quad .980$ 
Table 22 (continued)

\begin{tabular}{lll}
\hline Items & $\mathrm{M}$ & $\mathrm{SD}$ \\
\hline $\begin{array}{l}\text { 81. When using computers I worry that I might press the wrong } \\
\text { button and damage it* }\end{array}$ & 1.56 & 1.035 \\
\hline * Items were reverse scored when scale average was created. & & \\
\hline
\end{tabular}

Thems were reverse scored when scale average was created.

\section{Pearson Correlation}

To answer this question, a two-tailed Pearson correlation was used to determine the nature of relationships between perceived e-learning barriers and the self-efficacy. The results indicate a significant relationship $(p=.011)$ between self-efficacy and e-learning barriers ( $r=-.086 ; p<.05$ level) as shown in Table 23. The relationship between the two variables is negative, indicating an inverse relationship. These results support the hypothesis that there is a significant relationship between an employee's self-efficacy and perceived barriers.

Table 23

Correlation between E-learning Self-efficacy and Barriers

\begin{tabular}{llllll}
\hline & & Barriers & Self-efficacy & Mean & SD \\
\hline Barriers & Pearson Correlation & 1 & $-.086^{*}$ & 83.33 & 25.948 \\
& Sig. (2-tailed) &. & .011 & & \\
& $\mathrm{~N}$ & 864 & 860 & & \\
\multirow{5}{*}{ Self-efficacy } & & & & \\
& Pearson Correlation & $-.086^{*}$ & 1 & & \\
& Sig. (2-tailed) & .011 &. & & \\
& $\mathrm{~N}$ & 860 & 860 & & \\
& & & & & \\
\hline * Correlation is significant at the 0.05 level (2-tailed)
\end{tabular}


The relationship was further investigated by looking at each of the seven types of barriers identified earlier (DVs) against the overall ELSE score. The results are illustrated in Table 24 and a correlation matrix appears in Appendix $L$.

\section{Table 24}

Relationship between Each Type of Barrier and E-learning Self-efficacy

\begin{tabular}{ll}
\hline Type of Barrier & Self-Efficacy
\end{tabular}

\begin{tabular}{ll}
\hline 1. Dispositional Barriers & $-.076^{*}$ \\
2. Learning Style Barriers & $-.084^{*}$ \\
3. Instructional Barriers & -.020 \\
4. Situational Barriers & $-.090^{* *}$ \\
5. Organizational Barriers & -.029 \\
6. Content Barriers & -.060 \\
7. Technological Barriers & -.064 \\
\hline * Correlation is significant at the 0.05 level (2-tailed). \\
** Correlation is significant at the 0.01 level (2-tailed).
\end{tabular}

\section{Section Summary}

The hypothesis that that there is a significant relationship between selfefficacy and e-learning barriers was supported. The results indicate very high levels of self-efficacy, measured on a 5-point Likert scale. Learners seem to believe that computers are good aids to learning, help save a lot of time, and make learning more interesting. A look at the negative statements indicates that they disagree that working with computers worry them or that the jargon baffles 
them, or that they seem to have difficulties. These are indicators that the respondents were computer savvy as indicated in their levels of computer skills.

The relationship between the ELSE and BEL was negative. An inverse relationship indicated that subjects with high self-efficacy tended to rate elearning barriers low. Dispositional barriers $(r=-.076, p=.026)$, learning style barriers $(r=-.084, p=.013)$, and situational barriers $(r=-.090, p=.008)$ had a significant relationship with self-efficacy $(p<.05)$. The other four factors did not have significant relationships with self-efficacy.

\section{Chapter Summary}

Seven factors emerged from a factor analysis namely (a) Dispositional, (b) learning style, (c) instructional, (d) situational, (e) organizational, (f) contentsuitability, and $(\mathrm{g})$ technological barriers. Situational barriers being the most prevalent.

There were significant organizational differences in perceived barriers with the IT Consulting Company employees reporting the most barriers. Organization, computer training, computer competence, and e-learning self-efficacy emerged as significant predictors of e-learning barriers. Other demographic and background characteristics under study were not significantly related to perceived barriers.

Chapter 4 covered the results and Chapter 5 follows with conclusions, implications for practice, and recommendations for practice and future research. 


\section{CHAPTER V}

\section{DISCUSSION, CONCLUSIONS, IMPLICATIONS, RECOMMENDATIONS, AND SUMMARY}

The purpose of this study was to determine the relationship among elearning barriers, demographic variables, background variables, and self-efficacy. A valid and reliable survey (BELSE) was used to collect data. This was a selfreported, anonymous web-based survey administered to a sample of convenience comprising of 4807 employees in seven organizations.

Chapter Five delves deeper into the findings by analyzing, synthesizing, and drawing conclusions. These findings have various implications for various elearning stakeholders such as e-learners, instructional designers, support staff, administrators or management, course facilitators, software manufacturers and service providers. Recommendations and implications for practice and future research in e-learning and Human Resources Development (HRD) are drawn. 
The first research question determined the nature of barriers perceived by employees engaged in e-learning. A factor analysis using varimax rotation yielded seven types of barriers (factors) perceived by employee e-learners as discussed next. The findings of the present study updated Schilke's (2001) conceptual framework of barriers leading to seven categories of barriers as illustrated in Figure 7.

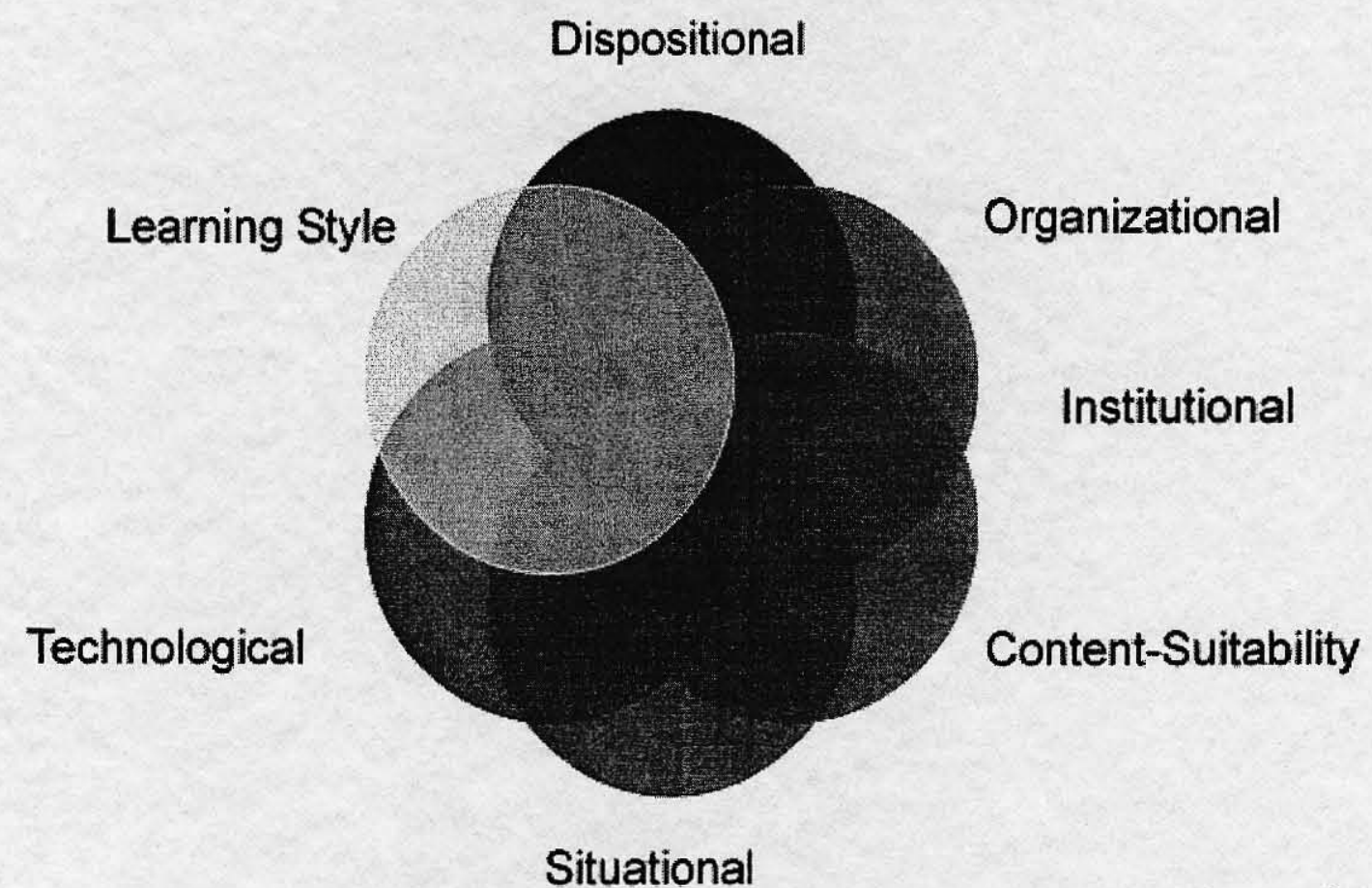

Figure 7: Types of e-learning barriers 


\section{Dispositional or Personal barriers}

In the present study, they were the weakest rated barriers $(M=1.54)$ on a 5-point Likert scale. Three barriers under this factor had the lowest ratings. These barriers had to do with an individual's personal characteristics or disposition such as time management problems, resistance to change, lack of confidence, adult pride, and language problems.

Implications and Recommendations

Dispositional barriers are worth paying attention to because they have been found to influence completion rate (Chu \& Hinton, 2001; Giles, 1999; Schilke, 2001; O'Connor, et al., 2003). The present study found a significant relationship between dispositional barriers and e-learning self-efficacy. Therefore, practitioners should take into consideration the learners' dispositions.

E-learners must understand their roles and responsibilities in e-learning. The "person" is one of the components of the social cognitive theory. Although a lot of changes can be made to the environment (organization, design, or technology), it is upon the individual person to realize that as an adult learner, one has to take responsibility for one's learning. A prospective or current elearner, for example, must participate in training if one's skills are lacking. Without the necessary skills, frustrations are bound to occur regardless of other changes in the system. Some employees mentioned procrastination or "Never getting to start". While time management training can be taught, it lies upon the 
individual to take control of their time. "Personal commitment to either an academic or occupational goals is the single most important determinant of persistence in college." (Cope \& Hannah, 195, p. 19 cited in Tinto, 1993, p. 43).

Bandura (1986) states that outcomes are not disconnected from actions; rather, most outcomes flow from actions. Therefore, one's behavior largely determines the outcomes one experiences. Employees ought to realize that their behavior in e-learning like in other life's event affects their outcomes. For example, an employee who commits more hours learning is more likely to complete a course and receive certification. What is imperative here is to recognize the link between one's actions and outcomes (perceived barriers). "Outcomes emanate from actions" (Bandura, 1986, p.392). "In social cognitive theory, people are agentic operators in their life course not just onlooking hosts of internal mechanisms orchestrated by environmental events." (Bandura, 1999, p. 4). Outcomes also depend largely on self-efficacy beliefs (Bandura, 1986). "In social, intellectual, and physical pursuits, those who judge themselves highly efficacious will expect favorable outcomes, self-doubters will expect mediocre performances of themselves and thus negative outcomes" (Bandura, 1986, p.392). E-learners need to be aware of this link between their e-learning selfefficacy beliefs and outcomes.

Sometimes e-learners do not understand how their role will actually change and this is a great source of concern and stress (Ullich, 1998). Role ambiguity occurs when there is a lack of clarity between an individual and others regarding what is expected of them (Ullrich, 1998 citing Spreitzer, 1996). Such 
ambiguity can affect a student's belief in his/her capacity to perform and hurt one's self-confidence (Ullrich, 1998). This makes it necessary to have adequate communication and advising opportunities to reduce role ambiguity. Ullrich (1998) warns that unless there is high-self confidence in learners and clear, concise and timely communication, resistance will occur and this could result in a failure of online programs.

\section{Learning Style Barriers}

These have to do with the preferred method of learning and media preferences. Although learning style barriers were not prevalent $(M=2.00)$ among the surveyed employees.

\section{Implications and Recommendations}

O'Connor, et al. (2003) found $33 \%$ of employee e-learners indicated that learning style mismatch is an influential factor in e-learning dropout. The need to consider learning styles has been highlighted by many researchers such as ASTD \& Masie (2001) and Kirk (2002).

The present study's findings indicated that learners do have different learning styles or preferences (some employees showed a preference for instructor-led instruction, more interaction, passive learning, and hands-on experiences). Instructional designers and facilitators should first determine learning styles of the learners and adapt content and delivery media and methods to meet varying styles. Instruction should be designed, developed, and 
facilitated, with an appreciation that learning styles differ. Using multi-media or blended learning approaches are suggested. This will ensure that as many learning styles are catered for.

\section{Instructional Barriers}

Contrary to Schilke's (2001) findings that institutional factors (instructor and instructional barriers) were the most commonly mentioned factors among online college students, the results of the present study indicated few instructional barriers among employees $(M=1.96)$. This finding is positive because instructional design-related factors have been reported to influence dropout rate (O'Connor, et al., 2003).

Instructional barriers mentioned included lack of progress reports, limited feedback, limited learner engagement, poor instructional design, limited reference materials, access and navigational problems, unclear or inconsistent instructions, inability to save work, information overload, lack of instructor presence, limited interaction, and poor coordination.

\section{Implications and Recommendations}

Although instructional barriers were few, their presence has implications for facilitators and instructional designers, who should to pay attention to the design, accessibility, and communication. Content should be well chosen, written, developed, and delivered considering that in e-learning, content is what e-learners interact with the most. The instructor's presence (if one is used) must 
be felt by learners though interaction and feedback. Organizations need to ensure that essential resources are provided to enhance e-learning.

\section{Organizational Barriers}

Organizational barriers were weakly rated $(m=1.84)$. Barriers mentioned under this category included cultural problems with credibility of e-learning, lack of time for study, interpersonal barriers, limited online course availability, problems with the registration system, lack of awareness of online courses availability, lack of credit or certification after completion, and non-involvement in decision making.

\section{Implications and Recommendations}

Organizational factors such as support have been reported to influence dropout rate in e-learning (ASTD \& Masie, 2001; O'Connor, et al., 2003). Other influential organizational factors that may affect course completion include distance education policies (O'Connor, et al., 2003; Sheets, 1992), availability of support services (Giles, 1999), and course management (Magalhaes \& Schiel, (1997) among others. These factors have implications for support staff who market, provide support services, and manage online courses.

The findings have implications for administrators or management who need to craft appropriate policies for e-learning, especially those that will prioritize time for learning at work, enhance communication, and provide support services to e-learners. 
Organizations should provide incentives for e-learning. Since success in building self-efficacy should be measured in terms of self-improvement (Bandura, 1994), self-improvement efforts such as engaging in and completing online training should be rewarded to enhance employees' self-efficacy. Pay-forknowledge or some skill recognition are key considerations in Web-based training (Colbrunn \& Tiem, 2000) just like in other organizational learning efforts (Kreitner \& Kinicki, 2002).

Having skills and high self-efficacy is not enough (Bandura, 1986). "Persons may possess constituent skills and a strong sense of efficacy that they can execute them well, but they still choose not to perform the activities because they have no incentives to do so" (Bandura, 1986, p.395). This is why e-learning stakeholders must provide incentives.

Self-efficacy also does not translate into action whenever people do not have access to necessary physical resources such as equipment. Physical or social constraints further impose limits on what people can do (Bandura, 1986). Consequently, for e-learning to be successful, skills are not enough, resources are equally important. The discrepancy between internal factors (people's capabilities) and external factors (resources) should be resolved.

\section{Situational Barriers}

Situational barriers are related to the situation or environment one is in (Schilke, 2001). Situational barriers were the most prevalent in the present study $(M=2.81)$. Three of the top five barriers were situational barriers, namely: over- 
commitment to multiple roles and responsibilities, lack of time for study, and interruptions during study.

Implications and Recommendations

The implication for policy makers and supervisors is to provide opportunities or time for training. Training time for face-to-face delivery is usually planned for and reserved but the asynchronous nature of e-learning has brought its own challenges. Lack of time for study was the most prevalent barrier in this study and unless employers and employees prioritize study time, online learning efforts will continue to suffer. Interruptions during study could be improved through environmental changes such as using "study-in-progress" signs or using rooms specifically meant for e-learning.

\section{Content-Suitability Barriers}

These were the second highest rated barriers $(M=2.31)$ following situational barriers $(M=2.81)$. Examples of these barriers included limited course relevance, content not being audience-specific, poor quality content, limited rigor, and poorly constructed assessments.

Implications and Recommendations

Instructional designers and facilitators must ensure that the course content fits or matches the needs of the learners. Dick, Carey and Carey (2001) recommend conducting needs assessments through instructional-, context-, and 
learner analysis as critical steps for good instructional design. Witkin and Altschuld (1995) recommend doing needs assessments to identify organizational needs. Instruction should be viewed from a systems perspective (Dick, Carey \& Carey, 2001) to reduce these barriers. Content must be rigorous and of quality otherwise it will affect the credibility of e-learning.

\section{Technological Barriers}

Technological barriers in the present study were few $(M=2.05)$. A recent study by O'Connor et al., (2003) shows that technological factors such as Internet connection problems (4.5\%) and lack of access to a computer $(1.1 \%)$ seem to have minimal effect on e-learning drop out. These findings are positive indicators of improvements in e-learners' experiences with technology. The present study's participants seemed to have the necessary resources ( $88 \%$ owned a computer with Internet) to engage in e-learning. According to O'Connor, et al. (2003), $87.7 \%$ or the respondents had access to high-speed Internet resources via company Intranet or cable/DSL modem.

High levels of computer competency were reported by $96 \%$ of the respondents. In a study by O'Connor et al. (2003), $80 \%$ indicated high computer literacy. Apparently, these findings communicate good news, but the presence of technological barriers cannot be ignored. Some of the barriers mentioned in this category included poor quality of the Leaming Management System (LMS), connectivity, and navigational problems, lack of training, technical support 
limitations, loss of data, and inability to save or transfer data. Essential measures need to be taken to reduce such barriers.

\section{Implications and Recommendations}

These findings imply that choice of technology is a key factor. Loss of data and inability to save or transfer data indicate software limitations. "Deciding what technology to use and how to use it effectively probably rank as the two biggest questions faced by organizations as they attempt to design delivery of distance learning" (Schreiber \& Berge, 1998). When choosing technology, it is absolutely important to look at both the advantages and disadvantages of each instructional technology (Belanger \& Jordan, 2000) and to consider the needs of the audience before making choices of media or design to be used. For example, before choosing web-based courses, access issues must be addressed including students' accessibility to e-mail, computers, Internet connection, and Web browsers (Porter, 1997). In addition, technical support could help with connectivity and navigational problems. Providing training to those whose skills are lacking is essential in reducing such barriers.

Computer competency emerged as a significant predictor of e-learning barriers in the present study. To increase their computer skills, employees require opportunities to use and interact with technology because according to Moingeon and Edmondson (1996, p. 43), an "experimental mindset" is an essential factor in facilitating organizational learning. Moingeon and Edmondson (1996) advocate for support and opportunities to try out new things (such as e- 
learning technologies in this context), curiosity about how technology works, and opportunities to "play" (cited in Kreitner \& Kinicki, 2002, p. 679). Trialability determines the degree to which an innovation (such as e-learning) can be experimented with on a limited basis (Rogers, 1997). Employees should be exposed to technology and given opportunities to interact with it.

\section{Conclusion}

Clearly, an interplay of forces interfere with participation of adults in educational and training activities (Sheets, 1992) as discussed above and as illustrated in Appendix $M$, which shows the types of barriers emerging from other research including the present study. These findings support what other researchers have found. Online learning like any other technology comes with some costs and/or obstacles. Further, barriers are multi-dimensional and systemic, emerging from and encompassing various parts of the system. This research synthesis reveals more similarities than differences in the nature of barriers. While the categories in which the barriers are placed slightly differ in these studies (for example, other researchers have placed learning style barriers under dispositional barriers category), there is a general consensus that elearners are faced with multidimensional barriers. 
Research Question Two: Differences in Barriers across Organizations

\section{Research Question and Hypothesis}

The second research question asked whether there are differences in perceived barriers based on an employee's organization. They hypothesis that there would be significant organizational differences in employees' perceptions of barriers failed to be rejected.

To answer this research question, a multivariate analysis of variance (MANOVA) test was conducted. The results showed the following:

1. Significant differences in perceived barriers among the seven organizations.

2. Significant differences among the three organizations in the service sector (IT Consulting, Health Services, and Wholesale).

3. No significant differences between the two government-funded agencies (Public School District and US Military).

4. No significant differences between the two organizations in the manufacturing sector (IT Manufacturing and Oil Exploration and Manufacturing).

While the statistical significant differences stand out, an analysis of the open-ended responses indicated some similarities in the barriers encountered across these organizations. Appendix I (Tables A1-A7) summarizes e-learning barriers experienced by employees in the seven organizations. In some cases, the employees' quotes are used to convey the nature of the problem experienced. 
The fact that there were significant differences among the seven organizations indicates that there were organizational factors in play that affected e-learners' perceptions. Possible explanations for these differences could be explained by various factors that other researchers have found to affect organizational learning such as:

- Delivery media (Champagne, et al., n.d.)

- Organizational culture (Kreitner \& Kinicki, 2002)

- Work environment (Berge, Muilenburg, \& Haneghan, 2002)

- Stage of adoption of e-learning (Berge, Muilenburg, \& Haneghan, 2002; Rogers, 1995)

- Organizational readiness (Colbrunn \& Tiem, 2000); Resource availability (Colbrunn \& Tiem, 2000)

- Time for study at work (Gieskes, Hyland, \& Magnusson, 2002; O'Connor, et al., 2003; Colbrunn \& Tiem, 2000), among other factors.

- Support system (Kirk, 2002; Kreitner \& Kinicki, 2002; O'Connor et al., 2003; Pollard \& Hillage, 2001).

- Communication (Colbrunn \& Tiem, 2000; Rogers, 1995).

These factors are explored in detail and the implications they have on elearning and HRD are discussed next. These research studies indicate that these organizational factors could have influenced employees' perceptions. The degree of influence these factors had on employees' perceptions was beyond the scope of this study, but their effect on e-learning deserves further attention in future research.

Implications and Recommendations

Reinvent delivery media. The significant organizational differences might be explained by the fact that these organizations used different e-learning media. In a literature review by Champagne et al., (n.d.), nearly all studies reviewed suggested that differences between the groups were solely due to the distance 
learning media used rather than to individual student differences such as learning style, self-efficacy, or motivation. The implication for organizations is to review their technologies with an eye to customization or reinvention. Rogers (1995) posits that technological innovations usually are reinvented to meet the adopters' needs. "Adopting an innovation is not necessarily the passive role of just implementing a standard template of the new idea." (Rogers, 1995, p.17). Adopting e-learning is an active process.

Work environment. Berge, Muilenburg, and Haneghan (2002) examined the effect of work environment on one's perceptions of barriers. They found that businesses and corporations tend to be below average on most barriers compared to colleges and universities. Therefore the nature of business (Berge, Muilenburg, \& Haneghan, 2002; Timura, 1996) could impact training opportunities and influence employees' perceptions. Opportunities for study in a quiet and supportive environment are essential regardless the nature of business.

Stage of adoption of e-learning. Rogers (1995) asserts that rates of adoption of an innovation differ depending on factors such as trialability, observability, relative advantage, compatibility, and complexity of the innovation. E-Learning is an innovation that is still undergoing diffusion in organizations and society. The stage of adoption of e-learning that an organization is in affects perceptions of barriers (Berge, Muilenburg, \& Haneghan, 2002). The general trend was for organizations that were further along in their stage of adoption of distance training reported that barriers were less of an issue than those at earlier 
stages (Berge, Muilenburg, \& Haneghan, 2002). Those with institutionalized DT rated all the barriers below the overall means (Berge, Muilenburg, \& Haneghan, 2002). In the present study, organizational differences may have had to do with stage of adoption (Berge, Muilenburg, \& Haneghan, 2002).

Organizational culture. Factors such as organizational culture affecting organizational learning. For example, low trusting cultures detract from spontaneous learning that is critical within learning organizations (Kreitner \& Kinicki, 2002). Some of the organizations in the present study were still "suspicious" of e-learning. Kreitner and Kinicki (2002) recommend that in order to reduce interpersonal, group, and organizational barriers to learning, a commitment to learning is essential.

Organizational readiness. This is a key factor impacting Web-based training and cultural readiness should be determined (Colbrunn \& Tiem, 2000). "Although many employees are ready and eager to take advantage of the convenience that web-delivered training offers, the organization and its existing culture may not be supportive." (Colbrunn \& Tiem, 2000, p. 35-36). People issues may get in the way of completing web-based training (Colbrunn \& Tiem, 2000). Technical readiness is also critical. The target audience must have ready and consistent access to the Internet or Intranet, with standard browsers, and a reliable technical support team (Colbrunn \& Tiem, 2000).

Resource availability. Equipment sufficiency and availability is a common organizational hurdle (Colbrunn \& Tiem, 2000). Web-based training requires investments in hardware and software. Bandwidth and uniformity in specifications 
is essential for consistency (Colbrunn \& Tiem, 2000). Desktop computers, laptops or computer labs equipped with the essential software are critical for any e-learning program. Thus their availability and reliability to influence employees' perceptions.

Time for study at work. Interrupted learning processes are a training barrier (Gieskes, Hyland, \& Magnusson, 2002; O'Connor, et al., 2003) thus 'Time allocation is the most important immediate factor." (Colbrunn \& Tiem, 2000, p. 36). Employees are encouraged to engage in e-learning at their own time although many employees believe that training should be a part of on-the-job time (Colbrunn \& Tiem, 2000). Unfortunately, coworkers and supervisors cause constant interruptions, forcing a trainee to postpone one's learning and in many organizations. Management should determine when and where online training will be completed (Colbrunn \& Tiem, 2000).

In the organizations under study, perhaps time for study during work hours is not prioritized, and it is no wonder that lack of time for study emerged as one of the top five barriers in this study. Time for study during office hours is essential (O'Connor, et al., 2003). Workplace learning can be enhanced by providing time for study at work, introducing policies, and through instructional design such as converting longer modules into shorter, more informal learning formats such as Electronic Performance support systems (EPSS) (O'Connor, et al., 2003). Other recommendations include use of study rooms such as computer labs, use of signs on office doors during study can help avoid interruptions, and employer support are recommended. 
Organizational support. The fact that some participants indicated resistance in their organizations confirms what Kreitner \& Kinicki $(2002$, p. 681) posit that "Organizations naturally resist learning". Many researchers have emphasized the need for management support for e-learning. Top management's support is a priority before launching an e-learning program (Kirk, 2002). Kreitner and Kinicki (2002) note that it is essential for leaders to "instill intellectual and emotional commitment to learning" (p. 682). Even after initiating a training initiative, organizational support is critical because it influences elearning dropout rate (O'Connor, et al., 2003). In addition to management support, around the clock (24/7) technical support and good instructional design can be efforts towards ensuring that study time is wisely spent and not wasted dealing with technological issues.

Learner Support. Although reduced cost is often cited as a benefit of elearning there are hidden costs of e-learning, that are largely related to the provision of learner support (Pollard \& Hillage, 2001). Good online learning requires adequate learner support, which is clearly needed in most of these organizations. Support could be internal or external, for example, staff who are proficient in a certain skill or have extensive experience can provide personal coaching and support (Pollard \& Hillage, 2001). Managers have an important role in motivating learners to continue with online learning (Pollard \& Hillage, 2001). "Managers must go the extra mile to pat learners on the back, give them recognition, and encourage them to learn with their peers." (Cross, 2000 cited in Pollard \& Hillage, 2001, p.31). 
E-learning policy and communication. Colbrunn and Tiem (2000)

recommend that policy must be communicated openly and honestly in order to prepare employees to take online training. Communication is an essential process for any innovation to diffuse (Rogers, 1995). Organizations should therefore prioritize communication and streamline the lines of communication.

The finding of significant organizational differences in e-learning barriers clearly indicates the imperative for organizations to conduct a thorough needs analysis that delves deeper into why their e-learners are experiencing specific problems. Such needs analysis should systematically investigate unmet needs or problems (e-learning barriers), understand causes of such needs, and use the information gathered to develop quality programs (Witkin \& Altschuld, 1995). A needs analysis should be systemic, ongoing, and involving a wide variety of stakeholders (Witkin \& Altschuld, 1995). Needs assessments are means to an end. In the case of e-learning, the goals is to reduce barriers and to increase employees' self-efficacy.

Learning organizations should be proactive and innovative instead of being reactive (Kreitner \& Kinicki, 2002). Organizations new to e-learning or planning to offer online courses should investigate their audience needs, technological capabilities, culture, among others to before any content is written. Time taken beforehand will prove beneficial in the long run and can be a key solution to most barriers being encountered by e-learners. Such a proactive approach would also substantially cut costs and raise the return on investment in the long run. 


\section{Conclusion}

Whether the statistical differences in barriers among the seven organizations emerged due to their different nature of business, stage of adoption of e-learning, culture, location, policy, communication, or e-learning offerings deserves further investigation.

The above discussion on research question 2 centered on the significant differences in perceived barriers emerging from the present study and how these differences could be explained by various organizational attributes.

Research Question Three: Relationship among Barriers and Demographics

\section{Research Question and Hypothesis}

The third research questioned investigated the relationship between perceived barriers and demographic variables (age, gender, ethnicity, job position, marital status, and level of education). The hypothesis was that these demographic variables would have significant relationships with perceived barriers.

Multiple regression using Forward entry method was used to establish the relationship between perceived barriers and demographic characteristics. Age, gender, ethnicity, marital status, and level of education did not enter the regression equation and were not significantly correlated with e-learning barriers. The hypothesis was thus rejected. An employee's organization was the only variable that had a significant relationship with e-learning barriers $(r=.117)$. 
Considering the continued trend of diversification of the work force, demographic characteristics were put under consideration in this study. There has been an emphasis on the need to know students' characteristics or demographics (Feldhaus, 1999; Keegan, 1996; Smith, 1998) since they are factors that affect students' persistence or attrition in DE.

Studies differ on the effect of demographic variables on distance learners' perceptions, with recent studies by Litchfield, Oakland, and Anderson (2002) and Feldhaus (1999) arguing that demographics do not have a significant impact on e-learner perceptions. The results of this study confirmed and conflicted with other research on the effect of learner demographics on learner perceptions.

The demographic characteristics of the participants in this study revealed a very diverse population. The majority of the employees were middle-aged (32-38) males of European descent, which is the same population that has benefited from conventional education (Gorard \& Selwyn, 2000). Consequently, this skewed over-representation by e-learners of European-descent illuminates doubts as to whether e-learning has enhanced accessibility for non-traditional students. E-learning has been acclaimed for its ability to reach more learners and to broaden access to those who have been sidelined in the past (ASTD \& NGA, 2001; Bonk, 2001; Kirk, 2001). Perhaps, considering that various ethnicities, females, and age groups were represented points in the direction of increasing accessibility.

The results of this study show that through the use of e-learning, the organizations that were studied were able to reach geographically dispersed 
employees. Five of the organizations under study had employees outside the United States of America. Although their specific location was conducted was not asked, their comments from the open-ended response question revealed that some employees were located across the globe, both on land and at sea (in the case of the US military personnel). Some employees indicated that they were located in Britain, India, and the Algerian desert.

Age

The mean age range of the participants was 32 to 38 years (31\%). $80 \%$ were below 45 years. This study found that the relationship between an employee e-learner's age and perceived barriers was not significant. Prior research shows inconsistent findings on the effect of age on DL experiences. The findings of this study confirm what Giles (1999) found that age was not a significant predictor or persistence or dropout among a group of college students. It also confirms Feldhaus (1999) study of college students where a majority of the students felt that age does not make any difference in one's DL experiences.

The insignificant finding on age is contrary to findings by Koul and Jenkins (1990) who found that in certain cases, age was a barrier to study participants being able to fully embrace digital technology. The results also contradict Fjortoft's (1995) findings that age is a significant predictor of persistence in DL and that older students (above middle age) have more difficulty with DL. The present study's post-hoc ANOVA showed significant differences in barriers between age groups $(F(5,1756)=2.634 ; p=.023)$ with those in the $32-38$ age 
group experiencing the most barriers $(M=85.13)$. This finding of age differences in perceptions is similar to Dyck and Smither (1994).

Implication. The fact that age was insignificant implies that all people regardless of age can benefit from e-learning as a tool for developing human resources. Further research is essential in this area due to the conflicting research findings.

\section{Gender}

A large percentage (65\% to $70 \%$ ) of adult students are women (Donaldson, Graham, Martindill \& Bradley, 2000 cited in Kramarae, 2001). However, in the present study, men dominated the sample and gender disparity was clearly evident with only $36 \%$ female respondents. The results show that there is no significant relationship between an employee's gender and e-learning barriers, which confirms reports by Feldhaus (1999), Giles (1999), and Sheets (1992). However, other researchers such as O'Connor (2003), Tsai, et al. (2001) and Kramarae (2001) report that gender is an influential factor in e-learning.

An ANOVA post-hoc test in the present study revealed gender differences between males and females on barriers $(F(1,9056)=13.7 ; p=.000)$ at the .05 alpha level. Other studies indicate gender differences in relation to self-efficacy (Cassidy \& Eachus, 2002), attitudes towards the Internet (Tsai, et al., 2001), and course completion (O'Connor, et al., 2003). "The Third Shift" concept, highlighted in Kramarae (2001) research indicates that gender differences do exist due to indirect costs associated with e-learning, tuition, family factors, and 
time demands. Perhaps, these factors explain why situational barriers were the highest rated e-learning barriers facing employees in the present study.

Implications. Practitioners should not be selective in their use of e-learning based on the audiences' gender. The fact that gender was insignificant implies that both males and females can equally benefit from e-learning as a tool for developing human resources. Both genders must be accorded equal opportunities and support for e-learning. Further research is essential in this area due to the conflicting research findings.

\section{Level of Education}

Stanton (1998) reported that nearly two-thirds of distance learners possess college degrees. Over a third of this study's sample (36.5\%) had a bachelor's degree. The results support Sheet's (1992) claim that the education background of distance students ranges from less than high school to completion of a university degree and beyond. This sample was a highly diverse group in terms of level of education, ranging from high school education to the doctoral level.

The findings of this study revealed no significant relationship between an employee's level of education and e-learning barriers. This is contrary to Feldhaus' (1999) finding that the diversity of educational background was the most significant factor causing barriers. However, the Feldhaus study looked at students enrolled in two-way audio-video courses, which is a different delivery media from e-learning, which was examined in the present study. 
Implication. The implication for practitioners is that e-learning is a viable delivery tool for training all populations regardless of their level of education. Elearning should not be limited to the highly-educated workforce but extend its use to less-educated audiences. Simply put, the level of education is not necessarily the overarching factor that determines whether somebody will perceive barriers or not. There are more influential factors than one's level of education.

\section{Marital Status}

A majority $(68.7 \%)$ of the employees in this study were married, but marital status did not emerge as significant predictor of e-learning barriers, confirming what other studies have found (Sheets, 1992).

Although marital status was not a significant factor, it should not be ignored because it could have implications on enrollment, effort, time for study, support, and persistence. E-learning brings learning activities into the home and can involve family members in a variety of ways (Kramarae, 2001). E-learners are working people with busy schedules (Timura, 1995), likely to be married, and with have other responsibilities that may take priority over course work (Timura, 1995). Circumstances surrounding traditional spousal roles could be barriers in starting and completing education. Kramarae's (2001) study on women learning online suggested that some women indicated that a spouse's approval and support for course taking is especially important and women needed to reassure their families that online studies would have minimal impact on family life. Many e-learners admit that their family responsibilities come first, making setting 
educational goals a complex task especially for women with partners (Kramarae, 2001).

Implication. The fact that marital status was insignificant implies that all people regardless of their marital status could benefit from e-learning. A support system is essential for everyone involved. Further research is essential in this area due to the conflicting research findings.

\section{Ethnicity}

The findings of this study indicated ethnic diversity characterized the groups that were studied. The over-representation of e-learners of European descent (49\%) clearly confirms other research findings that e-learning beneficiaries tend to be white; the same population that has most benefited from traditional education (Gorard \& Selwyn, 2000).

The present study found an insignificant relationship between e-learning barriers and an employee's ethnicity. Past studies have somewhat conflicted in their findings on the significance of ethnicity in e-learning. Feldhaus (1999) found that race made no difference in white males and females' ability to learn and ethnicity was not a significant predictor of persistence or dropout in college computer-conferenced courses (Giles, 1999). Charner and Fraser (1986) noted that race was a factor in non-participation in adult education and the Feldhaus (1999) study revealed that race was a barrier to minorities' learning process. 
The ethnic composition of the sample used in the present study included employees from around the world. There were employees of African, Asian, European, Latino, Pacific Islands, and Native-American descent.

Implications. The fact that ethnicity was insignificant implies that all ethnicities are using e-learning and barriers are not ethnic-specific. The findings indicate an under-representation of minorities, which calls efforts that target minorities to increase their representation in e-learning in order to reduce the digital divide. All efforts towards reducing barriers should seek to be all-inclusive. Further research is essential in this area due to the conflicting research findings.

\section{Research Question Four: The Relationship among Barriers and Background Variables}

\section{Research Question and Hypothesis}

\section{Research Question 4}

The fourth research question investigated the relationship between perceived barriers and an employee's (a) job position, (b) study location, (c) computer ownership, (d) computer training, (e) computer competency, (f) prior experiences with computers and the Internet, and (g) prior experiences with elearning in current and previous organizations. The hypothesis was that there would be significant relationships in barriers based on these variables.

Multiple regression showed a significant relationship between perceived barriers and only two background characteristics: (a) computer competency and 
(b) computer training. There was evidence of multicollinearity among the predictor variables in the equation. The other predictor variables did not emerge as significant predictors of barriers. A discussion of each one of these variables follows.

Job Position

In general, distance students tend to be employed (Keegan, 1996) and this was the case for this study's sample. Various occupations were represented in the sample with a majority being support staff (43.7\%). $32.8 \%$ were managers or administrators.

The present study found that job position was not a significant predictor of e-learning barriers. Sheets (1992) similarly found that the occupational status of learners is not significantly related to program completion.

Similarities and differences in barriers do exist depending on job position. For example, Berge (2002) analyzed the strongest and weakest barriers to distance education by job function and differences in their perceptions. For example, increased time commitment was the strongest barrier facing e-learners across the board regardless of job function (support staff, teachers, faculty, trainers, researchers, and college students) (Berge, 2002). On the other hand, incentives and compensation were the number two barrier among faculty and trainers while it was rated ninth by support staff (Berge, 2002), indicating differences in perceptions depending on one's job function. 
Implications. It is worthwhile to note that although some of these variables do not indicate direct or significant relationships, their ability to influence elearning indirectly and/or cumulatively should not be entirely ruled out. For example, computer ownership was significantly correlated with job position $(r=-.059 ; p=.048)$ and also with study location $(r=-.180 ; p=.000)$ although none of these three predictor variables were significantly correlated with elearning barriers. Perhaps this indicates that one's job position could influence their financial ability to afford a computer and pay for Internet costs, thereby affecting one's study location. Apparently, if one does not have access to free equipment, then one's study location options, access, and frequency of use could be limited.

On the other hand, job position was significantly correlated with owning a computer with Internet connection, another indicator that affordability could be an issue. Stanton (1998) found that half of all Internet users are professionals or managers. Since $43.7 \%$ are support staff, they probably could not afford to buy a computer and if they did, then they may not have Internet connection at home.

Gorard and Selwyn (2000) reported that virtual universities face major obstacles when registering populations who do not have computers or access to the Internet. The implication for employers is to provide resources for use in elearning such as computers. Access, especially for employees in lower-level paying jobs and in remote locations, should be taken into account. The US Army is an example of an employer that offers an incentive to e-learners by offering free laptops. Employers could follow this model or go even further to pay for 
Internet-related costs especially for employees in international locations such as developing countries where phone and Internet connection costs are high.

This findings show that e-learning can be utilized for all employees in all job positions. Those in lower cadres or in upper management should be afforded e-learning opportunities because barriers are not unique to any job position.

\section{Location of Study}

The respondents were asked to indicate where they do most of their online learning. A majority study in the office (55.8\%) and only $15.7 \%$ study at home, while $26.4 \%$ study in both locations and only $1.5 \%$ study in other locations.

Implications. The relationship with perceived barriers was not significant, indicating that the location where employees undertake e-learning does not significantly influence their perception of e-learning barriers. Similarly, other research investigating the influence of study location by Hilgenberg and Tolone (2000) found no significant differences in satisfaction between students studying from the main-site and remote-site. However, the latter looked at distance education courses delivered through a two-way audio and video system, which is different from e-learning. In contrast with the current study, Wagner, Warner, and Schramm (2002) found that location of study or place of access could impact student perceptions. The purpose of their study was to determine students' perceptions concerning the effectiveness of online MBA courses among college 
students. Wagner, Warner, and Schramm (2002) found that place of access was significantly related to students' willingness to recommend the course to others.

The implication is that all e-learners regardless of their job location can utilize e-learning. E-learning should be used for those in-house and outside the organization. However, since these studies conflict in their findings, more research on the effect of study location is warranted.

Study location was significantly correlated to owning of a computer that has Internet connectivity $(r=-.180 ; p=.000)$, a variable that could indirectly affect one's study location options. It is no surprise that study location was not a significant predictor of barriers in the present study because the majority $(88 \%)$ of the respondents reported that they own a computer with Internet connection. Access to a course impacts students' perceptions because students find it a great benefit if they have the ability to access a course before work, during breaks, or after work (Wagner, Werner, \& Schramm, 2002). Prospective elearners could be encouraged to purchase equipment (computers and essential software) and Internet connection in order to access courses.

\section{Ownership of a Computer with Internet Connection}

The relationship between owning a computer with Internet connection and barriers was not significant. This means that whether an employee owned a computer with Internet connection was not a significant predictor of e-learning barriers. The fact that a majority ( $88 \%)$ of the respondents reported that they owned a computer that has Internet connectivity supports this finding. 
Study location was significantly correlated with owning of a computer that has Internet connectivity $(r=-.180 ; p=.000)$. The fact that $88 \%$ reported owning a computer with Internet connectivity indicates that they could vary their location of study by logging in from multiple locations: at home, in the office, and from other locations. Having Intranet connection has been found to influence completion of e-learning courses $(r=.11, p=.031)\left(O^{\prime}\right.$ Connor et al., 2003) and in the present study, $56 \%$ did most of their online learning in the office.

The present study found that overall employees experienced positive learning experiences. The participants believed that computers are good aids to learning, help save a lot of time, and make learning more interesting. A look at the negatively worded items indicates that respondents disagreed that working with computers worries them or that the jargon baffles them, or that they seem to have difficulties. These are indicators that the respondents are computer savy as portrayed by their levels of computer competence.

Implication. Access is what is important regardless of whether owns a computer or not. Organizations should provide reliable equipment and opportunities for access.

Computer Competence and Training

Several studies have reported relationships between computer training and barriers. Technological training has been found to influence student perception (Wagner, Werner, \& Schramm, 2002) and computer self-efficacy (Cassidy \& Eachus, 2002). Berge, Muilenburg, and Haneghan (2002) reported 
that the experience or levels of barriers tend to decrease as computer expertise increases. Those with the lowest expertise are significantly above the average need for technical support (Berge, Muilenburg, \& Haneghan, 2002). Thus insufficient computer competence levels are a barrier to training (Gieskes, Hyland, \& Magnusson, 2002).

Implications and Recommendations

Provide training and development opportunities. Computer skills and training emerged as significant predictors of e-learning barriers, thus computer training should be provided. The need for computer competence and training was clearly evident throughout including comments from the open-ended question. Several quotes such as the one below affirm the technological barriers encountered by employees regardless of experience. This highlights the need for employers to offer computer software training.

"I have worked with computers for the past 11 years and I'm having problems moving around (the) site. I can't imagine what people with little experience are having."

In the present study, $41 \%$ of the respondents rated themselves as being experts and $54.3 \%$ as having intermediate computer competence. With such levels of computer skill and knowledge it is no wonder that technological barriers were rated weak ( $M=2.05$ ) on a 5-point Likert scale. Further, the participants' had strong e-learning self-efficacy, which was inversely related to barriers $(r=-.086 ; p=.011)$. Cassidy and Eachus (2002) compared untrained and trained 
groups and found that the trained group had significantly higher self-efficacy.

Computer training is therefore an important consideration for e-learning.

Enhancing self-efficacy requires more than just conveying positive appraisals (Bandura, 1994). Organizations should not only raise people's (elearners') beliefs in their capabilities, they should also structure situations in ways that will lead to success and avoid placing people in situations prematurely where they are likely to fail (Bandura, 1994). For example, demanding e-learning for employees who have no equipment or have poor computer skills could lead to failure, thus hindering their perceived e-learning self-efficacy. "Although selfefficacy judgments are functionally related to action, a number of factors can affect the strength of the relationship" (Bandura, 1986, p. 395). Perceived efficacy by itself can affect the level of motivation but it does not produce performance if one lacks the necessary sub-skills (Bandura, 1986). That is why it is important to provide training if skills are lacking.

Training promotes e-learners' operative capability. "Operative efficacy calls for continuously improvising multiple sub-skills to manage ever changing circumstances, most of which contain ambiguous, unpredictable, and often stressful elements. Even routinized activities are rarely performed in exactly the same way" (Bandura, 1986, p. 391). Computer and learning technologies are in a state of flux; thus the skills used for e-learning are continuously changing. This places a demand for employees to continuously acquire new skills and competencies. 
Quality versus quantity. Employers thus must provide computer and other software training that employees do not possess but require for e-learning. What is imperative is to realize that "it is the quality not the quantity of experience which is a critical factor in determining self-efficacy beliefs." (Cassidy \& Eachus, 2002, p. 135).

Employee commitment to learning. The implication for employees is that they should be ready to engage in life-long learning if they are to function competently. Continuos education through an ongoing commitment to education at all levels, and the support for growth and development are factors that facilitate organizational learning (Kreitner \& Kinicki, 2002).

Employers and supervisors could provide training opportunities through a variety of ways:

Vicarious experiences. This refers to creating and strengthening selfefficacy through social models (Bandura, 1994; Martocchio \& Hertenstein, 2003). Observing the success or failure of one's peers or models in doing similar tasks (in this case e-learning) can strongly influence one's self-efficacy (Campeau \& Higgins, 1995; Cassidy \& Eachus, 2002; Kreitner \& Kinicki, 2001). "Leaders can promote the value of learning by modeling the desired attitudes and behaviors." (Kreitner \& Kinicki, 2003, p. 682). Competent models transmit their knowledge through their behavior or teach their observers strategies for managing the environmental demands (Bandura, 1994). In this case, models can demonstrate e-learning strategies. Learning effective means of coping with environmental demands raises perceived self-efficacy (Bandura, 1994). In the case of e- 
learning, the observers could be novice employee e-learners and models could be those who have been successful in e-learning.

Thus to facilitate organizational learning through vicarious experiences, organizations could:

- Strive for relatively open boundaries with opportunities to observe others and an environment where problems are shared and errors are discussed and not hidden (Moingeon \& Edmondson, 1996, in Kreitner \& Kinicki, 2002). In elearning, this could encompass a discussion of technical barriers.

- Provide social models who are as similar as possible to the targeted observers (Bandura, 1994). In the case of employee online training, other employees who have had prior e-learning experiences could be models.

- Models must possess the competencies aspired to by the observers (Bandura, 1994). Therefore, employees who have been successful in elearning with the appropriate knowledge and skills could serve as mentors to new online learners.

- Modeling influence is more effective when models are similar to those observing them (Bandura, 1994). Therefore opportunities should be created at work where peers can learn from each other, for example, by building learning communities where employees can share acquired knowledge such as tips for online learning or by providing demonstration or chat sessions where peers could be involved as guest speakers. 
- Prioritize learning at work where peers are supported to train others and work with each other.

Prior Experience with Computers and the Internet

A study by Dyck and Smither (1994) found that for both younger (under 30 years) and older subjects, higher levels of computer experience were associated with lower levels of computer anxiety (a barrier). Similarly, Cassidy and Eachus (2002) reported that computer experience is the most significant predictor of computer self-efficacy (Cassidy \& Eachus, 2002).

A path model by Eastin and LaRose (2000) showed that Internet experience influences Internet Self-efficacy, which in turn influences Internet use and ultimately outcomes.

\section{Implications and Recommendations}

The indirect nature of relationships, for example, between computer experiences, self-efficacy, and barriers calls for further study.

Support and positive feedback should be offered to employees to ensure that their experiences are positive, as this is likely to boost their self-efficacy and probably reduce barriers.

"Prior experience is an antecedent of self-efficacy" (Eastin \& LaRose, 2000 p.4 citing Lewis, 1985). Although the test of relationship between perceived barriers and an employee's prior experiences with e-learning in prior and present organizations did not emerge as a significant, there is an indirect relationship 
since experiences predicts self-efficacy (Cassidy \& Eachus, 2002), and selfefficacy predicts e-learning barriers.

\section{Conclusion}

Sheets (1992) noted that it is possible that less than $10 \%$ of the variance regarding the prediction of persistence in distance learning is accounted for by demographic variables. Actually, the findings of this study supported this notion because only $3 \%$ was accounted for by demographic variables. It is no wonder that Sheets (1992) recommended that future studies should focus on other personal and situational factors that go beyond gender, age, and educational background, as presented above. The present study heeded to this advice and examined the influence of self-efficacy on perceived barriers.

\section{Research Question Five: The Relationship between Barriers and E-learning Self-Efficacy}

\section{Research Question 5}

The fifth and last research question investigated the relationship between perceived barriers and an employee's self-efficacy. The hypothesis predicted that a significant relationship exists between an employee's selfefficacy and perceived barriers. E-learning self-efficacy was a significant predictor of e-learning barriers. The significant relationships indicated their perception of their ability to undertake e-learning, not necessarily their level of skill because "Self-efficacy is not concerned with the skills one has but with 
judgments of what one can do with whatever skills one possesses." (Bandura, 1986, p. 391).

The ELSE scale measured the beliefs that the respondents held regarding their ability to undertake e-learning. A Pearson correlation yielded a significant relationship between perceived barriers and e-learning self-efficacy $(r=-.086 ; p=.011)$. The relationship was further investigated by looking at each of the seven types of barriers identified earlier (factors) against the overall ELSE score (Appendix L). Specifically, the results indicate significant relationships between self-efficacy and dispositional $(r=.026)$, learning style $(r=.013)$, and situational barriers $(r=.008)$. The fact that these correlations are rather low should be noted.

The relationship between the ELSE and BEL was negative. An inverse relationship suggests that the fewer the barriers an employee perceived the higher his/her e-learning self-efficacy was likely to be. Overall, the participants of this study had strong beliefs of self-efficacy $(M=74.93)$ and perceived few barriers $(M=83.33)$.

Success in any task is attained after generating and testing alternative forms of behavior and strategies, which requires perseverance and effort (Bandura, 1986). Those with self-doubt or low self-efficacy are quick to abort a task or process if their initial efforts prove deficient (Bandura, 1986). In the e-learning arena, participants with low self-efficacy are likely to quit e-learning altogether if they encounter barriers in the process. To increase self-efficacy, 
practitioners could provide experiential opportunities for trying out e-learning though demonstration courses and training.

The inverse relationship between barriers and self-efficacy confirms the findings of Collins (1982) cited in Bandura (1986) who found that highly selfefficacious students were usually quicker to discard faulty strategies and to display more positive attitudes towards a subject. Further, Cassidy and Eachus (2002) indicated that the perception that one has the capability to perform a task is likely to increase the likelihood of that task being successfully completed.

Implications and Recommendations

"Among the different aspects of self-knowledge, perhaps none is more influential in people's everyday lives than conceptions of their personal efficacy" (Bandura, 1986, p.390). In the context of this study, the influence of self-efficacy on e-learning, which is significantly related to barriers has several implications for e-learning stakeholders because self-efficacy has been reported to influence people's affective, cognitive, motivation, and self-regulation processes (Bandura, 1994). Specifically, self-efficacy influences:

- Task choice (Bandura, 1994; Cassidy \& Eachus, 2002)

- Amount of effort one puts on a task (Bandura, 1986; Cassidy \& Eachus, 2002)

- Persistence or perseverance when faced with obstacles (Bandura, 1986; Cassidy \& Eachus, 2002)

- Behavior (Bandura, 1986, 1994)

- Motivation (Bandura, 1986, 1994; Cassidy \& Eachus, 2002)1

- Causal attributions (Bandura, 1994)

- Performance (Bandura, 1986; Joo et al., 2000)

- Stress and depression (Bandura, 1994)

- Attitudes (Bandura, 1986, 1994)

- Outcome expectations (Bandura, 1986, 1994) 
- Success or failure (Cassidy \& Eachus, 2002; Kreitner \& Kinicki, 2001)

- Nature of feedback received (Kreitner \& Kinicki, 2001)

- Psychosocial functioning (Bandura, 1986)

- Goals set and commitment to such goals (Bandura, 1994)

- Perceived e-learning barriers (Mungania, 2003)

In the context of the present study, e-learning self-efficacy is likely to influence employee e-learners' affective processes (anxiety, stress), cognitive processes (goals and task orientation), motivation (causal attributions, outcome expectancies, and goals), and self-regulation processes (activities and environment). When faced with barriers, an employee's self-efficacy will affect some or all of the above-cited factors, an indication that self-efficacy is a critical factor in e-learning. E-learning self-efficacy beliefs must be strengthened and below are some of the recommendations and implications the findings of the present study have for practitioners.

Self-efficacy reflects what individuals believe they can do with the skills they possess (Eastin \& LaRose, 2000). Because perceived self-efficacy operates partially independently of underlying skills (Bandura, 1986), it is important to look beyond training as a way of reducing barriers. Other strategies that can promote self-efficacy are required. How can this be accomplished? In addition to other strategies, the four sources of self-efficacy beliefs (Bandura, 1986) can be tapped into as described below.

Enhancing self-efficacy through providing positive experiences. Prior experiences of success or failure are the most powerful source of self-efficacy (Bandura, 1989; Campeau \& Higgins, 1995; Cassidy \& Eachus, 2002). The 
MANOVA results showed that prior experience was not significantly related to barriers in the present study, although experience has been shown to affect selfefficacy (Eastin \& LaRose, 2000). However, a post-hoc analysis to determine the nature of the relationship between prior experience and self-efficacy shows a significant correlation $(r=-.112 ; p=.001)$, with prior experience accounting for $11 \%$ of the variance. Clearly, self-efficacy beliefs are supported by one's prior experiences (Kreitner \& Kinicki, 2001) and every employee's online experiences should be as positive as possible because, as the present study found, experience could influence their e-learning self-efficacy.

Eighty percent of the sample had taken between one and ten online courses, an indicator that this was an experienced group. In total, $86.5 \%$ of the respondents indicated that overall their e-learning experiences had been positive, and that they had strong e-learning self-efficacy beliefs. This further shows the effect of prior experiences on promoting e-learning self-efficacy and supports the view that practitioners should strive to provide positive e-learning experiences. Critical impressions are formed during one's first e-learning experience and one's initial experience determines one's optimism about subsequent e-learning experiences (Rossett, 2002). The implication for practice is to provide first time elearners with positive experiences with as few barriers as possible.

Enhancing self-efficacy through verbal persuasion. Participants expressed the need for feedback and support. Peoples' self-efficacy beliefs can be raised through verbal persuasion (Bandura, 1986) by others such as supervisors, peers, relatives, or significant others. This has implications for many e-learning 
stakeholders because the feedback given to an employee can affect their selfefficacy. Managers need to become e-learning advocates and verbally persuade employees of its value and credibility. Experimental groups receiving both vicarious experiences and verbal persuasion have been found to show gains in self-efficacy compared to control groups receiving training only (Martocchio \& Hertenstein, 2003 citing Eden \& Kinmar 1991). Persuasion of one's capabilities to master some activity are likely to lead to greater effort to sustain that activity (Bandura, 1994). On the other hand, disbelief in one's capabilities creates behavioral validation (Bandura, 1994). Positive reinforcement, internal and external feedback (Bandura, 1994, Martocchio \& Hertenstein, 2003) to nurture self-efficacy are recommended. Future researchers should embark on a study of these and other possible ways to increase self-efficacy among e-learners.

Enhancing self-efficacy through affective arousal. To some extent, people rely on physical and emotional arousal to judge their capability (Bandura, 1994; Campeau \& Higgins, 1995; Cassidy \& Eachus, 2002; Kreitner \& Kinicki, 2001). Anxiety (Campeau \& Higgins, 1995; Cassidy \& Eachus, 2002), stress, depression, and tension are some of the affective characteristics of people with low self-efficacy and are usually interpreted as signs of vulnerability to poor performance (Bandura, 1994). Although overall barriers were not rated highly, techniques that enhance positive mood, which enhances perceived self-efficacy (Bandura, 1994) should be used. To boost self-efficacy among employees, the challenge for e-learning stakeholders is to remove barriers that could lead to feelings of inadequacy and to reduce stress caused by e-learning barriers. 
Bandura (1994) states that people who have a high sense of self-efficacy are likely to view affective arousal as an energizing facilitator of performance.

To boost self-efficacy, computer training is not enough as Bandura (1986) argues:

Efficacy in dealing with one's environment is not simply a matter of knowing what to do. Nor is it a fixed act that one does or does not have in one's behavioral repertoire... Rather it involves a generative capability in which cognitive, social, and behavioral sub skills must be organized into integrated courses of action to serve innumerable purposes (p. 391).

This quote indicates that different skills and resources are called for and more than one factor affects self-efficacy. The present study's findings tie into the social cognitive theory concept of "triadic reciprocity" between cognition, behavior, and the environment illustrated in Figure 8.

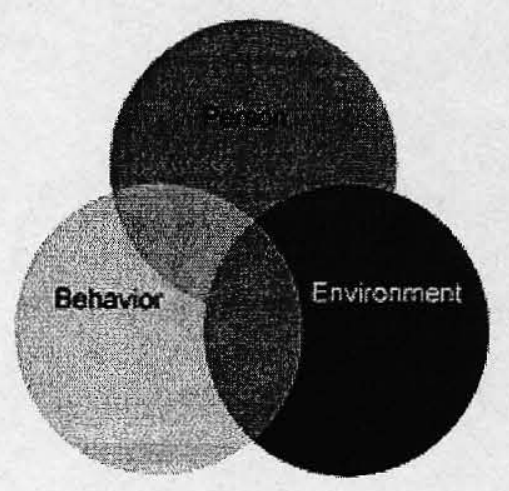

Figure 8: Triadic reciprocity between person, behavior, and the environment

The findings resulted in four predictors of barriers: (a) computer competency, (b) computer training, (c) self-efficacy, and (d) organizational factors. The first three factors relate to an employee's cognitive attributes. In particular, self-efficacy has been found to influence activity and environment selection (Bandura, 1994). Since self-efficacy is domain specific (Joo, Bong, \& 
Choi, 2000), e-learning self-efficacy was measured and the results showed that e-learning self-efficacy affects one's perception of barriers. The results of this study were somewhat consistent with Bandura's social cognitive theory that personal efficacy affects human accomplishments (Bandura, 1994).

An employee's organization relates to the environment an employee is in Environmental factors are influential and the present study found a significant correlation between an employee's organization and perception of barriers.

Assess e-learners' self-efficacy. Why is determining self-efficacy important? Bandura's claim that "people must have a robust sense of personal efficacy to sustain the perseverant effort needed to succeed." (Bandura, 1994, Section III, 1). "Examining self-efficacy as a training outcome is pertinent, and it holds implications for subsequent job performance." (Martocchio \& Hertenstein, 2003, p. 417). The researcher supports this notion that self-efficacy is a basic evaluation criteria that should be measured (Martocchio \& Hertenstein, 2003), backed by finding that self-efficacy emerged as a significant predictor of eleaning barriers. Research evidence also shows the positive influence selfefficacy has on declarative knowledge especially in computer software training (Martocchio \& Hertenstein, 2003).

As with any other evaluation, determining e-learning self-efficacy is not a one-time event because it arises from gradual acquisition of complex cognitive, social, linguistic, and/or physical skills through experience (Gist, 1987 cited in Kreitner \& Kinicki, 2001). E-learning stakeholders should be equally concerned 
with e-learners self-efficacy as they are with other skills because to function competently, one requires both skills and self-efficacy (Bandura, 1986).

The issue is how to intervene in order to ensure that the gap between knowledge and skill and action is closed. This can be achieved through interventions that help increase self-efficacy and through training. It is no wonder these two variables (computer competency and training) significantly predicted elearning barriers.

While there is always an emphasis on skills, possessing skills is one thing but being able to use them is another. That is why different people with similar skills or the same person on different occasions may perform poorly in one situation and extraordinarily in another (Bandura, 1986). In essence, self-efficacy is situational and domain specific. The researcher recommends determining the self-efficacy level of e-learners and putting measures that enhance self-efficacy in place. Although one might be successful in other endeavors, it does not necessarily mean that they are confident about one's e-learning. Knowing this in advance could help put appropriate interventions in place.

\section{Conclusion}

The discussion of the findings clearly indicates the multi-dimensional nature of e-learning barriers, which can be resolved by employing system-wide interventions. Some of the measures that have the potential to reduce barriers, raise e-learning self-efficacy among employees, and to improve e-learning 
offerings were discussed. However, since solutions to barriers were beyond the scope of this study, they need to be investigated in future research.

Implications for Using Web-based Surveys for Organizational Research

Web-surveys are a recent addition to research tools for organizational research. Web surveys such as the one used in this study had several advantages such as time and cost savings, broader reach of geographically dispersed respondents, and greater accuracy and fewer missing values (cited in Simsek \& Veiga, 2001). Some of the most problematic and controversial aspects of Internet surveys include representativeness of samples, sampling frames, response rates, anonymity, and confidentiality (Simsek \& Veiga, 2001). For example, the researcher could not follow-up with the non-respondents since the survey was anonymous. Some of the lessons learned and implications for practice with regard to the use of Web-based surveys include:

Communication: Contact persons in the seven organizations championed the study, which is a critical aspect of organizational research. To keep them informed, the researcher used the timeline (see Table 2) and sent regular emails on what they needed to do, when, and how. This was sent to them in advance and communication was frequent, usually via email and occasionally by phone. Their advice was also sought since they knew their respective organizations better than the researcher did. They were instructed to modify emails to respondents to fit their organizational culture. 
Security of the data: The need to back up data, not only on the computer but also on a secure server is critical. Computer crashes, viruses, or lost disks can result in loss of valuable data. Unlike mailed surveys, Web-surveys rely entirely on electronic data, which can be lost with a click of a button. The researcher's recommendation is to constantly backup data in multiple locations.

Confidentiality and access: Using passwords can boost confidentiality online and limit access to the appropriate sample. Some knowledge of HTML is helpful and in the present study, the researcher used a HyperText Markup Language (HTML) code as the survey "header" to restrict access. Once a potential respondent typed in the survey's URL (website address), a pop-up window would request for a password, which was intended keep the general Internet public from responding to the Web survey. The researcher had earlier communicated the password to the respondents through the contact persons in each organization. Although emails have confidentiality limitations, this was the only means of communication. Personal information was kept confidential and the results reported the aggregate data. Storing data in a third party server (not the organization's server) is recommended, as this boosts respondents' perceived confidentiality of their responses.

Anonymity and volunteer considerations: The researcher promised anonymity and did not seek any personal identifiers such as names, addresses, or their emails. Other researchers such as Biner, (1993), Franklin, Yoakam, and Warren (1996), and Magalhaes and Schiel (1997) have emphasized voluntary and anonymous questionnaires. Unless knowing people's names will add value 
to a research study, the survey can be set up anonymously. However, total anonymity has implications for future follow-ups on non-respondents.

Timing: The day that the survey is released or emails are sent to potential respondents is critical in Web-based organizational surveys. After consulting with the contact persons, they recommended sending emails to potential respondents on Fridays or Mondays. Friday notifications were recommended to target employees who work over the weekend, those who may have time to respond at home, and to ensure that on Monday, everyone will have that email in their email inbox at the beginning of the week hence boosting chances of response.

Knowing organizational schedules could be helpful in determining the timing and researchers should take into consideration the business seasons (fiscal or academic year). For example, employees of the public school district were on summer vacation at the time of data collection and this affected the response rate because many employees reportedly did not use their "school" emails as often during the summer. Surveys targeting teachers or students should take into consideration the effect summer break could have on the response rate. Another example is the business seasons. Researchers must keep important dates in mind, for example, end of the fiscal year for each organization. Seeking this information in advance can guide the research timeline. The summer break (in the public school district) and the end of the fiscal year in some of the participating organizations might have affected this study's response rates. 
Testing: Before sending out any emails to potential respondents, the researcher tested the survey to ensure that the (a) survey website could open using the allocated password, (b) data was being collected in the database, and (c) data could be downloaded from the database into an appropriate format. The researcher's numerous tests and pilot test confirmed the usability of the survey before the main study.

Results: The researcher let the respondents know how they could get the results of the survey by emailing the researcher, whose email address was included at the end of the survey and in all the emails.

In-house Champion: It became very clear that for an external researcher needs an in-house champion who will assist in the administration of the instrument or communicate and motivate employees to participate. The researcher utilized contact persons in each organization most of whom were in authority and had direct access to the target employees.

Just like any other research study, the present study had some limitations as discussed next.

Limitations

There were certain limitations that the researcher faced while collecting and analyzing the data that are worth noting because future researchers could benefit from these experiences. 
Sampling method. This study was based on a purposive sample made up of employee e-learners drawn from a convenience population in seven organizations. "A convenience sample also makes it difficult to randomly assign individuals to groups, a hallmark of a true experiment." (Creswell, 2003, p. 164). Thus the findings of this study are generalizable only to those organizations that are similar to those under study, although these findings are definitely valuable for a variety of e-learning stakeholders.

Limited access. Since the data collection for this study was conducted online using a Web-based survey, access was limited to only those who have been granted the access password and to those who had access to a computer, email, and the Internet at the time of data collection.

Response rate. The researcher was not able to ascertain the exact response rate in one organization due to communication problems. There was uncertainty about pre-determining the main study's response rate because Websurveys have a very wide range of response rates from $7 \%$ to $76 \%$ (Simsek \& Veiga, 2001). Similar varying response rates were reported by the contact persons in organizations under study - ranging from $10 \%$ to $100 \%$ in their previous surveys. The big difference in response rates between the pilot study $(52.5 \%)$ and the main study (18\%) clearly illustrate this limitation. The $18 \%$ response rate is a limitation to the generalizability of these results. Some of the reasons regarding non-response were evident in the comments by some participants such as a lack of commitment, fear of evaluation, and time limitations. 
Access to participants. The researcher relied on the willingness and reliability of the contact persons in each participating organization to forward requests to the targeted population. This was a limitation because the researcher did not have direct access to the population. For example, it affected the response rate because one of the contact persons was unavailable to send the second reminder.

Subjectivity. This study depended on self-reported data from the participants. This study had an evaluation component to it since e-learners gave their reactions towards their e-learning experiences. "Every evaluation has some aspect of bias within it, ranging from choosing metrics to foregone conclusions" (Kidney, 2001, p.27). To minimize bias, the present study used subject matter experts and a pilot group to the reliability of the scales, leading to measures with high validity and reliability. However, some forms of bias such as social desirability effects where some e-learners may state that there are no barriers to e-learning, because they believe that this is the socially acceptable position, cannot be ruled out.

Communication. During the data collection process, there was a communication breakdown in Organization 7 (military). Communication problems emerged especially in the military organization, due to their culture and hierarchy. Some of the commanders gave instructions that were erroneous, leading to the elimination of some cases (five employees) who cited problems that they faced during their online courses (not taught by the military) in other institutions. For example, one employee wrote, "I completed almost all of my Bachelor's Degree 
on line. And for some of these questions it varies greatly depending on both the instructor and the students in the class." This clearly indicates that this particular individual could have responded to the survey without paying attention to the instructions that required them to only include their perceptions regarding elearning in their current organization. While their other experiences could be valid, they were outside the scope of this study. Also, there was evidence of some employees who had not participated in e-learning in the public school district, but completed the survey. This employee said, "Actually have not taken any course beside the initial course, which qualifies me to complete e-learning." Such cases were identified and eliminated from the final data but readers should interpret the results from the military organization and the public school district with caution.

Specificity. There were comments that were not very specific enough to reveal the actual problem. For example, some would state that they had server or LMS problems. This really does not reveal much about the exact nature of the problem encountered.

Sample sizes. The results might also have been skewed due to the disproportionate sample sizes in some of the organizations, ranging from 8 to 256. Standard error of the statistic increases with a small sample size (Hinkle, Wiersma, \& Jurs, 1994).

Multiplicity of barriers across various factors. E-learning barriers were divided into categories (emerging from the factor analysis and the open-ended responses). When interpreting these barriers, the researcher cautions that the 
presence of these barriers and their placement in each category should not be used primarily to lay blame on any particular group because these barriers emerge from multiple factors and not any one particular source.

Certain problems such as connectivity and access were common, but it was not possible to place the original source of the problem. Access barriers can be faced at home, in the office or from other locations. It was not clear whether access was a download problem due to size of files, Internet speed, or if it resulted from a lack of knowledge on how to do access the course. Registration function problems is another issue that could result from technology (software configurations), instructional design (function not enabled), or effectiveness of organizational processes. This indicates that although a barrier could be placed under one category, it actually could be a result of many other factors. As a matter of fact, all e-learning stakeholders need to realize that solutions to these barriers will be more effective if all parties are involved in resolving them.

Confidentiality and anonymity issues. The researcher promised confidentiality and anonymity by not asking respondents for their email addresses, names or any other personal identifiers. However, this made it virtually impossible to follow up with the non-respondents, an essential research practice. Researchers can and should provide anonymity if demanded by the participants but should recognize the repercussions of such anonymity in following up.

Fear or threat of evaluation research. The present study evaluated employees' perceptions towards their e-learning experiences. It became clear to 
the researcher that some of the individuals and organizations contacted seemed threatened or reluctant to participate in the present study. In the process of recruiting organizations to participate, the researcher encountered several cases that indicated their unwillingness to participate because of the exposure that a research study would reveal about their organization. One potential organization noted that they were unwilling to participate because of recent organizational investigations following the 'ENRON' scandal. Organizational leaders definitely need to realize the value (the good) that emerges from an evaluation and research such as this one. Future researchers need to be forewarned about possible resistance when recruiting research participants. Researchers can and should provide anonymity when discussing results if required.

Differences in groups by response date: It was not possible to determine differences by groups based on their response date (early versus late respondents) because the dates of survey completion were not captured in the electronic data file. During the actual data collection, the researcher accessed the server at the beginning of each week and determined the number of respondents for the previous week. At the end of the study, the server data were deleted out of the server including the completion dates thus it was not possible to compare the early versus late respondents. 
Change of context. Future research should focus on other types of organizations not examined in this study. For example, studies on e-learning experiences in the non-profit sector need to be done. The organizations involved in this study were large organizations with employee sizes of up to 100,000 . Four of these organizations were international for-profit companies. It is time for researchers to turn their attention to small-sized organizations using e-learning.

Triangulation and use of mixed methods. At the conceptualization of this research study, the researcher encountered an array of variables that accompany e-learning making it difficult to capture all of them in a survey. The researcher used an open-ended question in both the pilot study and main study and these elicited rich and valuable data because the participants had an opportunity to list other barriers that they experienced that had not been captured in the survey. Creswell (2003) notes the increasing use of mixed methods in all fields. Several types of data collection methods commonly used include experiments, surveys, interviews, content analyses, demographic analyses, and focus groups (Franklin, Yoakam, \& Warren, 1996). Future studies on e-learning could incorporate other research methods and techniques.

Solutions to e-learning barriers. Knowing barriers experienced by elearners is not enough. The researcher attests to Magalhaes and Schiel's (1997) recommendation of seeking suggestions for improvement from learners. Identifying barriers and solutions is not a one time event but should be a 
continuous process due to the constantly evolving environments, employees, course offerings, and learning technologies.

Best practices in e-learning: Barriers do exist but so do best practices in elearning. The present study revealed weak barriers, an indication that these organizations are engaged in some best practices. Apparently some of these organizations have learned a lot through their experiences with e-learning. Elearning barriers can be reduced by organizations sharing their best practices. Future studies need to research and document what these best practices are.

Multidimensional view of e-learning barriers. As did the present study, future research on e-learning barriers should not limit their focus on technological issues. Findings clearly show heterogeneous barriers. Hatcher and Mungania (2002) suggest an evaluation matrix that could guide future evaluation studies on who, where, when, and what information to seek when evaluating e-learning. Evaluation studies in e-learning need to be continuous due to variables that are in a constant state of flux.

International studies. "The nature of e-learning clearly defies any traditional geographical boundaries" (Mungania, 2003, p. 496), thus future elearning research should embrace organizations in the developing world that offer online training. The results indicated that employees in the India-based IT Consulting company experienced the most barriers compared to the other organizations across six of the seven factors. The Oil exploration and manufacturing company, a Global company had the highest situational barriers $(M=3.00)$. It was not clear whether location played a factor. More international 
studies with country specific information could add value since e-learning is engulfing all cultures. The participants of the present study, for example, were not limited by geographical location, thus confirming the ubiquity of e-learning. Web surveys such as the one used in the present study also indicates the utility of the Internet as a viable tool for data collection for geographically dispersed populations.

Comparative studies. The results of the present study indicated significant differences among barriers in organizations. There were sectorial differences and similarities. Future studies should delve deeper into this issue to determine the exact nature of these differences and/or similarities, why they occur, and their impact on e-learning. E-learning experiences in small versus large organizations and non-profits versus for-profits, among other categorizations need to be compared. The possibilities of comparative studies on e-learning that will provide more extensive data are unlimited.

Learner characteristics. As discussed earlier, most of the findings of the present study either confirmed or contrasted with what other research has found with regard to the influence of e-learners' demographics and background characteristics. Clearly, such conflicting results indicate that this is an area that deserves further research.

In addition, the population accessing e-learning indicates disparities. For example, gender disparity was clearly evident in the population with $36 \%$ being female. This wide gap makes it questionable why there are much fewer women engaging in e-learning. 
Considering the continued trend of the use of e-learning around the world and globalization in general, the imperative of e-learner demographics have various implications for e-learning as other researchers have noted. Knowledge of learner characteristics could be used to predict learners' persistence or attrition (Giles, 1999); to inform on learners being served (Franklin, Yoakam \& Warren, 1996), and to aid in program planning and policy formulation (Sheets, 1992). Further research is warranted.

Research subjects. In 1999, Feldhaus commented, "Research has not moved into the realm of student-based perceptions regarding the DE experiences" (p.6). This is a gap that this and other studies have bridged but researchers need to move beyond evaluating learners to include other subjects such as instructors (on-site teacher), mentors (distance facilitators), support staff, administrators, instructional designers, management, and community members as recommended by Hatcher and Mungania (2002). This study only focused on barriers faced by e-learners and excluded experiences of other e-learning stakeholders who are involved in the design, development, teaching or implementing e-learning. The preponderance of research on students especially in higher education settings indicate a need for future studies to focus more on other e-learning stakeholders.

Comparison of blended learning with e-learning. This study targeted employees who have participated in e-learning courses that were delivered $100 \%$ online. In addition to online instruction, many organizations are increasingly incorporating various instructional media with the recent trend being "blending 
learning" (Hofmann, 2002; Masie, 2002). Thus future studies could compare barriers in blended learning versus e-learning. Due to the multi-faceted variables as indicated by the results of the present study, those who engage in such studies should be forewarned that blended learning involves innumerable factors thus case studies are recommended.

Survey questions. Since research is about improving the current practice and knowledge, the researcher noted some revisions that could make the instrument better. For example, the survey should include a question asking about the location of the participants, especially in a survey dealing with international populations, where geographic location becomes an important consideration. It would be informative to know how geographical location could be a barrier to accessing content due to technology, language, or country restrictions exist. Secondly, a question asking respondents whether or not they completed online course(s), needs to be included. For the open-ended question on barriers, it would have been helpful to know which particular course an employee was referring to for the purpose of making changes to that particular course. Some respondents were confused by the order of the questions because the barrier questions were primarily in a negative mode while the self-efficacy questions used both positive and negative modes. Respondents seemed to have a problem dealing with reverse-worded questions. These are some of the revisions that will be made to the instrument for future use.

Data collection procedure. A Web survey was used for data collection in this study. Some of the problems experienced with the Web-survey include 
technological and logistical problems. The researcher relied on the willingness and reliability of the contact persons in each participating organization to forward requests to the targeted population to respond to the survey. This was a limitation because the researcher did not have direct access to the population thus losing a certain level of independence. The contacts were extremely valuable in this study and they were cooperative. However, direct communication with respondents is a key advantage in every study and having to go through an intermediary inhibits this process.

Culture. Cultural issues emerge when dealing with international populations; thus cultural sensitivity is quintessential. The effect of culture was evident during data collection. For example, discomfort was evident among some of the international participants in divulging their demographic characteristics. Many left such items blank while others complained about their inclusion in the survey. While demographics are a regular feature in most US surveys, international populations seemed apprehensive about demographic questions especially pertaining to race and ethnicity.

Timing of data collection. When conducting an evaluation, it is important to consider the timing of the administration of the final questionnaire (Biner, 1993). Although the researcher consulted with the contact persons to determine the best timing for data collection, the fact that organizations operate on different fiscal years and holiday schedules impacted the data collection. For example, employees of the public school district employees were out on summer vacation and this impacted their response rate. Similarly, during the data collection, one 
organization was closing their fiscal year and this led to an extension of the deadline to respond. Researchers should note that timing is critical and the researcher must collaborate with the client or contact persons when scheduling for data collection. Biner (1993) suggests that the administration of the survey should be scheduled well in advance of the actual date of administration.

Generalizability: Generalizability was limited to some extent because a sample of convenience was used. However, in general, social science research findings can be generalizable to similar groups or organizations. E-learning offerings differ within and among organizations, but research findings such as this study's could be informative to e-learning stakeholders. Future studies could replicate this study using random sampling.

Use of research findings: According to Hawksley and Owen (2002, p. 42), "What distinguishes providers with the most successful outcomes from others was the use they made of the survey results, feedback from learners or the record of complaints". The recommendation is to use the results from this and other research studies to make modifications that will enhance e-learning programs. "Companies and educational institutions are encouraged to take a highly systematic approach to designing, developing, delivering, and evaluating the results of all e-learning offerings" (Kirk, 2002, p. 10). 
This study has added to our knowledge on e-learning barriers and their predictors, e-learning self-efficacy, the use of Web-surveys in organizational surveys, and the state of e-learning in organizations. This study used existing theories such as the social cognitive theory, Internet- and computer self-efficacy, but it also updated existing conceptual frameworks on e-learning barriers.

Specifically, the present study's findings clearly revealed the positive experiences (limited barriers) with e-learning. Employee e-learners indicated high self-efficacy ratings, nonetheless, some barriers were perceived in the process of starting, continuing, and completing e-learning.

The nature of e-learning barriers is multi-dimensional and systemic in nature as indicated by the seven factors or types of barriers that emerged, namely: (a) Dispositional, (b) learning style, (c) instructional, (d) situational, (e) organizational, (f) content-suitability, and (g) technological.

E-learning barriers exist in all organizations but the nature of these barriers significantly differs among organizations. However, there are some similarities too. The bottom line is that barriers must be addressed and measures to reduce them put in place. The results of the present study show laudable results of positive experiences with e-learning in the participating organizations. Overall, barriers were rated low and participants rated their e-learning experiences positively. 
Four factors emerged as significant predictors of e-learning barriers in this study, namely, an employee's (a) e-learning self-efficacy, (b) computer competence, (c) computer training, and (d) organization.

E-learning barriers have a negative relationship with computer competence, computer training, and e-learning self-efficacy, an indication that what organizations need to do is to raise the employees' level of computer competency through increased computer training opportunities and strive to increase e-learning self-efficacy through various techniques. Strong self-efficacy belief are essential if one is to remain task oriented when faced with obstacles (Bandura, 1994). E-learners will definitely encounter barriers along the e-learning journey. The heterogeneous nature of e-learning barriers clearly indicates that all e-learning stakeholders have some responsibility in resolving them and everyone must make a concerted effort to reduce individual, group, organizational, and environmental barriers.

Helping employees improve their knowledge and skills has always presented many challenges and will continue to do so. Technological barriers were present thus e-earning stakeholders must recognize that technology is only a tool for teaching and learning that they are empowered to reinvent (customize) it to meet their needs. Besides the threat of barriers, lie limitless opportunities and possibilities. The ultimate challenge is to learn from past successes, mistakes, and research findings. 


\section{REFERENCES}

Ahn, I. C. (1999). Relationship of personality types and learners' performance in computer-mediated distance education. (Doctoral dissertation, Purdue University, 1999).

American Society for training and Development (ASTD) \& National Governors Association (NGA). (2001, June). A vision of e-learning for America's workforce. Report of the Commission on Technology and Adult Learning. Alexandria, VA: ASTD.

American Society for Training and Development (ASTD) \& Masie Center (Masie). (2001). E-learning: If we build it, will they come? Alexandria, VA: ASTD.

ASTD. (1998). Learning Technology Research Report. Alexandria, VA: ASTD.

Babbie, E. (1998). Survey research methods. ( $2^{\text {nd }}$ ed.). Belmont, CA: Wadsworth Publishing Company.

Bandura, A. (1999). A social cognitive theory of personality. In L. Pervin \& O. John (Ed.), Handbook of personality ( $2^{\text {nd }}$ ed., pp. 154-196). New York: Guilford Publications. (Reprinted in D. Cervone \& Y. Shoda [Ed.], The coherence of personality. New York: Guilford Press.)

Bandura, A. (1997). Self-Efficacy. Harvard Mental Health Letter, 13(9), 3-4.

Bandura, A. (1994). Self-efficacy. In V. S. Ramachaudran (Ed.). Encyclopedia of Human Behavior, 4, 71-81. San Diego: Academic Press, 1998). Retrieved on December 14, 2003, from http://www.emory.edu/EDUCATION/mfp/BanEncy.html

Bandura, A. (1986). Social foundations of thought and action. Englewood, CA: Prentice Hall.

Bandura, A. (1977). Self-efficacy: Toward a unifying theory of behavioral change. Psychological Review, 84, 191-215.

Baumgartner, G. (2000). Strategies for effective online education. New York: Forbes Custom Publishing. 
Belanger, F. \& Jordan, D. H. (2000). Evaluation and implementation of distance learning: Technologies, tools, and techniques. Hershey, PA: Idea Group Publishing.

Berge, Z. L. (2002). Obstacles to distance training and education in corporate organizations. Journal of Workplace Learning, 14(5), 182-189.

Berge, Z. L. (Ed.). (2001). Sustaining distance training: Integrating learning technologies into the fabric of the enterprise. San Francisco: Jossey-Bass.

Berge, Z. L. (1998, Summer). Barriers to online teaching in post-secondary institutions. Online Journal of Distance Learning Administration, 1(2). Retrieved on January 9, 2004, from www.westga.edu/ distance/Berge12.html

Berge, Z. L., Muilenburg, L., \& Haneghan J. V. (2002). Barriers to Distance Education and Training: Survey Results. Quarterly Review of Distance Education, 3(4), 409-418.

Berge, Z. L. \& Muilenburg L.Y. (2000). Barriers to distance education as perceived by managers and administrators: Results of a survey. In M. Clay (Ed.). Distance Learning Administration Annual. Retrieved on January 9,2004 , from http://www.emoderators.com./barriers/man admin.shtml

Biner, P. M. (1993). The development of an instrument to measure student attitudes toward televised courses. The American Journal of Distance Education, 7(1).

Bischoff, A. (2000). The elements of effective online teaching: Overcoming barriers to success. In K. W. White \& B. H. Weight (Eds.). The online teaching guide: $A$ handbook of attitudes, strategies and techniques for the virtual classroom. Needham Heights, MA: Allyn and Bacon.

Bonk, C. J. (2001, May). Online teaching in an online world. Bloomington, IN: CourseShare.com. Retrieved on January 9, 2004, from http://www.publicationshare.com/docs/corp survey.pdf

Broskoske, S. L. \& Harvey, F. A. (2000). Challenges faced by institutions of higher education in migrating to distance learning. (ERIC Document Reproduction Service No. ED455761).

Campeau, D. R. \& Higgins, C. A. (1995 June). Computer Self-Efficacy:

Development of a measure and Initial Test. MIS Quarterly, 189-211. 
Cassidy, S. \& Eachus, P. (2002). Developing the computer self-efficacy (CUSE)

Scale: Investigating the relationship between computer self-efficacy, gender, and experience with computers. Journal of Educational Computing Research, 26(2), 133-153.

Champagne, M. V., Wisher, R. A., Pawluk, J. L. \& Curnow, C. K. (n.d.) An assessment of distance learning evaluations.

Chandler, D. (2003). Technological or Media Determinism. Retrieved on December 30, 2003, from

http://www.aber.ac.uk/media/Documents/tecdet/tdet01.html

Charner, I., \& Fraser, B., S. (1986). Different strokes for different folks: Access and barriers to adult education and training. (ERIC Document Reproduction Services No. ED268367).

Chidambaram, L. \& Zigurs, I. (2001). Our virtual world: The transformation of work, play and life via technology. Hershey, PA: IDEA group Publishing.

Chu, H. \& Hinton, B. E. (2001). Factors affecting student completion in distance learning mediated HRD baccalaureate program. In A. O. Aliaga (Ed.). Proceedings of the Academy of Human Resource Development (AHRD) 2001 Conference, 1, 85-92.

Christoph, R. T., Shoenfeld, G. A., \& Tansky, J. W. (1998). Overcoming barriers to training utilizing technology: The influence of self-efficacy factors on multi-media based training deceptiveness. Human Resource Development Quarterly, 9(1), 25-38.

Colbrunn, S. R. \& Tiem, D. M. (2000). From binders to browsers: Converting classroom training to the Web. Performance Improvement, 39(2), 35-40.

Coldeway, D. O. (1986). Learner characteristics and success. In I. Mugridge \& D. Kaufman (Eds.), Distance Education in Canada, pp. 81-87. London: Croom Helm.

Colton, S. (2001). Developing an instrument to analyze the application of adult learning principles to World Wide Web distance education courses using the Delphi technique. (Doctoral dissertation, University of Louisville, 2001).

Conway, M. \& Thomas, S. (2003 January). Using electronic surveys. Info-line, Issue No. 0301. Alexandria: American Society for Training \& Development (ASTD). 
Cookson, P. S. (1990). Persistence in distance education: A review. In M. Moore, P. Cookson, J. Donaldson, \& B. A. Quigely (Eds.). Contemporary issues in American distance education. Oxford: Pergamon Press.

Creswell, J. W. (2003). Research design: Qualitative, quantitative, and mixed methods approaches. ( $2^{\text {nd }}$ ed). Thousand Oaks: Sage Publications.

Creswell, J. W. (1994). Research design: Qualitative and quantitative approaches. Thousand Oaks: Sage Publications.

Cyrs, T. E. \& Conway, E. D. (1997). Teaching at a distance with the merging technologies: An instructional systems approach. New Mexico: Center for Educational Development, New Mexico State University.

Delcourt, M. A. B. \& Kinzie, M. B. (1993). Computer technologies in teacher education: The measurement of attitudes and self-efficacy. Journal of Research and Development in Education, 27(1), 35-41.

Dereshiwsky, M. I. \& Moan, E. R. (2000, November). Good connections: Strategies to maximize student engagement. Education at a Distance, 14(11).

Dhanarajan, G. (1998). Delivery of Training Programs: Changing design. (ERIC Document Reproduction Services No. ED420745).

Dick, W., Carey, L., \& Carey, J. O. (2001). The systematic design of instruction. $\left(5^{\text {th }}\right.$ ed.). New York: Longman.

Dyck, J. L. \& Smither, J. A. A. (1994). Age differences in computer anxiety: The role of computer experience, gender, and education. Journal of Educational Computing Research, 10(3).

Digital Divide Network (2003). Retrieved February 5, 2003 from http://www.digitaldividenetwork.org/content/sections/index.cfm?key=3

Eastin, M. S. \& LaRose, R. (2000). Internet Self-efficacy and the psychology of the digital divide. Journal of Computer-Mediated Communication, 6(1). Retrieved January, 9, 2004, from http://www.ascusc.org/icmc/vol6/issue1/eastin.html

Evans, C. (1989 fall). Breaking through barriers to adult learning. Equity and Excellence, 24(3), 28-29.

Fahy, P. J. (1991). Adult Literacy Learning and Computer Technology: Features of Effective Computer-Assisted Learning Systems. (ERIC Document 
Feldhaus, C. R. (1999). An exploratory study: Differences in the online learning experiences as perceived by participants of different backgrounds. (Doctoral dissertation, University of Louisville, 1999).

Fjortoft, N. F. (1995, October). Predicting persistence in distance learning programs. Paper presented at the Mid-Western Educational Research Meeting. Chicago, IL. (ERIC Document Reproduction Service No. ED387620).

Franklin, N., Yoakam, M., \& Warren, R. (1996). Distance Learning: A guidebook for system planning and implementation. Bloomington, IN: Indiana University, School of Continuing Studies, 7-1, 7-22.

Furnell, S. M., Evans, M. P., Phippen, A. D, Abu-Rgheff, M, N. (1999). Online distance learning: Expectations, requirements, and barriers. Virtual University Journal, 2, 34-44.

Galusha, J. M. (1998). Barriers to learning in distance education. (ERIC Document Reproduction Service No. ED416377).

Garland, M. (1993). Student perceptions of the situational, institutional, dispositional, and epistemological barriers to persistence. Distance Education, 14(2), 181-198.

Gieskes, J. F. B., Hyland, P. W., \& Magnusson, M. G. (2002). Organizational learning barriers in distributed product development: Observations from a multinational corporation. Journal of Workplace Learning, 14(8), 310-319.

Giles, I. M. (1999). An examination of persistence and dropout $n$ the online computer-conferenced classroom. (Doctoral dissertation, Virginia Polytechnic Institute and State University, 1999). (UMI No. 9953808).

Gilpin, V. (2000). Best practice in innovative learning: Information technology as a catalyst for change. A summary of recent African experience. Retrieved on September 19, 2001 from www.crite.net/Conferences/2000/isc1/Focus On Africa.html

Gist, M. A. (1987). Self-efficacy: Implications for organizational behavior and human resources management. Academy of Management Review, 1, 472.

Glanz, J. (1998). Action research: An educational leader's guide to school improvement. Norwood, MA: Christopher-Gordon Publishers, Inc. 
Gorard, S. \& Selwyn, N. (2000). Researching the role of digital technology in widening participation. (ERIC Document Reproduction Service No. ED45442).

Harry, K. \& Peratton, H. (1999). Open and distance learning for the new society. In K. Harry (Ed). Higher education through open and distance learning: World review of distance education and open learning: Volume 1. London: Routledge.

Hatcher, T. (2002). Ethics and HRD: A new approach to leading responsible organizations. Cambridge, MA: Perseus Publishing.

Hatcher, T. \& Mungania, P. (2002). A matrix for the development of instruments to evaluate web-based courses and programs. In The18h Annual Conference on Distance Teaching \& Learning Proceedings. Retrieved December 8, 2003, from www.uwex.edu/disted/conference/proceedings/DL2002 W2.pdf

Heylighen, F. (2003). Web Dictionary of Cybernetics and Systems. Retrieved on December 30, 2003, from http://pespmc1.vub.ac.be/ASC/indexASC.html

Hill, T., Smith, N. D. \& Mann, M. F. (1987). Role of efficacy expectations in predicting the decision to use advanced technologies: The case of computers. Journal of Applied Psychology, 72(2), 307-313.

Hilgenberg, C. \& Tolone, W. (2000). Student perceptions of satisfaction and opportunities for critical thinking in distance education by interactive video. The American Journal of Distance Education, 14(3), 59-73.

Hinkle, D. E., Wiersma, W., \& Jurs, S. G. (1994). Applied statistics for the behavioral sciences. ( $3^{\text {rd }}$ ed.). Boston: Houghton Mifflin Company.

Hofmann, J. (2002). Blended learning case study. In A. Rosette. The ASTD Elearning Handbook. McGraw-Hill: New York, 516-519.

Igbaria, M. \& Parasuraman, S. (1989). A path analytic study of individual characteristics and computer anxiety and attitudes toward microcomputers. Journal of Management, 15, 373-388.

Jackson, Y. C. (2000). The role of e-learning technology on improving project management skills: A bilingual application in project risk management. (Doctoral dissertation, University of Houston, 2000).

Joo, Y. J., Bong, M., \& Choi, H. J. (2000). Self-efficacy for self-regulated learning, academic self-efficacy, and Internet self-efficacy in Web-based instruction. Educational Technology, Research and Development, 48(2), 5. 
Kahl, T. N. \& Cropley, A. J. (1986). Face-to-face versus distance learning: Psychological consequences, and practical implications. Distance Education, 7(1), 38-48.

Keegan, D. (1996). Foundations of distance education. $3^{\text {rd }}$ Ed. New York: Routledge.

Kember, D. (1989). A longitudinal-process model of drop-out from distance education. Journal of Higher Education, 60(3), 278-301.

Kember, D. (1990). The use of a model to derive interventions, which might reduce drop-out from distance education courses. Higher Education, 20, 11-24.

Kidney, G. (2001). An evaluation model for web-based instruction and a case study of its application. (Doctoral dissertation, University of Houston, 2001).

Kirk, J. (2002). E-learning: An executive summary. (ERIC Document Reproduction Service No. ED461762).

Kirk, J. J. (2001). An exploration of perceived differences in teaching roles between on-site and on-line instruction. In Aliaga, O., (Ed.). Proceedings of the 2001 AHRD conference.

Knox, A. B. (1977). Adult development and learning: A handbook on individual growth and competence in the adult years for education and the helping professions. San Francisco: Jossey-Bass.

Koresdoski, A. E. (2001). The value of distance learning MBA programs to employers and employees. (Doctoral dissertation, Nova Southeastern University, 2001).

Koul, B. N. \& Jenkins, J. (Eds.). (1990). Distance education: A spectrum of case studies. London: Kogan Page in association with the International Extension College.

Kramarae, C. (2001). The third shift: Women learning online. Washington, DC: AAUW Educational Foundation.

Kreitner, R. \& Kinicki, A. (2002). Organizational behavior. $5^{\text {th }}$ Ed. Boston: Irwin McGraw-Hill. 
Levine, T. \& Donitsa-Schmidt, S. (1998). Computer use, confidence, attitudes, and knowledge: A causal analysis. Computers in Human Behavior, 14, 125-146.

Litchfield, R. E., Oakland, M. J., \& Anderson, J. A. (2002). Relationship between intern characteristics, computer attitudes, and use of online instruction in a dietetic training program. The American Journal of Distance Education, 16(1), 23-36.

Lord, M. (2002). Retrieved March 30, 2002, from http://www.usnews.com

Magalhaes, M. G. M. \& Schiel, D. (1997). A method of evaluation of a course delivered via the World Wide Web in Brazil. The American Journal of Distance Education, II(2), 64-69.

Martocchio, J. J. \& Hertenstein, E. J. (2003). Learning orientation and goal orientation context: Relationships with cognitive and affective learning outcomes. Human Resources Development Quarterly, 14(4), 413-434.

Masie, E. (2000 February). Ford and Delta Airlines subsidize workforce home PCs. TechLearn Trends, 159.

Masie, E. (2000). Blended learning: The magic is in the mix. In A. Rossett (Ed.). The ASTD E-learning handbook: Best practices, strategies, and case studies for an emerging field, (pp. 58-63). New York: McGraw-Hill.

Meister, J. (2002). Pillars of e-learning success. New York: Corporate University Exchange.

Moingeon, B. \& Edmondson, A, (1996). Organizational learning and competitive advantage. Thousand Oaks, CA: Sage Publications.

Moe, M. T. (2002). Emerging trends in post-secondary education: The view to 2012. Retrieved September 9, 2003, from www. usdla.org

Moore, M. G. (2000). Technology-driven change: Where does it leave the faculty? The American Journal of Distance Education, 14(1). Editorial.

Morgan, C. K. \& Tam, M. (1999). Unraveling the complexities of distance education student attrition. Distance Education, 20(1), 96-108.

Muilenburg, L. Y. \& Berge, Z. L. (2001). Barriers to distance education: A factor analytic study. The American Journal of Distance Education, 15(2), 7-22.

Mungania, P. (2003). Review: The ASTD E-learning Handbook. In D. F. Russ-Eft (Ed.). Human Resource Development Quarterly, 14(4), 493-497. 
Mungania, P. (2003). The seven e-learning barriers facing employees. Retrieved on November 7, 2003, from http://www.masie.com/researchgrants/\#study

National Academy of Engineering [NAE], 2001). Retrieved on December 30, 2003 , from

http://www.nae.edu/nae/techlithome.nsf/213b456ec744a79985256b92005 c2dcd/85256b250080528885256b370066dd22?OpenDocument

Nisar, T. M. (2002). Organizational determinants of e-learning. Industrial and Commercial Training, 34(7), 256-262.

Nunnally, J. C. \& Bernstein, I. H. (1994). Psychometric theory. $3^{\text {rd }}$ Ed. New York: McGraw-Hill.

O'Connor, C., Sceiford, E., Wang, G., Fourcar, Szocki, D., \& Griffin, O. (2003). Departure, abandonment, and dropout of e-learning: Dilemma and Solutions. Retrieved November 16, 2003, from www.masie.com

O'Malley, J. \& McCraw, H. (1999, winter). Student perceptions of distance learning. Online learning and the traditional classroom. Online Journal of Distance Learning Administration, II(IV), p.1-11. Retrieved January 15, 2002, from www.westga.edu/ distance/omalley24.html

Oblinger, D. G., Barone, C. A., \& Hawkins, B. L. (2001). Distributed Education: Challenges, choices, and a new environment. Washington, DC: American Council on Education.

Ornstein, A. C. \& Levine, D. U. (1987). Foundations of education. $\left(5^{\text {th }}\right.$ ed.). Boston: Houghton Mifflin Company.

Palloff, R. N. \& Pratt, K. (1999). Building learning communities in cyberspace: Effective strategies for the online classroom. San Francisco: Jossey-Bass Publishers.

Pedhazur, E. (1997) Multivariate regression in behavioral research $\left(3^{\text {rd }}\right.$ ed. $)$ Fort Worth, Texas: Houghton Muffin.

Peratton, H. (2000). Open and distance learning in the developing world. Routledge: London.

Pollard, E. \& Hillage, J. (Eds.). (2001). Exploring e-learning. The Institute for Employment Studies. Report No. 376. Brighton: UK

Porter, L. R. (1997). Creating the virtual classroom: Distance learning with the Internet. New York: John Wiley \& Sons, Inc. 
Postman, N. (1993). Technopoly: The surrender of culture to technology. New York: Vintage Books.

Robinson, R. B. Jr. \& Pearce, J. A. II. (1992). Management. New York: Random House.

Rogers, E. M. (1995). Diffusion of innovations. ( $5^{\text {th }}$ Ed.). New York: The Free Press.

Rosenberg, M. J. (2001). E-learning: Strategies for delivering knowledge in the digital age. New York: McGraw Hill.

Rossett, A. (Ed.). (2002). The ASTD E-learning handbook: Best practices, strategies, and case studies for an emerging field. New York: McGraw Hill.

Rossett, A. (2001). Foreword. In Rosenberg, (2001). E-learning: Strategies for delivering knowledge in the digital age. New York: McGraw Hill.

Rubenson, K. (1986). Distance education for adults: Old and new barriers for participation. In G. van Enckevort, K. Harry, P. Morin, \& H. Schultz (Eds.). Distance Higher Education and the Adult Learner: Innovations in Distance Education, 1, (pp. 39-55). Heerlen, The Netherlands: Dutch Open University.

Schank, R. (2002). Designing world-class e-learning: How IBM, GE, Harvard Business School \& Columbia University are succeeding at e-Learning. New York: McGraw-Hill.

Schilke, R. A. (2001). A case study of attrition in web-based instruction for adults: Updating Garland's model of barriers to persistence in distance education. (Doctoral dissertation, Northern Illinois University, 2001). UMI No. 3013802.

Schreiber, D. A. \& Berge, Z. L. (Eds.). (1998). Distance training: How innovative organizations are using technology to maximize learning and meet business objectives. San Francisco: Jossey-Bass.

Shannon, D. M., Johnson, T. E., Searcy, S. \& Lott, A. (2002 July). Survey professionals using electronic surveys. College Park: University of Maryland. (ERIC/AE Digest Series EDO-TM-02-02).

Sheets, M. F. (1992 Spring). Characteristics of adult education students and factors, which determine course completion: A review. New Horizons in Adult Education, 6(1). 
Simmons, D. E. (2002). The forum report: E-learning adoption rates and barriers. In A. Rossett (Ed.). The ASTD E-learning Handbook: Best practices, strategies and case studies for an emerging field, (pp. 19-23). New York: McGraw Hill.

Simsek, Z. \& Veiga, J. F. (2001 July). A primer on Internet organizational surveys. Organizational Research Methods, 4(3), 218-235.

Stanton, J. M. (1998). An empirical assessment of data collection using the Internet. Personnel Psychology, 51, 709-725.

Stevens, J. P. (2002). Applied multivariate statistics for the social sciences. $\left(4^{\text {th }}\right.$ ed.). Mahwah, New Jersey: Lawrence Erlbaum Associates, Inc.

Taylor Nelson Sofres[TNS] (2001). E-learning in USA \& Canada benchmark survey. Retrieved on March 25, 2003, from http://www.skillsoft.com/solutions/files/whitepapers/whitepapers/tn survey. pdf

Tinto, V. (1993). Leaving college: Rethinking the causes and cures of student attrition. Chicago: University of Chicago Press.

Tsai, C. C., Lin. S. S. J. \& Tsai, M. J. (2001). Developing an Internet attitude scale for high school students. Computers \& Education, 37, 41-51.

Torkzadeh, G. \& Koufteros, X. (1994). Factorial validity of a Computer SelfEfficacy Scale and the impact of computer training. Educational and Psychological Measurement, 54(3), 813-821.

Timura, M. (1995). Perceptions of human resource administrators regarding decisions to support distance learning activities for employees. (Doctoral dissertation, University of Connecticut, 1995).

Ullich, M. (1998). Making the move to online learning. Making the move to online learning. (ERIC Document Reproduction Service No. ED427741).

Urdan, T. A. \& Weggen, C. (2000). Corporate e-learning: Exploring a new frontier. W R Hambrecht \& Company.

Wagner, R., Warner, J., \& Schramm, R. (2002). An evaluation of student satisfaction with distance learning courses. In The18h Annual Conference on Distance Teaching \& Learning Proceedings, 419-423.

Webster, F. (2002). Theories of the information society. $\left(2^{\text {nd }}\right.$ ed.). London: Routledge. 
Whalen, T. (1999). The business case for corporate training applications of Webbased tele-learning. (Masters thesis, University of Ottawa, Canada, 1999).

Williams, S. W. (2001). Experiences of Web-based instruction among AfricanAmerican students enrolled in training and Development Graduate Courses. In O. Aliaga, (Ed.), Proceedings of the 2001 Academy of Human Resource Development (AHRD) conference.

Winner, L. (1977). Autonomous technology. Cambridge, MA: The MIT Press

Witkin, B. R. \& Altschuld, J. W. (1995). Planning and conducting needs assessments: A practical guide. Sage Publications: Thousand Oaks.

Wong, C. J. (1999). Developing an Internet-based Distance Education Program: The Planning Phase. In J. Price, J. Willis, D. Willis, M. Jost, \& S. BogerMehall (Eds.). Technology and Teacher Education Annual 1999 (p. 865869). Charlottesville, VA: Association for the Advancement of Computing in Education (AACE). 
APPENDICES 
Letter to the Human Studies Committee at the University of Louisville

April 28, 2003

Human Studies Committee

SOM Instructional Building

Room 230

Louisville, KY 40202

\section{Dear Sir or Madam:}

This is a request for an expedited review for a research study. The purpose of this study is to investigate the nature of the barriers facing employees engaged in online training in organizations and the relationship of these barriers and elearner demographics, background, and self-efficacy.

The present study will commence in May 2003. The subjects of this study will be employees of seven organizations who have participated in e-learning (Webbased training).

The principal investigator in this study is $\mathrm{Dr}$. Tim Hatcher. This study is a doctoral dissertation research by Penina Mungania in the College of Education and Human Development.

Enclosed are the required documents for your review and approval. Your fast response will be appreciated.

Sincerely,

Tim Hatcher (Ph.D.)

Principal Investigator

\section{Enclosures}


Appendix B

Email to the Subject Matter Experts

From: $\quad$ Penina Mungania

To: $\quad$ Subject matter experts (SMEs)

Subject: $\quad$ Review of instrument on e-learning barriers

Thank you for agreeing to participate as a subject matter expert to review the instrument. This instrument will be Web-based and will be used to gather data from employees in various organizations who have participated in e-learning at their place of work.

The Human Subjects Committee has approved this study. I appreciate your time, effort and feedback that you'll provide to make this a better study.

\section{Instructions}

1. The instrument contains three parts. Part I seeks background data, Part II covers e-learning barriers, and Part III covers computer self-efficacy.

2. Under each item, please provide your feedback on:

i) Appropriateness of that item in that category

ii) Wording of the items.

iii) Clarity of the instructions and the items.

iv) Under Part II on barriers, please indicate whether these items are placed in the appropriate category

3. Note that the headings categorizing barriers within each section will be removed in the final instrument.

4. In the final version to the respondents, the items within each part will be scrambled in no particular order.

5. You may use a different font/bold or use a different color for your comments.

6. Please email your comments to me by

Sincerely,

Penina Mungania 
Appendix C

Email Sent to the Pilot Group

From: $\quad$ Contact person in each organization

To: $\quad$ Emails of pilot group

Date May 1, 2003

Subject: Pilot of the survey on E-learning barriers

You have been randomly selected to participate in pre-testing a survey whose purpose is to determine the barriers or obstacles you may have encountered in your online training experiences in this organization.

In an effort to improve our e-learning offerings, we are seeking feedback from you as an employee who has participated in e-learning in the past.

For confidentiality purposes, the survey is hosted on a server outside of this organization and only the researcher has access to the research data.

Confidentiality will be ensured to the extent that the researcher can. The survey is also anonymous.

We are asking you to participate in the pilot study in order to obtain feedback about the clarity of the survey and to detect any technological problems you may encounter in the process of completing this survey. Your feedback is valuable to us and will be used to make improvements to this survey.

The questionnaire is divided into 3 parts. Part I seeks background information about you and your experiences with e-learning. Part II aims at determining barriers that you have encountered and Part III is about your perception towards computers and the Internet.

\section{Instructions}

1. Please time yourself during the completion of the questionnaire to determine how long it will take you to complete the questionnaire and note it under the last question in this survey. 
2. As you complete this questionnaire, make note of the items/questions or instructions that are unclear by typing in your comments in the space provided in the second last question of the survey.

3. Click here (URL) to gain entry to the survey. This should take you to the website that hosts the survey. Once you get on this website, type in $* \star \star \star \star \star * * *$ as your password.

4. Submit the completed survey by clicking on the "SUBMIT" button at the end of the survey.

5. Please read the consent form below, which informs you of your rights.

\section{Subject Informed Consent}

Introduction and Background Information. As an employee who has participated in e-learning/online training, you are being invited to participate in a research study to determine barriers or obstacles that you may have faced while you were engaged in online training. Please note that your responses will be anonymous.

Procedures. Data collection for this study will be obtained through a Web-based survey. Please follow the instructions to access the online survey.

Potential Risks. There are no foreseeable risks associated with this study.

Benefits. As a result of participating in this study, you will be enhancing the understanding of the kinds of e-learning barriers facing employees hence enlighten organizations and the public about the plight of e-learners.

Compensation. Although there is no payment for your participation in this study, the emerging results could be beneficial to you.

Confidentiality. The data collected in this research study is anonymous and will be kept confidential to the extent permitted by law. The server hosting the survey and the raw data resides outside of your organization. Once this research study is completed, the results will be analyzed and reported in an aggregate form.

Voluntary Participation. Your participation is voluntary. You may refuse to participate or to answer any questions that you are uncomfortable with and discontinue at any time.

Research Subject's Rights and Contact Persons. You may contact the researchers

Dr. Tim Hatcher hatcher@louisville.edu or Penina Mungania penina.mungania@louisville.edu. Or you may call the Human Studies Committees office (502) 852-5188. You will be given the opportunity to discuss any questions about your rights as a research subject, in confidence, with a member of the committees. These are independent committees composed of members of the University community, staff of the institutions, as well as lay 
members of the community not connected with these institutions. The Committee has reviewed and approved this study.

Consent. By completing and submitting the electronic survey, you are agreeing to voluntarily participate in this study. 
Appendix D

\section{A Survey of E-learning Barriers and Self-efficacy}

\section{Informed Consent}

You are invited to participate in a research study examining barriers that you may have encountered during your e-learning experiences. This is an anonymous survey and your responses will be kept confidential to the extent permitted by law. Your participation is voluntary and you may choose to stop participating at any time. Responding to and submitting this Web survey electronically will indicate your willingness to participate.

The questionnaire is divided into 3 parts. Part 1 seeks background information about you and your experiences with e-learning. Part 2 aims at determining barriers that you have encountered and Part 3 is about your perception towards computers and the Internet.

\section{Operational Definitions}

E-learning: Any training or professional development course provided by your present employer that is delivered electronically $100 \%$ via the Internet or an Intranet; during which you as an employees did not have face-to-face interaction with the other trainees or with the instructor.

Barrier: Any obstacle you may have encountered in the process of starting, continuing, and completing an online course. Think of all the obstacles you have encountered in all of your e-learning experiences.

\section{Instructions}

1. If you have been involved in one or more online (Web-based) course(s), please respond to these questions keeping in mind all the e-learning courses you have participated in, that have been offered by your present employer.

2. Indicate your response to each question by clicking on the item under the pull-down menu or the button next to your answer.

3. Respond to all questions as truthfully as possible.

4. Respond to the survey questions from your experiences as a learner even if you have been/are involved in instructional design or in facilitating online courses.

5. Complete the survey in one sitting (if you exit and return to the survey, your original responses will be lost).

6. Please time yourself as you begin completing this survey (pilot group only). 
7. Please submit your responses by clicking on the SUBMIT SURVEY button at the end of the survey.

Part I: Demographics and Background Characteristics

1. Which type of organization do you work for?
1. Manufacturing
2. Oil Manufacturing
3. Public School District
4. Health Insurance
5. Wholesale distribution
6. IT Consulting Services
7. Military

2. What is your age?
1. $18-24$
2. $25-31$
3. $32-38$
4. $38-45$
5. $46-52$
6. 53 and above

3. What is your gender?
0 Female
1 Male

4. What is your ethnic background?
1. African descent
2. Asian descent
3. European descent
4. Hispanic descent
5. Indian
6. Pacific Islander
7. Other

5. Which title best describes your work position? (choose one only)
1. Manager or administrator
2. Support staff
3. Teacher or instructor
4. Commissioned officer (military)
5. Non-commissioned officer (military)
6. Other

6. What is your marital status?

0 Single

1 Married 
7. What is the highest level of education you have attained?

1. No high school diploma

2. High school diploma or GED

3. Some college courses

4. Bachelors degree

5. Master's degree

6. Specialist degree

7. Doctorate

8. Where do you do most of your e-learning?

1. In the office

2. At home

3. Both at home and in the office

4. Other (specify)

9. Do you own a computer at home that has Internet connectivity?

0 Yes

1 No

10. Which statement best describes your e-learning experience?

1. This is my first online course

2. I was enrolled in an online course(s) in 2002

3. I was enrolled in an online course(s) in 2001

4. I have taken online courses before 2001

11. I have had prior online courses outside this organization

0 Yes

1 No

12. How many e-learning courses have you participated in so far?

1. $1-3$

2. $4-6$

3. $7-9$

4. Over 10

13. How would you rate your competence with computers?

1. Novice (very limited knowledge and experience with computers)

2. Average (intermediate knowledge and experience with computers)

3. Expert (advanced user with a lot of computer experience)

14. Have you ever taken a course (online or instructor-led) to improve your computer skills?
0 . Yes
1. No 
15. Overall, my e-learning experiences have been

0 . Positive

1. Negative

\section{Part II: BEL Scale}

Perceived E-learning Barriers. Rate each of the barriers/obstacles below according to how you perceive the strength of that barrier to starting, continuing, and completing your previous and/or current elearning experiences. In responding to these questions, think of an average of all your experiences. Use the 1-5 scale below. For example, clicking on 5 "very strong barrier" indicates that you regard that item as a major obstacle. Clicking on 1 "Not a barrier" indicates that you do not regard that item as barrier or that it was/is not applicable in your e-learning experiences.

$1=$ Not a barrier or Not applicable

2 = Weak Barrier

$3=$ Moderate Barrier

$4=$ Strong Barrier

$5=$ Very Strong Barrier

Table AIV1

Items on the BEL Scale

16. Awareness of online course availability

17. Over commitment to multiple roles and responsibilities

18. Concerns about the legitimacy of e-learning certificates or diplomas

19. Content difficulty

20. Content's relationship to job requirements or career plans

21. Courses offered were not those I desired

22. Difficulty contacting administrative and support staff

23. Difficulty obtaining reference materials

24. Discomfort with the technology

25. Fit between my learning style (the way I prefer to learn) and e-learning

26. E-learning seems impersonal

27. Fear of failure

28. Fear or insecurity regarding a loss of privacy or confidentiality online

29. Feeling isolated due to lack of interaction with other students and instructor

30. Gap between presented content and my expectations

31. High cost of hardware, software, repairs, or a service provider

32. Inconsistent access to the course (e.g. access to computer hardware, 
software or connectivity)

33. Information overload due to too much learning material

34. Instructor's knowledge, skills, and attitudes

35. Insufficient support from my family, friends, or significant others

36. Interruptions at work, home or wherever I study

37. Lack of confidence in my ability to participate in e-learning

38. Motivation to learn online

39. Lack of prerequisite knowledge

40. Insufficient support from coworkers to engage in e-learning

41. Lack of support from my employer and supervisor for e-learning

42. Unreliable technical support or support services

43. Lack of technical expertise or my unfamiliarity with e-learning technology

44. Lack of time to study

45. Lack of training on how to learn online

46. Limited access or communication with the instructor

47. My resistance to change

48. Physical health barriers such as eye strain, Carpal Tunnel Syndrome, or physical immobility

49. Poor communication skills required for e-learning such as using email or discussion boards

50. Problems with language (reading level) used in course materials

51. Procrastination or time management problems

52. Psychological barriers such as anxiety or stress

53. Quality of the learning materials

54. Slow speed of Internet connection

55. Timeliness or frequency of feedback from the instructor

56. Clarity of course expectations

57. Unclear instructions from instructor(s)

Part III: ELSE Scale

E-learning Self-Efficacy Scale. Below are a number of statements regarding how you feel about your ability to use computers and the Internet. Please indicate the strength of your agreement or disagreement with the statements using the 5-point scale below. Click on the number that most closely represents how much you agree or disagree with each of these statements. There are no correct or incorrect responses; it is your view that is important. $1=$ strongly disagree

2 = disagree

$3=$ undecided

$4=$ agree

$5=$ strongly agree 
Table AIV2

Items on the ELSE Scale

58. I understand terms/words relating to Internet

59. I have the necessary skills for using e-learning software

60 . I can turn to an online discussion group when help is needed

61. I can use the Internet to gather data

62. I can troubleshoot Internet problems

63. I can usually deal with most difficulties that I encounter when learning online

64. I find working with computers easy

65. I seem to have difficulties with most of the software applications I have tried to use

66. Computers frighten me

67. I enjoy working with computers

68. Computers make me much more productive

69. I am confident in my abilities to make use of computers in learning

70. I find it difficult to get computers to do what I want them to

71. I find working with computers confusing

72. I would rather that we did not have to learn how to use computers

73. I usually find it easy to learn how to use a new software application

74. Using computers makes learning more interesting

75. I always seem to have problems when trying to use computers

76. Some computer packages definitely make learning easier

77. Computer jargon baffles me

78. Computers are good aids to learning

79. Computers help me to save a lot of time

80. I find working with computers very frustrating

81. When using computers I worry that I might press the wrong button and damage it

82. If you experienced any other barriers that were not listed above, please type them in this text box.

\section{CLICK HERE TO SUBMIT}

Thanks a lot for taking your time to fill in this questionnaire. If you would like to receive the results of this study, please contact penina.mungania@louisville.edu 
1. In the box that follows please comment on the clarity and appropriateness of the questions you just answered. Please identify the item number first, followed by your comments.

For example: Item \#63..........(type your feedback here)

2. Is this Web-based survey (Internet-based) appropriate for this kind of study on e-learning barriers?

0 Yes (if you answer yes, please respond to the next question)

1 No (if you answer no, please skip the next question)

3. What problems did you encounter in the process of accessing and completing this survey?

4. How long did it take you to respond to this questionnaire? Minutes (Please type the number of minutes it took you to complete the survey) 


\section{Appendix E}

\section{Pre-Notification Email to all Employee E-learners}

From: $\quad$ Contact person in each organization

To: $\quad$ Emails of e-learners

Date May 1, 2003

Subject: Upcoming Research Study on E-learning

We would like to notify you of an upcoming research study that our organization has chosen to participate in order to improve our e-learning offerings.

The survey will be seeking feedback from you as an employee who has participated in e-learning in the past. This is a part of a research study being conducted by Penina Mungania, a doctoral candidate at the University of Louisville.

This is a pre-notification email, informing you that we would encourage you to participate in this study. In the next couple of days, I will send you details of how to access the survey.

Thank you. 
Appendix F

Email to Employee E-learners to Participate

From: $\quad$ Contact person in each organization

To: $\quad$ Emails of all e-learners

Date May 2003

Subject: $\quad$ Survey on E-learning Barriers

You are invited to participate in a study whose purpose is to determine the barriers or obstacles you may have encountered in the process of starting, continuing, and completing e-learning courses in this organization.

In an effort to improve our e-learning offerings, we are seeking feedback from employees who have participated in e-learning in this organization. Your feedback is valuable to us and will inform e-learning practices, from which you could benefit. You will need approximately ${ }^{* \star * *}$ minutes to complete the survey

For confidentiality purposes, the survey is hosted on a server outside of this organization and only the researcher has access to the research data.

Confidentiality will be ensured to the extent that the researcher can. The survey is also anonymous.

Click on this link ${ }^{\star * \star \star \star \star \star \star \star \star *}$ to gain entry to the survey. This should take you to the website that hosts the survey. Once you get on this website, type in ${ }^{\star \star \star \star \star \star \star \star \star}$ as your password. If you already participated in the pilot study, do not respond again.

If you already completed this survey during the pilot testing or if you have NOT participated in e-learning, please do not respond to the survey.

Please read the consent form below. This informs you of your rights as a research subject. We appreciate your time responding to this survey. Your thoughtful and honest responses are very important to the completion of this study. 


\section{Subject Informed Consent}

Introduction and Background Information

As an employee who has participated in e-learning/online training, you are being invited to participate in a research study to determine barriers or obstacles that you may have faced while you were engaged in online training. Please note that your responses will be anonymous.

\section{Procedures}

Data collection for this study will be obtained through a Web-based survey.

Please follow the instructions to access the online survey.

\section{Potential Risks}

There are no foreseeable risks associated with this study.

\section{Benefits}

As a result of participating in this study, you will be enhancing the understanding of the kinds of e-learning barriers facing employees hence enlighten organizations and the public about the plight of e-learners.

\section{Compensation}

Although there is no payment for your participation in this study, the emerging results could be beneficial to you.

\section{Confidentiality}

The data collected in this research study is anonymous and will be kept confidential to the extent permitted by law. The server hosting the survey and the raw data resides outside of your organization. Once this research study is completed, the results will be analyzed and reported in an aggregate form.

\section{Voluntary Participation}

Your participation is voluntary. You may refuse to participate or to answer any questions that you are uncomfortable with and discontinue at any time.

\section{Research Subject's Rights and Contact Persons}

You may contact the researchers Dr. Tim Hatcher hatcher@louisville.edu or Penina Mungania penina.mungania@louisville.edu or you may call the Human Studies Committees office (502) 852-5188. You will be given the opportunity to discuss any questions about your rights as a research subject, in confidence, with a member of the committees. These are independent committees composed of members of the University community, staff of the institutions, as well as lay members of the community not connected with these institutions. The Committee has reviewed and approved this study. 
Consent

By completing and submitting the electronic survey, you are agreeing to voluntarily participate in this study. 
Appendix G

Reminder Emails to Pilot and Main Group

From: $\quad$ Contact person in each organization

To: $\quad$ Emails of e-learners

Date June 2003

Subject: Reminder to Complete the E-learning Survey

Two weeks ago, an email was sent to you requesting you to participate in a survey seeking your experiences with e-learning.

This is a reminder for you to respond to the survey hosted at ${ }^{* \star \star \star \star \star \star \star \star \star}$ in case you have not done so already. Use ${ }^{\star \star \star \star * *}$ as the password to gain entry into the survey.

Your input is valuable to us so please take a couple of minutes and respond to the survey. 
Appendix $\mathrm{H}$

Thank You Email

From: Contact person in each organization

To: $\quad$ Emails of e-learners

Date June 2003

Subject: Appreciation

We would like to thank you for participating in the recent research study on barriers facing employee e-learners in organizations.

Your participation was valuable and will inform the e-learning practices. In case you are interested in finding out the results of this study, please contact the researcher at penina.mungania@louisville.edu

Once again, thank you very much and best wishes in all you do.

Penina Mungania 
Appendix I

Perceived Barriers across all the 7 Organizations

Reported in the Open-Ended Response Question

Table Al1

Perceived Personal Barriers Across All Organizations

Time management problems

- Getting started with the course is a problem for some students. It was not clear whether this is a procrastination problem or a technological issue.

Adult pride/language problem

- This barrier is evident in one employee's comment, "My personal multilanguage superiority prevents me from learning in an environment with others talking in the same language around me: I cannot concentrate on writings on screen while others around me are talking loudly."

Learning style or preferences

- Several employees indicated that their learning style preferences were not met. For example, some employees showed a preference for instructor-led instruction.

- Preference for hands-on experience required by those who learn best from experience, not simply reading about a topic. "I learn by doing more than reading."

- Some indicated a preference for "Passive learning".

- Preference for interaction, "Courses I took were nothing more than an abbreviated text with little or ineffective interaction." Others said, "I learn best from instructor lead course(s) because of the one on one interaction and communication with class mates." or "I learn best from instructor-led course because of the one on one interaction and communicate with class mates." 
Table Al2

Perceived Instructional Design-Related Barriers Across All Organizations

Lack of progress reports/Learning Management System (LMS)

- Failure for the LMS to provide a link between the taken courses and the results obtained. For example, scores are not updated to the learners' records, and the status for that learning activity is not changed.

- Failure to record an employee's progress through the modules as they are completed.

- One employee said, "I completed a course from the SmartForce and, even though I showed a score of $100 \%$, it did not say that I received credits for it. So, I believe that my time was wasted and I could not find any assistance in resolving the situation."

Limited learner engagement

- One learner cited, "Standard course learning material just doesn't work at a pace that is conducive to holding my attention."

- Poor quality of online instruction: one employee noted, "Courses I took were nothing more than an abbreviated text with little or ineffective interaction."

- Some content did not have real world application and lacked opportunities for e-earners to apply what they had learned.

Poor instructional design

- Inconsistency between different courses.

- Inconsistency in accessing different courses.

- Too many links on one page to other pages/references that "lost" learners in the process of looking at the links.

- Course titles and course tracks changed in the middle of the courses.

- Some of the courses are not logically designed.

- Inability to print or download files. "Being able to have a paper copy enables 
you to study without being at a desk, and gives you something to refer back to."

\section{Reference Materials}

- Limited reference materials to support e-learning.

Access and Navigation problems

- Poor table of contents.

- Poor navigation moving through the course.

- Access problems to some course sections.

- Course format was disorganized making navigation difficult.

- Restricted movement from one module to another.

- Some of the course links require a password requiring students to remember multiple passwords.

- The course presentation is not learner-friendly indicating poor planning and design of the course and/or materials.

Limited use of multimedia

- Lack of audio materials to enable continuous learning when one gets distracted during the learning process.

- Lack of hard copy/printed materials.

- Lack of hands-on/interactive learning environment.

Unclear or inconsistent instructions

- Employees complained about unclear instructions about things like online courses location and search tools.

- Some employees noted that login procedures and passwords differed, such that the password they are sent to log into a course or to sign up are does not match the actual log-in at the entry page, thus denying them entry. One employee said, "usually the worst part of the e-learning is logging on to the web site". 
Inability to save work

- The inability to bookmark where one stopped was a common problem. Consequently some employees had to redo some lessons and had problems continuing with the course if they took a break and were forced to restart. According to one employee, "In the middle of the course, when I needed to stop and come back to it, I would click the appropriate box to save my work and exit which at the time was the "bookmark" box. When I would come back to the course, all of my work and assessments for that course were erased. I would have to go through the course again from the beginning".

- Employees do not have an easy way of determining where they are in a course, which relates to the inability to bookmark problem.

Information overload

- Too much information in one location.

- Courses were far too lengthy for timely completion.

\section{Limited Feedback}

- There was evidence of lack of feedback on incorrect answers and course completion notification. One employee expressed problems completing the course as captured in this comment:

"When I reached the end of the course and it was supposed to run a completion routine it did not (do) so. I did not have successful completion with feedback as to my knowledge of the course material". 


\section{Table Al3}

\section{Perceived Instructor-Related Barriers Across All Organizations}

\section{Feedback}

- Irregular feedback: there were differences in response time among members of the training group.

- Timeliness of feedback: common comments included, "response time when providing answers is very slow and contributes to extended time utilized to complete a learning session." Another employee complained that s/he had to wait for more a week for responses to important questions/issues, while another one said, "Many times they were on alternative assignments and I waited more than a week for responses to important questions/issues".

- Little response from the instructor regarding a problem in the system.

- Lack of feedback concerning status: one student even after completing a course still had "In Progress" status and has not received any feedback.

\section{Lack of instructor presence/interaction}

- Employees were unaware of whether there was an online instructor or not.

\section{Poor Coordination}

- Lack of coordination to keep members of the training group in step with course progress.

Instructor's skills

- There was mention of an instructor who was unskilled in teaching online synchronously or asynchronously and of instructors who were not able to respond to detailed technical questions. 
Table Al4

Perceived Organizational Barriers Across All Organizations

Cultural problems concerning credibility of e-learning

- Recognition of online course certificates. One employee of the military said that online course certificates are not accepted by the military for entry into service. "Military' aversion to something other than what they determine is valid."

- Management is not convinced on the quality and equality of online degrees and traditional degrees. One employee said, "I am having a hard time trying to convince management that an advanced on-line degree would be equal to obtaining a non- on-line advanced degree."

- Esteem of e-learning: one employee said, "It is not accepted that E-learning courses take the same amount of time as a normal course - everyone has the expectation that e-learning must go "on the side".

Lack of time for study

- Lack of training schedule within which e-learning should take place.

Interpersonal barriers

- One employee cited having a problems with the project manager.

Lack of information about course availability, location, and results

- Not all courses were online. One student said, "I think the biggest barrier to elearning is finding the courses that are available."

- Finding courses that are applicable to development and growth for the position.

- Employees are very confused especially when trying to find out information about courses. Some said that even talking with co-workers did not seem to help.

- Some employees reported that although they were interested in taking certain courses, some of the courses were never available and there was always a waiting list. 
- Lack of a catalogue of online courses and several employees found it very frustrating locating and using the catalogue of online courses.

- Many employees said that they have no idea where the courses are listed, where it is available, what is available.

- Lack of knowledge about certification for completed courses or the final goal.

- Many expressed that there were limited offerings specifically in computer programs such as Access and Excel.

Registration system problems

- The course registration system is not user-friendly making it difficult to locate a specific course. For example, employees had problems finding the right courses to take and finding out which courses are Internet-based or instructorled.

- Inability to enroll to a course. One employee tried several times to sign up for actual courses but always got sent back to introductory course, which s/he had already passed. Further, s/he "Signed up for "waiting list" on numerous courses, never able to take anything."

Lack of credit or certification after completion

- One employee said, "I completed a course from the SmartForce and, even though I showed a score of $100 \%$, it did not say that I received credits for it. So, I believe that my time was wasted and I could not find any assistance in resolving the situation."

Failure to involve employees in planning

- Employees feel left out of the decision-making process concerning e learning.

- Poor planning for e-learning. For example, an employee indicated that the course developers failed to plan for technical limitations and predictable problems. 
Table Al5

Perceived Situational Barriers Across All Organizations

Limited time for study

- Limited availability to complete training due to job duties, other commitments such as constant travel made e-learning a difficult task

- Finding the time for study was a barrier

- Course duration might have prevented one from taking time for study. For example, one student said, "I have never taken a e-course that did not last more than 1 hour."

- Very time consuming and slow

Interruptions during study

- Interruptions during learning especially in the office made learning difficult. 
Table Al6

Perceived Content-Related Barriers Across All Organizations

Course relevance

- Several employee thought that the courses offered were not relevant or applicable to their job.

- Employees' expectations regarding the course were not met.

- Unmet expectations: one employee said, "I was expecting to learn more than what I did."

Content not audience-specific

- The content gave the broad view instead of a relating it to the particular organization's view.

- E-learning is not suitable for all courses. An employee said, "E-learning works well for simple, informative topics such as training in employer policies, but it least effective for more involved topics such as advanced mathematics, or more cognitive topics such as equipment repair/troubleshooting".

- Appropriateness of the course content for the intended audience. One employee said, "courses mostly are set up and designed for global concerns, not for local or regional business-cultures".

Content was lacking in quality and rigor

- Wrong course content.

- The course materials tended to be set at too simplistic a level.

- The content covered is not specific enough.

- Outdated course content.

- Course content is very poor.

- Little high level content.

- Unclear content.

- Low course expectations appropriate for an entry-level course. For example, 
one employee noted that courses that are offered were too limited and very basic: suitable for new employees. This employee noted, "The only courses that I am interested in are only available as an instructor led or classroom. I need a challenge for a seasoned 9-1/2 yr employee."

\section{Poor assessments}

- Questions asked in the tests are poorly worded.

- Multiple choice questions rarely have accurate answers to the questions asked

- Lack of probing questions leading to a low-level learning experience. There were many of the exams that just testing the memory and do not add value.

- Multiple choice type questions used online do not require synthesis and application of the material.

- Exam questions do not mach the course content.

- Limited homework in online courses: One employee thought that homework from instructor-led courses is much more intense and relates well to the course than most online "homework".

- Questioning was disorderly: Some questions were asked before the content was covered. One student commented, "In the Excel Intermediary and Advanced Class, questions were asked before I learned the answer. I found this frustrating even though I was not graded on my answers".

- Insufficient hands-on exercises in the e-learning courses to practice

- Lack of questions that properly assess learning.

- Some of the courses' pre-assessments are confusing and disjointed.

- The assessment questions did not cover the content adequately. One employee wrote, "It would appear that the questions are written by someone who have no idea of the product, solution or area in the content of the learning materials". 
Table Al7

Perceived Technology-Related Barriers Across All Organizations

Learning Management Systems' (LMS) quality

- Technical problems in the e-learning tool itself.

- E-learning is not fully supported by the LMS.

- Poor sound quality even when downloaded to local disk.

- Difficulty accessing courses. One student said, "log in, remembering passwords, downloads, checking settings, updating drivers, being redirected to a different site was time consuming and annoying".

- The LMS is of low quality.

- Lack of a search function in the LMS.

- Lack of a course site map.

- Lack of record of courses taken.

- Problems with the 'help' function.

- Server problems with LMS or server/site used to deliver training.

Connectivity problems

- Despite having high-speed connections, some e-learners had to restart. This was the most frustrating and time-consuming aspect. Connectivity seemed to be a major barrier. However, it wasn't' clear whether this was an issue at home, office or from other locations.

- Internet failure especially when taking tests due to Internet failure.

- Connectivity problems: An employee wrote, "The sole factor that ruined my experience of e-learning was the abysmal Internet connection that we suffer here in the Algerian desert." While others cited slow home connection speeds.

- Timed out sessions if an employee leaves a session for an extended period of time

- Extremely slow connection making it nearly impossible to complete especially 
where there were graphics.

- Problem getting the courses to launch.

- Poor connectivity: The course material downloads were lengthy leading to loss of interest in the course.

- Limited access: For example one employee said, "I never got Internet connection. I was using other system in office which was very very slow leading to impatience."

Lack of training

- Lack of training or knowledge of the product and its support system.

- Problems loading the courses on one's computer. It was not clear whether this is a download problem due to size of files or if it indicates a lack of knowledge on how to do it.

Navigation

- Navigation is not very easy and not very user friendly.

- Navigation within the LMS environment. Employees found it difficult to find a class to take and to get to the actual course content. One employee said, "I don't even go in there now because it's so hard to find my way around and there is no one to call or ask questions too about it".

- Takes a long time to get to the required course. This could be a navigation issue or a competency issue.

- Problem downloading files leading to missed courses before the problem was fixed

- Poorly constructed and difficult to navigate Websites.

\section{Lack of technical support}

- Many employees find it difficult to register for online courses and lack help on how to go through the process.

- Technological barriers that required outside support. One student said, "I was lucky to have instructor to come to my home on two occasions to work 
through technology problems. That could have been a barrier but the instructor's support took care of that barrier".

Loss of data and inability to save or transfer data

- Problems transferring work from one computer to another. For example, one could start a course at work but would be unable to continue at home, due to 'cookies'.

- Loss of data due to technological problems especially with the tests.

- Fear of losing work especially when taking tests due to lost connection or hardware failure.

- Computer failure forcing employees to redo the course again. 
Appendix $\mathrm{J}$

Table AJ1

Levene's Test of Equality of Error Variances

Type of Barrier

$\begin{array}{llll}F & d f 1 & d f 2 & \text { Sig. }\end{array}$

1. Dispositional barriers

8.795

840

.000

2. Learning Style barriers

1.7526

840

.106

3. Instructional barriers

$4.308 \quad 6$

840

.000

4. Organizational barriers

$4.416 \quad 6$

840

.000

5. Situational barriers

.393

6

840

.883

6. Content-Suitability barriers

$1.301 \quad 6$

840

.254

7. Technological barriers

$4.992 \quad 6$

840

.000 
Appendix K

Table AK1

Pairwise Group Comparisons Among Organizations

Organization

$\begin{array}{llll}1 & 2 & 3 & 4\end{array}$

$4 \quad 5$

$5 \quad 6$

$6 \quad 7$

1. IT Manufacturing $F$

$1.2243 .731^{* \star} 5.921^{* *} 9.293^{* *} 3.931^{\star *} 4.400^{* *}$

Sig. $\begin{array}{llllll}.287 & .001 & .000 & .000 & .000 & .000\end{array}$

2. Oil $E \& M$

$F$

$\begin{array}{lllll}.500 & .538 & .728 & 1.781 & .756\end{array}$

Sig.

$\begin{array}{lllll}.835 & .806 & .648 & .088 & .624\end{array}$

3. School district $F$

$1.0891 .677 \quad 3.774^{\star \star} .927$

Sig.

$\begin{array}{llll}.368 & .111 & .000 & .484\end{array}$

4. Health Insurance $F$

$$
4.574^{\star *} 11.03^{\star \star} 3.286^{\star *}
$$

Sig.

$.000 \quad .000 \quad .002$

5. Wholesale

$F$

$8.578^{\star *} 1.826$

Sig.

$.000 \quad .079$

6. IT Consulting

$\mathrm{F}$

$3.359^{\star \star}$

Sig.

.002

7. Military

F

Sig. 
Appendix $\mathrm{L}$

Table AL1

Correlations among Self-Efficacy and Seven Types of Barriers

\begin{tabular}{|c|c|c|c|c|c|c|c|c|c|}
\hline & & $\overline{S E}$ & 1 & 2 & 3 & 4 & 5 & 6 & 7 \\
\hline \multirow[t]{3}{*}{$\overline{\mathrm{SE}}$} & $\begin{array}{l}\text { Pearson } \\
\text { Correlation }\end{array}$ & 1 & -.076 & -.084 & -.020 & -.090 & -.029 & -.060 & -.064 \\
\hline & Sig. (2-tailed) & & .026 & .013 & .549 & .008 & .392 & .080 & .059 \\
\hline & $N$ & 860 & 859 & 859 & 859 & 859 & 860 & 860 & 859 \\
\hline \multirow{2}{*}{$\begin{array}{l}\text { Factor } 1 \\
\text { Disposi- } \\
\text { tional }\end{array}$} & $\begin{array}{l}\text { Pearson } \\
\text { Correlation }\end{array}$ & -.076 & 1 & .652 & .589 & .686 & .332 & .373 & .496 \\
\hline & $\begin{array}{l}\text { Sig. (2-tailed) } \\
N\end{array}$ & $\begin{array}{l}.026 \\
859\end{array}$ & 863 & $\begin{array}{l}.000 \\
863\end{array}$ & $\begin{array}{l}.000 \\
862\end{array}$ & $\begin{array}{l}.000 \\
862\end{array}$ & $\begin{array}{l}.000 \\
863\end{array}$ & $\begin{array}{l}.000 \\
863\end{array}$ & $\begin{array}{l}.000 \\
862\end{array}$ \\
\hline \multirow{2}{*}{$\begin{array}{l}\text { Factor } 2 \\
\text { Learning } \\
\text { Style }\end{array}$} & $\begin{array}{l}\text { Pearson } \\
\text { Correlation }\end{array}$ & -.084 & .652 & 1 & .544 & .606 & .322 & .405 & .417 \\
\hline & $\begin{array}{l}\text { Sig. (2-tailed) } \\
N\end{array}$ & $\begin{array}{l}.013 \\
859\end{array}$ & $\begin{array}{l}.000 \\
863\end{array}$ & 863 & $\begin{array}{l}.000 \\
862\end{array}$ & $\begin{array}{l}.000 \\
862\end{array}$ & $\begin{array}{l}.000 \\
863\end{array}$ & $\begin{array}{l}.000 \\
863\end{array}$ & $\begin{array}{l}.000 \\
862\end{array}$ \\
\hline \multirow[t]{3}{*}{$\begin{array}{l}\text { Factor } 3 \\
\text { Instructiona }\end{array}$} & $\begin{array}{l}\text { Pearson } \\
\text { ICorrelation }\end{array}$ & -.020 & .589 & .544 & 1 & .563 & .294 & .478 & .521 \\
\hline & Sig. (2-tailed) & .549 & .000 & .000 & . & .000 & .000 & .000 & .000 \\
\hline & $N$ & 859 & 862 & 862 & 862 & 862 & 862 & 862 & 862 \\
\hline \multirow[t]{2}{*}{$\begin{array}{l}\text { Factor } 4 \\
\text { Situational }\end{array}$} & $\begin{array}{l}\text { Pearson } \\
\text { Correlation }\end{array}$ & -.090 & .686 & .606 & .563 & 1 & .465 & .355 & .517 \\
\hline & $\begin{array}{l}\text { Sig. (2-tailed) } \\
N\end{array}$ & $\begin{array}{l}.008 \\
859\end{array}$ & $\begin{array}{l}.000 \\
862\end{array}$ & $\begin{array}{l}.000 \\
862\end{array}$ & $\begin{array}{l}.000 \\
862\end{array}$ & 862 & $\begin{array}{l}.000 \\
862\end{array}$ & $\begin{array}{l}.000 \\
862\end{array}$ & $\begin{array}{l}.000 \\
862\end{array}$ \\
\hline
\end{tabular}




$\begin{array}{llllllll}\mathrm{SE} & 1 & 2 & 3 & 4 & 5 & 6 & 7\end{array}$

$\begin{array}{llllllllll}\text { Factor } 5 & \text { Pearson } & -.029 & .332 & .322 & .294 & .465 & 1 & .258 & .334\end{array}$

Organiza- Correlati

tional

on

Sig. (2- $\quad \begin{array}{llllllll}392 & .000 & .000 & .000 & .000 & . & .000 & .000\end{array}$ tailed)

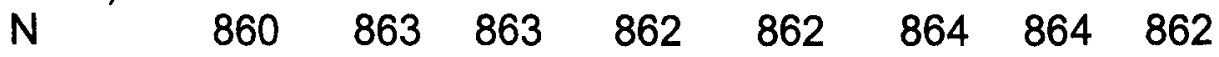

$\begin{array}{llllllllll}\text { Factor } 6 & \text { Pearson } & -.060 & .373 & .405 & .478 & .355 & .258 & 1 & .326\end{array}$

Content- Correlati

Suitability on

$\begin{array}{lllllllll}\text { Sig. }(2- & .080 & .000 & .000 & .000 & .000 & .000 & . & .000\end{array}$ $\begin{array}{lllllllll}\text { tailed) } & & & & & & & & \\ \mathrm{N} & 860 & 863 & 863 & 862 & 862 & 864 & 864 & 862\end{array}$

$\begin{array}{llllllllll}\text { Factor } 7 & \text { Pearson } & -.064 & .496 & .417 & .521 & .517 & .334 & .326 & 1\end{array}$ Techno- Correlati

logical on

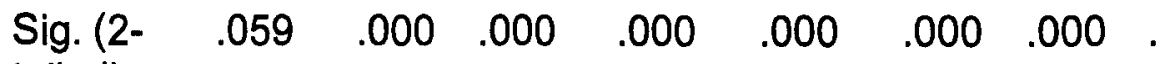
tailed)

$\begin{array}{lllllllll}N & 859 & 862 & 862 & 862 & 862 & 862 & 862 & 862\end{array}$

* Correlation is significant at the 0.05 level (2-tailed).

** Correlation is significant at the 0.01 level (2-tailed). 
Table AM1

Categories of Barriers in Distance Learning Based on Other Research

Researcher Emerging Factors or Type of Barriers

Mungania (2003)
(1) Dispositional
(2) Learning style
(3) Instructional
(4) Organizational
(5) Situational
(6) Content-suitability
(7) Technological barriers

Berge, Muilenburg, \& Haneghan (2002) (1) Situational

(2) Philosophical

(3) Psychological

(4) Pedagogical

(5) Technical

(6) Social

(7) Cultural barriers

Gieskes, Hyland, \& Magnusson, (2002)

(1) Interrupted learning processes

(2) Psychological and cultural blocks

(3) Organizational structure and leadership-related barriers

Berge (2002)

(1) Administrative structure

(2) Organizational change

(3) Technical expertise, support, and infrastructure

(4) Social interaction and quality

(5) Faculty compensation and time

(6) Threatened by technology

(7) Legal issues

(8) Evaluation/effectiveness

(9) Access

(10)Student support services 
Researcher Factors or Type of barriers

\begin{tabular}{ll}
\hline Schilke (2001) & (1) Situational \\
& (2) Dispositional \\
& (3) Epistemological \\
& (4) Institutional \\
& (5) Technological
\end{tabular}

Giles (1999)
(1) Demographic
(2) Personal
(3) Institutional
(4) Participative

Berge (1998)
(1) Epistemological
(2) Philosophical
(3) Psychological
(4) Pedagogical
(5) Technological
(6) Social
(7) Cultural

Tinto (1993)
(1) Dispositional
(2) Institutional
(3) External forces

Garland (1993)
(1) Situational
(2) Dispositional
(3) Epistemological
(4) Institutional

Fahy (1991)
(1) Financial
(2) Geographic
(3) Personal preferences

Coldeway (1986)
(1) Personal
(2) Contextual
(3) Institutional
(4) Course 


\section{CURRICULUM VITAE}

NAME

ADDRESS

EMAIL

DOB

EDUCATION

AWARDS:
Penina Mungania

Leadership, Foundations \& Human Resource Education (ELFH) Department College of Education \& Human Development Cardinal Blvd., $3^{\text {rd }}$ Floor University of Louisville Louisville, KY 40292

penina@aerckenva.org

1974

Bachelor of Education (Honors)

Kenyatta University, Kenya 1993-1997

MA Student Personnel Services in Higher Education Eastern Kentucky University 1998-2000

Ph.D., Human Resources Development University of Louisville, KY 2000-2004

Masie Center Dissertation Grant 2003

John Dewey Fellow

University of Louisville, $\mathrm{KY}$ 2001-2004

PEO International Peace Scholarships $1999 \& 2003$

DAAD Scholarship, Bielefeld, Germany 1999 
PROFESSIONAL MEMBERSHIPS

United States Distance Learning Association (USDLA)

Kentucky Distance Learning Association (KYDLA)

Academy of Human Resource Development (AHRD)

\section{PUBLICATIONS \& PRESENTATIONS}

Edge, D. \& Mungania, P. (2004 spring). Distance learning standards in the busy workplace. Training 2004 conference \& expo. Atlanta, Georgia.

Mungania, P. (2003 winter). Review: The ASTD E-learning Handbook. In D. F. Russ-Eft (Ed.). Human Resource Development Quarterly, 14(4), 493-497.

Mungania, P. (2003). The seven e-learning barriers facing employees. Available online at http://www.masie.com/researchgrants/\#study

Mungania, P. (2003). Employees' perceptions of barriers in e-learning. TechLearn Conference. Orlando, Florida.

Mungania, P. (2003). Barriers in Blended learning and E-learning. Spring Research Conference. Louisville, Kentucky.

Hatcher, T. \& Mungania, P. (2002). A matrix for the development of instruments to evaluate web-based courses and programs. The18th Annual Conference on Distance Teaching \& Learning Proceedings. Available online at www.uwex.edu/disted/conference/proceedings/DL2002 W2.pdf 